\title{
KARIN LANDMAYER
}

Controle do desgaste com inibidores de proteases e agente de estabelecimento de ligações cruzadas entre fibrilas de colágeno na resistência de união do conjunto adesivo-resina composta à dentina erodida

São Paulo 



\section{KARIN LANDMAYER}

Controle do desgaste com inibidores de proteases e agente de estabelecimento de ligações cruzadas entre fibrilas de colágeno na resistência de união do conjunto adesivo-resina composta à dentina erodida

\section{Versão Corrigida}

Dissertação apresentada à Faculdade de Odontologia da Universidade de São Paulo, pelo Programa de Pós-Graduação em Odontologia (Dentística), para obtenção do título de Mestre em Ciências.

Área de concentração: Dentística

Orientadora: Profa. Dra. Luciana Fávaro Francisconi dos Rios

São Paulo

2018 
Autorizo a reprodução e divulgação total ou parcial deste trabalho, por qualquer meio convencional ou eletrônico, para fins de estudo e pesquisa, desde que citada a fonte.

Catalogação-na-Publicação

Serviço de Documentação Odontológica

Faculdade de Odontologia da Universidade de São Paulo

Landmayer, Karin.

Controle do desgaste com inibidores de proteases e agente de estabelecimento de ligações cruzadas entre fibrilas de colágeno na resistência de união do conjunto adesivoresina composta à dentina erodida / Karin Landmayer ; orientador Luciana Fávaro Francisconi dos Rios. -- São Paulo, 2018.

104p. : tab., fig.; $30 \mathrm{~cm}$.

Dissertação (Mestrado) -- Programa de Pós-Graduação em Ciências Odontológicas. Área de Concentração: Dentística. -- Faculdade de Odontologia da Universidade de São Paulo.

\section{Versão corrigida}

1. Dentina. 2. Erosão dentária. 3. Inibidores de proteases. Adesivos dentinários. 5. Resistência de união. I. Francisconi-dos-Rios, Luciana Fávaro. II. Título. 
Landmayer K. Controle do desgaste com inibidores de proteases e agente de estabelecimento de ligações cruzadas entre fibrilas de colágeno na resistência de união do conjunto adesivo-resina composta à dentina erodida. Dissertação apresentada à Faculdade de Odontologia da Universidade de São Paulo para obtenção do título de Mestre em Ciências.

Aprovado em: 01 / 02 / 2019

\section{Banca Examinadora}

Profa. Dra. Daniela Prócida Raggio

Instituição: FOUSP

Julgamento: Aprovado

Profa. Dra. Neide Pena Coto

Instituição: FOUSP Julgamento: Aprovado

Profa. Dra. Marcela Charantola Rodrigues

Instituição: UNICSUL Julgamento: Aprovado 



\title{
Dedico este trabalho, acima de tudo, a Deus e à minha querida família,
}

\author{
A Deus, \\ Pois sem Ele nada seria possível.
}

\section{Aos meus pais, Tânia e Leonardo,}

Em quem sempre me espelho. Vocês são o melhor exemplo de amor e honestidade. Agradeço pelo legado de valores para poder me tornar quem sou, pelo apoio em cada etapa da minha vida (pessoal e profissional), pela amizade e amor incondicionais. Minha admiração por vocês não pode ser traduzida em palavras e meu amor, é imenso!

Amo MUITO vocês!

\section{Ao meu irmão, Leandro,}

Pela amizade e cumplicidade infinitas desde o início. Agradeço a Deus por ter você em minha vida e por viver momentos incríveis ao seu lado. Mesmo estando distantes, continuamos unidos, e meu amor por você é enorme!

\section{Ao meu namorado, Henrique,}

Por todo incentivo, paciência e companheirismo. Entrou na minha vida discretamente e quando percebi já estava completamente apaixonada. Que nossa caminhada seja sempre feita de cumplicidade, reciprocidade e, acima de tudo, muito amor. Te amo tanto, que nem sei!

Agradeço à sua família, agora a minha também, por quem tenho imenso apreço, por me acolherem sempre com muito carinho. 


\section{Aos meus avós,}

À minha vó Nina e ao meu vô Landinho, por serem imprescindíveis ao meu crescimento e o alicerce de toda nossa família.

À minha Oma Izolda e ao meu Opa Erich (in memorian), por tantos ensinamentos e anseio por me ver chegar até aqui. Tenho certeza que se orgulham de onde estiverem, torcem e olham por mim!

Tudo tem um começo, o meu foi vocês, e sou eternamente grata!

Que amor imenso... Eu os devo tudo!

\section{À minha tia, Thais, e primos, Bianca e Diego,}

Pelo exemplo de dedicação e esforço; e aos nossos "pequenos", que tão inesperadamente vieram e hoje tornaram-se essenciais em nossas vidas, por tanta alegria e amor.

À minha tia, Telma, tio, Wagner, e primo, Luis Gustavo,

Por me proporcionarem tantos momentos de felicidade e, mesmo com a distância, estarem sempre tão presentes em cada conquista minha. Esse trio é incrível!

Aos meus primos, Guilherme (Bebê) e Matheus, e tio, Schatz,

Que mesmo distantes no momento, estão sempre em meu coração, e são uma parte muito importante de minha vida. 


\begin{abstract}
À Socorro,
A quem tenho imenso carinho e gratidão, pois tem cuidado de mim e aguentado as minhas artes desde a infância.
\end{abstract}

Aos meus padrinhos, Edna e Alex, e aos de consideração, Geralda e Tadeu,

A quem meus pais confiaram a minha vida ao nascer e por serem presentes em cada fase dela. Obrigada por tudo; estão em meu coração!

Às minhas amigas e amigos: Caraminguas, Single Ladies, Turma do bolinha, Forasteiros, Joycita e Camilinha,

Por todos esses anos juntos, pelo apoio, incentivo e companheirismo. Obrigada por compartilharmos tantos momentos bons; e nos outros não tão bons assim, por me animarem. Amo vocês!

A todos os meus colegas, e já amigos, de pós-graduação,

Que tornaram esses dois anos mais leves. Em especial ao time Lu: Giovanni, Juan, Aloísio, Juliana, Bruna, Lucas e Maria, pelo espírito de equipe e amizade.

Agradeço imensamente a todos que colaboraram, de alguma maneira, para este sonho acontecer!!! 



\section{AGRADECIMENTOS}

\section{À Profa. Dra. Luciana Fávaro Francisconi dos Rios,}

Minha imensa gratidão pelo privilégio de sua orientação e por todos os ensinamentos compartilhados. Você é um exemplo de professora, pesquisadora, e porque não, amiga, diante dessa longa caminhada que trilhamos juntas até aqui. Desde a iniciação você é inspiração e, com certeza, foi incentivo para o mestrado.

Obrigada por toda a paciência e por estar sempre disposta a ajudar, mesmo sabendo das suas inúmeras atribuições. Além de tudo isso, é uma pessoa maravilhosa e um ser humano admirado por todos.

Obrigada, de coração!

Ao Prof. Dr. Vahan Agopyan, digníssimo reitor da Universidade de São Paulo.

Ao Prof. Dr. Rodney Garcia Rocha, digníssimo diretor da Faculdade de Odontologia da Universidade de São Paulo.

Ao Prof. Dr. Celso Luiz Caldeira, digníssimo coordenador do Programa de Pós-Graduação em Odontologia da Faculdade de Odontologia da Universidade de São Paulo.

Ao Prof. Dr. Rafael Yague Ballester, por disponibilizar recursos imprescindíveis para este protejo acontecer.

Ao Prof. Dr. Heitor Marques Honório, pelo suporte com a análise estatística e pelo conhecimento compartilhado.

A todos os funcionários que colaboram para com as atividades do Programa de Pós-Graduação em Odontologia, em especial, ao Antônio, à Silvana, ao Aldo, à Selminha, ao Leandro e ao David, pela compreensão, ajuda e confiança. 
Ao Serviço de Informação Documentária e Circulação da FOUSP, principalmente à Sra. Glauci Elaine Damásio Fidelis, por toda ajuda e disponibilidade.

À Coordenação de Aperfeiçoamento de Pessoal de Nível Superior - Brasil (CAPES), órgão de fomento de meu mestrado (Código de Financiamento 001; Programa de Demanda Social, de 06/2017 a 01/2019).

Ao laboratório de Microscopia Confocal do Centro de Facilidades de Apoio à Pesquisa (CEFAP-USP), em nome do técnico Mario Costa Cruz, por ser muito solícito e pela ajuda para obtenção das imagens.

A todos os professores e funcionários da FOUSP, principalmente do Departamento de Dentística, por sempre estarem dispostos a ajudar. 
"A mente que se abre a uma nova ideia jamais voltará ao seu tamanho original"

Albert Einstein 



\section{RESUMO}

Landmayer K. Controle do desgaste com inibidores de proteases e agente de estabelecimento de ligações cruzadas entre fibrilas de colágeno na resistência de união do conjunto adesivo-resina composta à dentina erodida [dissertação]. São Paulo: Universidade de São Paulo, Faculdade de Odontologia; 2018. Versão Original.

Buscou-se minimizar ou prevenir a degradação das fibrilas colágenas, tanto no controle da progressão do desgaste erosivo em dentina, quanto na preservação das interfaces adesivas aí estabelecidas, por meio do uso de agentes antiproteolíticos (clorexidina/CHX e epigalocatequina-3-galato/EGCG) ou, ao mesmo tempo, promotores de ligações cruzadas entre elas (proantocianidina/PAC). O papel de algumas dessas estratégias no estabelecimento, e conservação, de interfaces adesivas em dentina erodida, substrato adverso à interação com materiais adesivos, tem sido, porém, pouquíssimas vezes reportado. Este estudo in vitro propôs-se a avaliar, pois, o efeito de tais agentes, usados como estratégias para prevenção/controle do desgaste, na resistência de união $(R U)$ do conjunto sistema adesivo condicione e lave simplificado-resina composta à dentina erodida, comparada à normal. A dentina superficial oclusal de terceiros molares foi apenas submetida à ação de uma lixa de SiC (granulação 600; $1 \mathrm{~min}$; $\mathrm{N}$ : substrato normal) ou sequencialmente a desafio erosivo inicial (Coca-Cola ${ }^{\circledR} ; 5$ min). Recebeu, então, ou não (C: controle/sem aplicação), a aplicação de um dos géis com os seguintes princípios ativos - P: placebo/sem princípio ativo; $\mathrm{CHX}$ : digluconato de clorexidina a 0,12\%; EGCG: epigalocatequina-3-galato a $400 \mu \mathrm{m}$; PAC: proantocianidina a $10 \%$. Aquela de início desmineralizada ainda foi submetida a ciclagem de pH (Coca-Cola ${ }^{\circledR}$; imersões de $5 \mathrm{~min}$, 3x/dia, 5 dias; E: substrato erodido). Após condicionamento $\left(\mathrm{H}_{3} \mathrm{PO}_{4}\right.$ a $37 \%$; $15 \mathrm{~s}$; lavagem $30 \mathrm{~s}$; secagem com papel absorvente), o adesivo Adper ${ }^{\mathrm{TM}}$ Single Bond $2^{\circledR}$ foi aplicado em todos os espécimes e a porção coronária, reconstruída com a resina Filtek ${ }^{\mathrm{TM}} Z 350^{\circledR}$. Transcorridas $24 \mathrm{~h}$ (água destilada $/ 37^{\circ} \mathrm{C}$ ), os espécimes foram seccionados em palitos e testados ( $\mu$ TBS; $0,5 \mathrm{~mm} / \mathrm{min}$ ). As superfícies fraturadas de cada palito foram avaliadas utilizando-se um microscópio digital (50x de aumento). Os valores de $\mathrm{RU}$ obtidos foram organizados considerando- 
se cada dente como unidade experimental e os testes de Análise de Variância a 2 critérios e de Tukey aplicados $(\alpha=0,05)$. Um dente extra para cada grupo foi tratado exatamente como os outros, mas o corante fluorescente rodamina B foi previamente adicionado $(0,16 \mathrm{mg} / \mathrm{mL})$ ao sistema adesivo para permitir a avaliação qualitativa da interface adesiva por meio de Microscopia Confocal de Varredura a Laser. Analisandose os dados obtidos pôde-se observar que, diferentemente da variável aplicação de géis para prevenção/controle do desgaste erosivo $(p=0,076)$, a variável condição do substrato dentinário exerceu influência significante sobre os resultados $(p<0,001)$. Ademais, não houve interação entre elas $(p=0,979)$. Os valores imediatos de $R U$ ao substrato erodido foram, pois, sempre inferiores que aqueles ao substrato normal, independentemente da aplicação, ou não, de qualquer um dos géis para prevenção/controle do desgaste erosivo. Quanto ao padrão de fratura dos palitos testados, as falhas adesivas e mistas foram predominantes em relação às coesivas, independentemente se em dentina ou em resina. Menores porcentagens de falhas coesivas ainda puderam ser verificadas para o substrato erodido, com relação ao normal. No que se refere à análise qualitativa, observou-se, para o erodido, comparado ao normal, independetemente do tratamento para controle do desgaste, camada escura subjacente à de adesivo propriamente, representação da menor concentração de material marcado por rodamina $\mathrm{B}$, bem como tags resinosos com maior comprimento e em maior quantidade. Assim sendo, conclui-se, por ora, que as estratégias estudadas não foram capazes de favorecer, tampouco de prejudicar, o estabelecimento de interface adesiva em dentina erodida.

Palavras-chave: Dentina; Erosão Dentária; Inibidores de Proteases; Digluconato de Clorexidina; Epigalocatequina-3-Galato; Proantocianidina; Adesivos Dentinários; Resistência de União. 


\begin{abstract}
Landmayer K. Wear control with protease inhibitors and collagen cross-linking agent on bond strength of an adhesive plus a resin composite to eroded dentin [dissertation]. São Paulo: Universidade de São Paulo, Faculdade de Odontologia; 2018. Versão Original.
\end{abstract}

In order to minimize the degradation of collagen fibrils, both to control the progression of the dentin erosive wear and to preserve adhesive interfaces established there, antiproteolytic (chlorhexidine/CHX and epigallocatechin-3-gallate/EGCG) or, at the same time, collagen cross-linking agents (grape seed proanthocyanidin extract/PAC) started to be successfully used. Some of these strategies in the establishment and preservation of adhesive interfaces on eroded dentin, a substrate adverse to the interaction with adhesive materials, has been seldom reported yet. This in vitro study aimed to evaluate, thus, the effect of such agents, used as strategies for wear preventing/controlling, on bond strength (BS) of a simplified etch-and-rinse adhesive system adhesive plus a resin composite to eroded, and normal (parameter for comparisons) dentin. Superficial occlusal dentin of third molars was only ground with a SiC paper (600-grit; 1 min; N: normal substrate), or subsequently submitted to an initial erosive challenge (Coca-Cola ${ }^{\circledR} ; 5$ min). It, then, received or not (C: control/without application), application of one of the gels with the following active principles - P: placebo/without active principle; CHX: 0.012\% chlorhexidine digluconate; EGCG: epigallocatechin-3-gallate at $400 \mu \mathrm{m}$; PAC: 10\% proanthocyanidin. Initial demineralized dentin was still submitted to a $\mathrm{pH}$ cycling (Coca-Cola ${ }^{\circledR}, 5 \mathrm{~min}$ immersions, 3x/day, 5 days, E: eroded substrate). After acid-etched $\left(37 \% \mathrm{H}_{3} \mathrm{PO}_{4} ; 15\right.$ sec; 30 sec washing; drying with absorbent paper), the adhesive Adper ${ }^{\text {TM }}$ Single Bond $2^{\circledR}$ was applied in all specimens and resin composite buildups were constructed with Filtek ${ }^{\mathrm{TM} Z 350^{\circledR}}{ }^{\circledR}$. After $24 \mathrm{~h}$ (distilled water $/ 37^{\circ} \mathrm{C}$ ), specimens were sectioned in beams and tested ( $\mu$ TBS; $0.5 \mathrm{~mm} / \mathrm{min}$ ). Obtained BS values were organized considering each tooth as an experimental unit and two-way ANOVA and Tukey tests were applied $(\alpha=0.05)$. An extra tooth for each group was treated just like the others, but the adhesive system was marked by the addition of rhodamine $B(0.16 \mathrm{mg} / \mathrm{mL})$ to allow qualitative evaluation of the adhesive interface by means of Confocal Laser Scanning 
Microscopy. As opposed to the variable application of gels for wear preventing/controlling $(p=0.076)$, the condition of the dentin substrate had a significant influence on the results $(p<0.001)$. In addition, there was no interaction between them $(p=0.979)$. Immediate $B S$ values to the eroded substrate were always lower than that to the normal substrate, regardless of the application or not of any of the gels for wear preventing/controlling. As for the fracture pattern of the tested beams, adhesive and mixed failures were predominant in relation to the cohesive failures, regardless of whether in dentin or in resin. Lower percentages of cohesive failures could still be verified for the eroded substrate, relative to the normal one. Concerning the qualitative analysis, it was observed, for the eroded substrate, compared to the normal, independently of the treatment for wear preventing/controlling, a dark layer underlying that of the adhesive itself, which represents a lower concentration of rhodamine Blabeled material, as well as resinous tags with greater length and in greater quantity. Therefore, studied strategies were not able either to improve, neither to impair, the establishment of adhesive interface on eroded dentin.

Keywords: Dentin; Dental Erosion; Protease Inhibitors; Chlorhexidine Digluconate; Epigallocatechin-3-Galate; Proanthocyanidin; Dentin-Bonding Agents; Bond Strength. 


\section{LISTA DE ILUSTRAÇÕES}

Figura 4.1 A: Remoção do terço oclusal de cada terceiro molar, para exposição da dentina coronária, subjacente ao esmalte; B: a aspecto do espécime após remoção da porção radicular, por meio de corte paralelo ao primeiro

Quadro 4.1 Grupos experimentais.

Figura 4.2 A: Ação de uma lixa de carbeto de silício de granulação 600, por 1 minuto, sob refrigeração constante com água destilada, em uma politriz metalográfica, para padronizar a smear layer formada sobre a superfície de dentina, determinando-se o substrato normal $(\mathrm{N})$; B: subsequente erosão inicial por um refrigerante à base cola, determinando-se o substrato erodido $(\mathrm{E})$ 49

Figura 4.3 Aplicação de um dos géis, com diferentes princípios ativos, para prevenção/controle do desgaste erosivo (C: controle/sem aplicação; P: placebo/sem princípio ativo; CHX: digluconato de clorexidina a $0,12 \%$; EGCG: epigalocatequina-3-galato a $400 \mu \mathrm{m}$; PAC: proantocianidina a $10 \%)$

Figura 4.4 Ciclagem de $\mathrm{pH}$, para fatídico estabelecimento do substrato erodido (E): imersão em refrigerante à base de cola (Coca-Cola $\AA$; $6,30 \mathrm{ml}$ por espécime; um novo frasco aberto a cada desafio), três vezes ao dia (8, 13 e 18h), por 5 minutos, durante 5 dias, e armazenagem em saliva artificial, substituída diariamente, nos intervalos entre os desafios e durante a noite

Figura 4.5 A: Condicionamento da superfície de dentina de todos os espécimes com ácido fosfórico a 37\%, por 15 segundos; B: lavagem pelo dobro do tempo; C: secagem com papel absorvente. .54

Figura 4.6 A: Aplicação de adesivo, de forma ativa (15 s), em duas camadas finas, com um leve jato de ar para facilitação da evaporação do solvente; B: fotoativação por 10 segundos. 
Figura 4.7 A: Aposição do primeiro incremento de resina composta sobre o substrato; B: mensuração de espessura $(\sim 2 \mathrm{~mm})$, com paquímetro, após acomodação; C: fotoativação por 20 segundos.....................................55

Figura 4.8 A e B: Seccionamento do conjunto espécime dentário-resina composta, perpendicular à interface adesiva, no sentindo vestíbulo-lingual; C: seccionamento no sentido mésio-distal; D: obtenção de palitos com área de secção transversal de aproximadamente $0,81 \mathrm{~mm} 2$ .56

Figura 4.9 A: Fixação de um palito pelas extremidades, simetricamente em relação à interface adesiva, a um "Jig de Geraldeli"; B: adaptação do dispositivo contento o palito em máquina de testes universal Instron 5942; C: teste sob força de tração (célula de carga de $50 \mathrm{kgf}$ ) perpendicular à interface adesiva, a uma velocidade de $0,5 \mathrm{~mm} / \mathrm{min}$, até falha do palito

Figura 4.10 Microscópio digital utilizado para análise das superfícies fraturadas de ambos os segmentos de cada palito testado

Figura 4.11 Aspecto das superfícies de cada um dos segmentos de cada palito testado, em função dos possíveis padrões de fratura - A e B: falha adesiva; C e D: falha mista; E e F: falha coesiva em dentina; $\mathrm{G} \mathrm{e} \mathrm{H}$ : falha coesiva em resina. 58

Figura 4.12 Representação do dente extra de cada grupo, tratado exatamente como os outros, mas com o sistema adesivo previamente marcado pela adição do corante fluorescente rodamina $B(0,16 \mathrm{mg} / \mathrm{ml})$ e seccionado apenas mesio-distalmente, para avaliação qualitativa da interface adesiva por

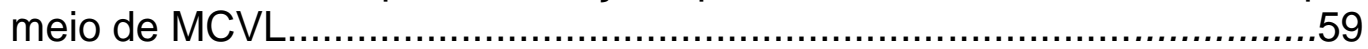


Figura 5.1 Imagens de MCVL das interfaces adesivas em função da condição do substrato ( $\mathrm{N}$ : normal, coluna à esquerda; $\mathrm{E}$ : erodido, coluna à direita) $\mathrm{e}$ da aplicação de géis para prevenção/controle do desgaste erosivo (C: controle/sem aplicação; P: placebo/sem princípio ativo; $\mathrm{CHX}$ : digluconato de clorexidina a 0,12\%; EGCG: epigalocatequina 3-galato a $400 \mu \mathrm{m}$; PAC: proantocianidina a $10 \%$, em cada linha) - A: N.C; B: E.C; C: N.P; D: E.P; E: N.CHX; F: E.CHX; G: N.EGCG; H: E.EGCG; I: N.PAC; J: E.PAC

Gráfico 5.1 Valores médios \pm desvio padrão de resistência de união (MPa) do conjunto sistema adesivo condicione e lave simplificado-resina composta à dentina em função da condição do substrato (N: normal; $\mathrm{E}$ : erodido) e da aplicação de géis para prevenção/controle do desgaste erosivo (C: controle/sem aplicação; P: placebo/sem princípio ativo; CHX: digluconato de clorexidina a 0,12\%; EGCG: epigalocatequina-3-galato a $400 \mu \mathrm{m}$; PAC: proantocianidina a $10 \%)$ .61

Gráfico 5.2 Percentual (\%) de falhas do tipo adesiva (A), mista (M), coesiva em dentina (CD) ou coesiva em resina (CR) em função em função da condição do substrato (normal; erodido) e da aplicação de géis para prevenção/controle do desgaste erosivo (C: controle/sem aplicação; P: placebo/sem princípio ativo; CHX: digluconato de clorexidina a $0,12 \%$; EGCG: epigalocatequina 3-galato a $400 \mu \mathrm{m}$; PAC: proantocianidina a $10 \%)$ 



\section{LISTA DE ABREVIATURAS E SIGLAS}

$\begin{array}{ll}\mathrm{A} & \text { adesiva } \\ \mathrm{ANOVA} & \text { análise de variância } \\ \mathrm{BS} & \text { bond strength } \\ \mathrm{C} & \text { controle / control } \\ \mathrm{CaCl} & \text { cloreto de cálcio } \\ \mathrm{CCs} & \text { cisteíno-catepsinas } \\ \mathrm{CD} & \text { coesiva em dentina } \\ \mathrm{CHX} & \text { clorexidina / chlorhexidine } \\ \mathrm{Cm}{ }^{2} & \text { centímetro quadrado } \\ \mathrm{CR} & \text { coesiva em resina } \\ \mathrm{E} & \text { substrato erodido / eroded substrate } \\ \mathrm{EGCG} & \text { epigalocatequina-3-galato / epigallocatechin-3-gallate } \\ \mathrm{FOUSP} & \text { Faculdade de Odontologia da Universidade de São Paulo } \\ \mathrm{h} & \text { hora(s) / hour(s) } \\ \mathrm{KCl} & \text { cloreto de potássio } \\ \mathrm{Kgf} & \text { quilograma-força } \\ \mathrm{KH}{ }_{2} \mathrm{PO}{ }_{4} & \text { fosfato de potássio monobásico } \\ \mathrm{M} & \text { mista } \\ \mathrm{MCVL} & \text { microscopia confocal de varredura a laser } \\ \mathrm{mg} / \mathrm{ml} & \text { miligrama por mililitro } \\ \mathrm{MgCl} 2.6 \mathrm{H}_{2} \mathrm{O} & \text { cloreto de magnésio hexahidratado } \\ \mathrm{min} & \text { minuto(s) / minute(s) } \\ \mathrm{mm} & \text { milímetro } \\ \mathrm{mM} / \mathrm{L} & \text { milimolar por litro } \\ \mathrm{mm} / \mathrm{min} & \text { milímetro por minuto / milimeter(s) per minute(s) } \\ \mathrm{mm}{ }^{2} & \text { milímetro quadrado } \\ \mathrm{MMPs} & \text { metaloproteinases da matriz } \\ \mathrm{MPa} & \text { megapascal(s) / megapascal(s) } \\ \mathrm{N} & \text { substrato normal / normal substrate } \\ \mathrm{NaCl} & \text { cloreto de sódio } \\ & \end{array}$




$\begin{array}{ll}\mathrm{NaN}_{3} & \text { azida sódica } \\ \mathrm{P} & \text { placebo / placebo } \\ \mathrm{p} & \text { nível de significância } \\ \mathrm{PAC} & \text { proantocianidina / proanthocyanidin } \\ \mathrm{pH} & \text { potencial hidrogeniônico } \\ \mathrm{rpm} & \text { rotação(ões) por minuto } \\ \mathrm{RU} & \text { resistência de união } \\ \mathrm{s} & \text { segundo(s) / second(s) } \\ \mathrm{SiC} & \text { carbeto de silício } \\ \mu \mathrm{m} & \text { micrômetro(s) / micrometer(s) } \\ \mu \mathrm{TBS} & \text { microtensile bond strength }\end{array}$




\section{LISTA DE SÍMBOLOS}

(

$\%$

$\mathrm{x}$

l

TM

${ }^{\circ} \mathrm{C}$

$\alpha$

$=$

$<$

$\mathrm{n}^{\circ}$ marca registrada / registered trademark

por cento

vezes

por / per

marca não registrada / unregistered trademark

grau(s) Celsius / degree(s) Celsius

nível de significância / significance level

igual / equal

menor / less than

número 



\section{SUMÁRIO}

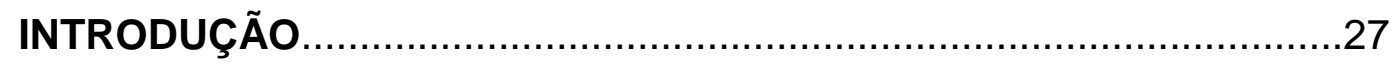

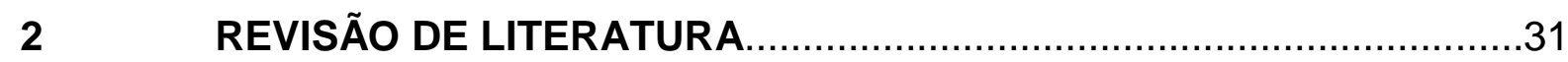

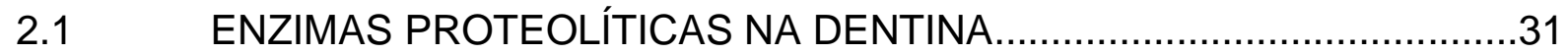

2.2 EROSÃO DENTÁRIA E O PAPEL DAS ENZIMAS PROTEOLÍTICAS.....33

2.3 RESTAURAÇÃO DO SUBSTRATO DENTINÁRIO ERODIDO..................36

2.4 INIBIDORES DE PROTEINASES E AGENTE DE ESTABELECIMENTO DE LIGAÇÕES CRUZADAS ENTRE FIBRILAS DE COLÁGENO.............38

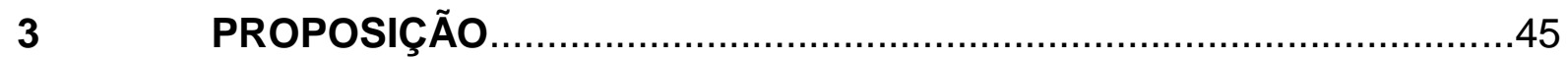

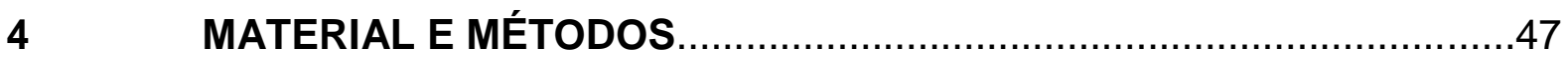

4.1 DELINEAMENTO EXPERIMENTAL................................................47

4.2 OBTENÇÃO DOS DENTES HUMANOS .........................................47

4.3 EXPOSIÇÃO DA DENTINA E DETERMINAÇÃO DOS GRUPOS

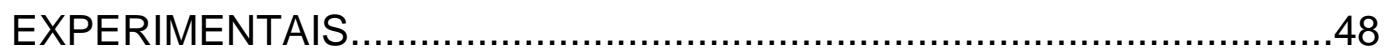

$4.4 \quad$ TRATAMENTO DO SUBSTRATO DENTINÁRIO....................................51

4.5 PROCEDIMENTOS ADESIVOS/RESTAURADORES...........................53

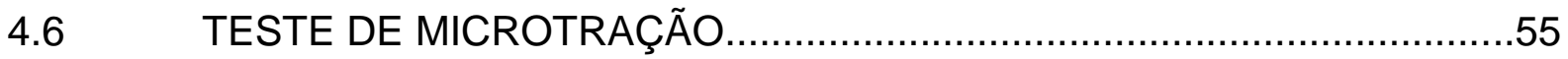

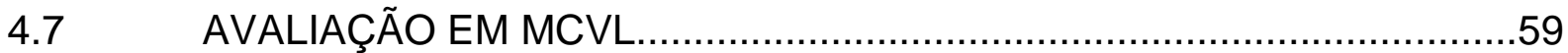

4.8 FORMA DE ANÁLISE DOS RESULTADOS ........................................59

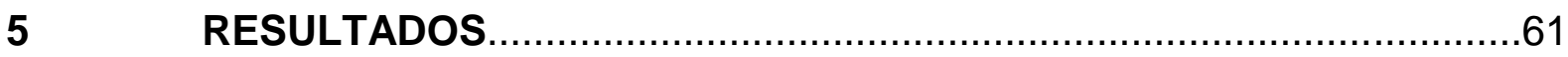

$6 \quad$ DISCUSSÃO

$7 \quad$ CONCLUSÃO

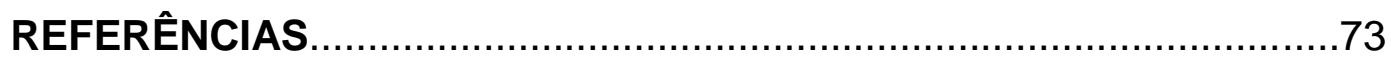

ANEXOS 

Enzimas intrínsecas, do próprio hospedeiro, como as metaloproteinases da matriz (MMPs) e as cisteíno-catepsinas (CCs), foram identificadas no complexo dentinopulpar, inclusive nos $10 \%$ da porção não-colágena da dentina (Turk et al., 1997; Dickinson, 2002; Visse; Nagase 2003; Li et al., 2004; Hannas et al., 2007; Tersariol et al., 2010; Nascimento et al., 2011; Scaffa et al., 2012). Participam da formação dentária e em fase posterior permanecem ali de forma latente, protegidas pelos minerais (Tjäderhane et al., 1998). Diante de uma queda de pH, essa proteção é perdida, e elas tornam-se ativas (Tjäderhane et al., 2013a), podendo causar a degradação da matriz extracelular, inclusive do colágeno nativo e desnaturado (Chaussain-Miller et al., 2006; Hannas et al., 2007).

A queda de $\mathrm{pH}$ pode ser decorrente de processos químicos relacionados à erosão dentária, cada vez mais frequente pela mudança de hábitos alimentares e aumento da prevalência de distúrbios gastrintestinais (Meurman; ten Cate 1996; Zero, 1996; Larsen; Nyvad 1999; Zero; Lussi, 2005; Tahmassebi et al., 2006; Magalhães et al., 2009a, 2014, Rios et al., 2009, 2011; Magalhães et al., 2014). De início, afeta o esmalte, e, se o amolecimento superficial (Oshiro et al., 2007; Lussi et al., 2011; Ganss et al., 2014) não for revertido, acaba por expor a dentina subjacente (Lussi et al., 2006; Vieira et al., 2006; Correr et al., 2009; Voronets; Lussi, 2010; Huysmans et al., 2011; Lussi; Carvalho, 2014). Ora, pode ocorrer remoção de minerais sitos entre as dentinas inter e peritubular; sequencialmente, a desmineralização da dentina peritubular, alargando-se a embocadura dos túbulos dentinários, e, por fim, a da dentina intertubular, que se torna rugosa e porosa, com uma camada superficial orgânica completamente desmineralizada, recobrindo uma zona parcialmente desmineralizada, sobre a dentina ainda mineralizada (Meurman et al., 1991; Kinney et al., 1995). O colágeno exposto após a perda mineral pode até evitar que os ácidos adentrem às camadas mais profundas da dentina, impedindo a progressão do desgaste erosivo (Klont; Ten Cate 1991a; Kleter et al., 1994; Ganss et al., 2004; Hara et al., 2005; Kato et al., 2009b, 2010a). Contudo, esse emaranhado superficial de fibrilas pode ser degradado tanto mecanicamente, como, conforme já enfatizado, pela ação das tais enzimas proteolíticas (Ganss et al., 2004, 2007; Hara et al., 2005; Kato et al., 2009a, 2010b; Magalhães et al., 2009b; Buzalaf et al., 2010; Tjäderhane et al., 2013a, 2015). 
As MMPs, tipicamente, e talvez as CCs, parecem desempenhar papel importante na progressão do desgaste erosivo, degradando as fibrilas colágenas expostas, clivandoas, e expondo o tecido subjacente, ainda mineralizado, à ação dos distintos meios ácidos, reiniciando-se o ciclo (Buzalaf et al., 2010; Tjäderhane et al., 2013a, 2015).

Progride, assim, a perda de estrutura dentária, que pode passar a exigir, em particular em níveis relativamente avançados, intervenção restauradora (Kilpatrick; Mahoney, 2004; Peutzfeldt et al., 2014). Na maioria dos casos, os procedimentos diretos adesivos, utilizando-se resina composta, são os de eleição (Lambrechts et al., 1996; Hemmings et al., 2000; Bartlett; Sundaram 2006; Loguercio et al., 2009; Dietschi; Argente, 2011).

A camada híbrida estabelecida no substrato dentinário erodido tem, porém, maior espessura que aquela em dentina hígida, o que se relaciona a inapropriada impregnação dos monômeros resinosos (Zimmerli et al., 2012). Sua constituição estruturalmente imperfeita e com porosidades, repleta de áreas não reforçadas por resina, e a excessiva umidade, típica desta condição, podem impedir a satisfatória conversão dos monômeros em polímeros e minimizar a imediata eficácia da adesão (Cruz et al., 2012; Zimmerli et al., 2012) bem como tornam os diferentes constituintes da interface mais suscetíveis à degradação (Sano et al., 1995a, 1995b; Hashimoto et al., 2003; Van Landuyt et al., 2007; Vaidyanathan; Vaidyanathan 2009; Zimmerli et al., 2012; Tjäderhane et al., 2015).

A fim de reduzir a ação das enzimas proteolíticas e assim minimizar ou prevenir a degradação das fibrilas colágenas, tanto no controle da progressão do desgaste erosivo em dentina, quanto na preservação das interfaces adesivas, lançou-se mão do uso de potenciais inibidores de sua atividade, como o digluconato de clorexidina (CHX) e o extrato de chá verde (epigalocatequina 3-galato - EGCG) (Gendron et al., 1999; Demeule et al., 2000; Hebling et al., 2005; Carrilho et al., 2007a, 2007b, Breschi et al., 2008, 2010; Loguercio et al., 2009; Magalhães et al., 2009b; Komori et al., 2009; Kato et al., 2010a; Buzalaf et al., 2012; Tjäderhane et al., 2013a, 2015; Malaquias et al., 2018). Por alternativa, buscaram-se os mesmos objetivos, não só por meio dessa inibição, mas potencialmente também pelo aumento da resistência das fibrilas colágenas à degradação, utilizando-se agentes ao mesmo tempo antiproteolíticos e promotores do estabelecimento de ligações cruzadas entre elas, como o extrato de semente de uva (proantocianidina - PAC) (Bedran-Russo et al., 2007, 2009, 2011; Al- 
Ammar et al., 2009; Castellan et al., 2011; Srinivasulu et al., 2012; Boteon et al., 2017a, 2017c; Leme-Kraus et al., 2017).

O papel de algumas dessas estratégias no estabelecimento, e conservação, de interfaces adesivas em dentina erodida tem sido, porém, reportado apenas por pouquíssimos estudos (Francisconi-dos-Rios et al., 2015a, 2015b; Giacomini et al., 2017; Farias-Neto et al., 2018). A aplicação de solução de CHX a 2\%, como primer antiproteolítico após condicionamento da dentina com ácido fosfórico, mostrou-se promissora à prevenção da diminuição dos valores de resistência de união, em médio prazo, do conjunto adesivo condicione-e-lave simplificado/resina composta à dentina, normal ou erodida, mas não tornou aqueles à segunda equivalentes àqueles à primeira (Francisconi-dos-Rios et al., 2015b). Ademais, em longo prazo, o efeito favorável tornou-se reduzido/irrelevante (Francisconi-dos-Rios et al., 2015a). Inoportunamente, adiante, o uso dessa mesma solução, com mesma finalidade, reduziu os valores de resistência de união à dentina normal e à erodida, ainda que apenas aqueles à primeira tenham sido negativamente acometidos pelo passar do tempo (Giacomini et al., 2017). Já o uso de solução de CHX, a 2\%, como agente para prevenção/controle do desgaste erosivo pareceu, contrariamente ao que se observa quando aplicada na forma de gel, a 0,012\%, para essa finalidade (Kato et al., 2010a; Boteon et al., 2017a, 2017b), não de todo interessante quando, do ponto de vista da resistência de união, na sequência, restaurou-se o substrato dentinário utilizando-se sistema adesivo do tipo condicione e lave simplificado em associação a resina composta (Farias-Neto et al., 2018). Uma vez mais, ainda, quando aplicada como primer antiproteolítico, prejudicou a adesão à dentina normal (Farias-Neto et al., 2018).

Pois bem, em se considerando que, à exceção do uso de soluções com ação antioxidante/fontes de vitamina C (suco de laranja) para estabelecimento do substrato dentinário erodido simulado (Giacomini et al., 2017), apenas sua asperização com ponta diamantada é capaz de torná-lo análogo ao normal, no que se refere aos valores de RU ao mesmo (Zimmerli et al., 2012), revela-se conveniente estudar alternativas, não invasivas, a essa opção. Há que se concordar que pode ser fundamental concentrar os esforços na identificação de estratégias que favoreçam a $R U$, já imediatamente, a substratos sabidamente desfavoráveis à adesão de materiais 
resinosos (Cruz et al., 2012; Zimmerli et al., 2012), onde, via de regra, em clínica, estabelecem-se as interfaces adesivas (Giacomini et al., 2017). 


\section{REVISÃO DA LITERATURA}

\subsection{ENZIMAS PROTEOLÍTICAS NA DENTINA}

Enzimas proteolíticas, como as metaloproteinases (MMPs) e as cisteínocatepsinas (CCs) (Birkedal-Hansen et al., 1993; Ingman et al., 1994) foram encontradas na dentina humana (Martin-De Las Heras et al., 2000) assim como na saliva (Makela et al., 1994). Na matriz colágena do tecido dentinário, mais especificamente na dentina mineralizada, já foram identificadas as do tipo colagenases (MMP-1, MMP-8, MMP-13 e MMP-18), responsáveis, como o próprio nome sugere, pela degradação de colágeno, e também as gelatinases (MMP-2 e MMP-9), incumbidas da degradação do colágeno especificamente desnaturado (gelatina). Existem, inclusive, MMPs de outros subgrupos em humanos, totalizandose 23 tipos, como as estromelisinas (MMP-3, MMP-10 e MMP-11), as matrisilinas (MMP-7 e MMP-26), as MMPs tipo membranas e outras (Visse; Nagase, 2003; Hannas et al., 2007).

Nos processos normais, essas enzimas desempenham um papel importante na degradação de componentes extracelulares para remodelação e manutenção tecidual durante a erupção dentária (Birkedal-Hansen et al., 1993; Tanaka et al., 1999; Cerri et al., 2010); ainda manifestam-se em processos de defesa imunológica (Ryan et al., 1996; Lafleur et al., 2003; Nagase; Brew 2003). Participam, contudo, no desenvolvimento de doenças periodontais, pulpares e de lesões de cárie (BirkedalHansen et al., 1993; Hannas et al., 2007), além de estarem presentes em diversas condições inflamatórias que envolvem dano tecidual em doenças pulmonares, cardíacas e cancerígenas (Sakashita et al., 2011; El-Badrawy et al., 2014; Li et al., 2014; Yousef et al., 2014; Xu et al., 2015).

$\mathrm{Na}$ estrutura dentária, as MMPs apresentam-se na forma latente, no entanto, quando ativadas, são responsáveis pela degradação da matriz extracelular (MEC), incluindo colágeno na forma nativa ou desnaturada. Visto que são endopeptidases zinco-dependentes, exigem ligação desse íon metálico ao seu sítio catalítico, para 
clivagem das ligações peptídicas das proteínas estruturais da MEC (Buzalaf et al., 2012).

A MEC pode, então, ser degradada quimicamente, em conjunto com a estrutura dentária desmineralizada (Kato et al., 2009b, 2010b), quando as MMPs são ativadas por fatores de crescimento, agentes químicos, forças mecânicas, ou até por uma queda de pH (Tjäderhane et al., 1998). Porém, antes da ativação, é necessário a lise do pró-domínio do sítio catalítico (Hannas et al., 2007), e a posterior neutralização do meio, para exercício da sua função.

Assim como as MMPs, as CCs também são vistas tanto na saliva quanto nos tecidos duros dentários (Hannas et al., 2007; Tjäderhane et al., 2013a). Estão presentes no compartimento lissomal intracelular; são ativadas, e agem, em pH ácido, mesmo que levemente, e já se tornam instáveis naquele neutro (Turk et al., 1995, 1997, 2012). Também foram encontradas extracelularmente, mas nesta condição podem se tornar, de maneira irreversível, rapidamente inativas em $\mathrm{pH}$ neutro, ainda que não sejam as alterações de $\mathrm{pH}$ as únicas responsáveis pela determinação de sua atividade. De qualquer maneira, quando ativas, promovem a degradação de diversos constituintes da MEC, como colágeno, laminina, fibronectina e proteoglicanos (Dickinson, 2002; Obermajer et al., 2008).

São 11 os tipos de CCs conhecidas em humanos: B, C, F, H, K, L, O, S, V, X e W (Turk et al., 2012). Podem participar de processos relacionados à saúde e à doença, como a remodelação óssea ou, até mesmo, na facilitação da invasão de células tumorais nos tecidos (Buck et al., 1992). Na odontologia, a catepsina K, por exemplo, é uma enzima que atua na degradação da matriz óssea e a única capaz de degradar o colágeno íntegro (Georges et al., 2009), contribuindo para com a progressão de doenças periodontais (Mogi; Otogoto, 2007), ou para com a remodelação óssea envolvida na movimentação ortodôntica (Tsuji et al., 2001). Já a catepsina B é expressa principalmente em dentina, normal, e mostra maior atividade naquela cariada, além de se apresentar em abudância em cavidades mais profundas (Nascimento et al., 2011; Vidal et al., 2014), em que, por meio da degradação da matriz orgânica desmineralizada, junto às MMPs, viabiliza a progressão da lesão (Tjäderhane et al., 1998; Tersariol et al., 2010).

Essas enzimas também possuem um pré e um pró-peptídeo: o pré-peptídeo se desliga da sua estrutura quando enviado para o retículo endoplasmático, e o própeptídeo é removido pela influência de outras proteinases ou pela autoativação, 
expondo-se seu sítio e propiciando-se sua ativação (Turk et al., 1997; Turk; Guncar 2003).

Com a queda de $\mathrm{pH}$, quadro tipicamente relacionado à cárie e, particularmente, à erosão dentária, e consequente ativação das enzimas proteolíticas, oportuniza-se a perda da estrutura dentinária (Kato et al., 2009a, 2010b). O meio ácido promove a desmineralização da matriz extracelular e faculta, ora, a ação das MMPs e CCs (Tjäderhane et al., 2001; Kato et al., 2010a).

\subsection{EROSÃO DENTÁRIA E O PAPEL DAS ENZIMAS PROTEOLÍTICAS}

Quanto à erosão dentária, é um tipo de desgaste definido pela perda irreversível de tecido duro que pode afetar tanto esmalte como dentina. Não há envolvimento bacteriano, podendo ocorrer por quelação ou, em especial, pelo contato da estrutura dentária com soluções ácidas (Larsen, 1990; Lussi et al., 2006), sejam elas intrínsecas, provenientes de fontes endógenas, como o suco gástrico (Magalhães et al., 2009a; Rios et al., 2009; Loke et al., 2016) ou extrínsecas, advindas de fatores exógenos, como alimentos e bebidas ácidas (Tahmassebi et al., 2006; Magalhães et al., 2009a; Rios et al., 2009; Loke et al., 2016).

O aumento da prevalência do desgaste erosivo tem chamado atenção, principalmente pelo número crescente de casos em pacientes mais jovens (Jaeggi; Lussi, 2014; Schlueter; Luka, 2018). Acredita-se que isso se deva ao aumento exagerado da ingestão de refrigerantes (Tahmassebi et al., 2006) e de outras bebidas prontas para consumo, por serem de fácil acesso e práticas, bem como à maior utilização de alimentos cítricos e bebidas repositoras de sais ou energéticas, por causa das mudanças comportamentais relacionadas à busca por um estilo de vida mais saudável (Lussi et al., 2004b).

Dentre as várias bebidas, refrigerantes à base de cola destacam-se por apresentar baixos valores de $\mathrm{pH}$ (por volta de 2,3), tipicamente inferiores ao crítico para desmineralização do esmalte e origem da erosão (<5,5 - Meurman and ten Cate 1996; Litonjua et al., 2003; Gravelle et al., 2015; Leme et al., 2011; Wang et al., 2014b). Com a queda do $\mathrm{pH}$ na saliva, seu efeito tampão é diminuído e, por conseguinte, a 
proteção ao substrato dentário (Farias et al., 2000; Ganss, 2006): grande quantidade de hidróxido de sódio $(\mathrm{NaOH})$ mostra-se necessária para neutralização da solução (Larsen; Nyvad 1999), bem como a quantidade de íons cálcio e fosfato, insuficiente para satura-lá em relação à apatita (Larsen; Nyvad, 1999).

Leme et al. (2011), ao avaliarem quatro produtos com grande potencial erosivo, verificaram, ainda, que o refrigerante à base de cola tem maior capacidade de solubilização das apatitas dentárias (Farias et al., 2000), seguido pelo refrigerante de limão, por bebidas isotônicas e por suco à base de soja. Ademais, ao analisarem a ação dessas bebidas, por meio de microscopia eletrônica de varredura, sobre o substrato dentário, verificaram presença expressiva de erosão e intensa desmineralização relacionada ao refrigerante à base de cola; nítida perda de minerais, àquele de limão; perda gradual e homogênea, ao suco à base de soja; e superfície irregular, às bebidas isotônicas.

Tanto em esmalte, como em dentina, a perda superficial e o potencial erosivo decorrente da exposição a refrigerante à base de cola é sempre maior que aquela verificada para outras bebidas ácidas (Leme et al., 2011). Outrossim, diante do contato frequente dessa bebida com o substrato, a saliva tem menor capacidade de tamponamento e não é capaz de reverter a redução de dureza do esmalte e da dentina por completo, resultando sempre na inconvertibilidade da perda de minerais (Fushida; Cury, 1999).

Substâncias ácidas promovem um amolecimento progressivo dos tecidos por meio da ação de íons hidrogênio, liberados pelo ácido quando em contato com a água, ao se ligarem aos íns carbonatos ou fosfatos da estrutura dentária, ou, ainda, daquela de ânions que se ligam ao cálcio (Larsen, 1990; Barbour et al., 2005; Zero; Lussi, 2005). Em esmalte, ocorre a dissolução dos cristais de hidroxiapatita presentes nas áreas interprismáticas ou nos próprios prismas: a princípio, o desarranjo, ou amolecimento superficial, é reversível e passível de recuperação pela ação da saliva. Com a contínua presença desses ácidos, contudo, a desmineralização deixa de ser superficial e ocorre perda irreversível de estrutura, que pode avançar, camada a camada, até alcançar a dentina (Voronets; Lussi, 2010).

Em dentina esse processo é mais complexo: a desmineralização inicia-se na região entre as dentinas peri e intertubular; em seguida, a peritubular é perdida, aumentando-se a embocadura dos túbulos dentinários; por fim, ocorre a exposição da matriz colágena da dentina intertubular (Meurman et al., 1991; Kinney et al., 1995). 
Sua presença é de extrema importância na modulação da progressão do desgaste, por seu efeito tampão (Ganss et al., 2004; Zero; Lussi, 2005; Kato et al., 2009b, 2010b). Quanto maior a quantidade de colágeno exposto, maior a dificuldade de penetração de ácidos na dentina parcialmente desmineralizada e, sob ela, na mineralizada, o que faz com que o processo desacelere (Klont; ten Cate, 1991a; Kleter et al., 1994; Kato et al., 2009b, 2010b).

Em paralelo ao que acontece para lesões de cárie em dentina, para o desgaste erosivo, não são propriamente, pois, os ácidos, em um caso produzidos pelo metabolismo bacteriano, no outro, advindos de fontes endógenas ou exógenas, que promovem a degradação da matriz orgânica deste substrato, propiciando o avanço da perda tecidual, embora sejam os responsáveis pela desmineralização da superfície (Tjäderhane et al., 1998; Sulkala et al., 2001; Chaussain-Miller et al., 2006; Hannas et al., 2007; Featherstone, 2008). Imcumbidas da degradação da matriz orgânica estão justamente as enzimas proteolíticas, ativadas pelo baixo pH (Katz et al., 1987; van Strijp et al., 1997; Tjäderhane et al., 1998; Featherstone, 2008).

Com a degradação das fibrilas de colágeno, a destruição da estrutura dentária se agrava, podendo atingir níveis para os quais restaurações tornam-se necessárias, a fim de se restabelecer forma anatômica (Kilpatrick; Mahoney, 2004; Peutzfeldt et al., 2014) e estética, e mesmo favorecer a higiene e diminuir a hipersensibilidade dentinária (Lussi et al., 2006).

No sentido, a resina composta tem sido considerada o material de eleição para estes casos, respeitando-se a prática da tão famigerada Odontologia Minimamente Invasiva (Lambrechts et al., 1996; Hemmings et al., 2000; Bartlett; Sundaram, 2006; Loguercio et al., 2009; Dietschi; Argente, 2011). Sua indicação só é possível, porém, em função da adesão micromecânica, propiciada pela aplicação de agentes intermediários denominados sistemas adesivos, entre a resina propriamente e a dentina, no caso, erodida (Milia et al., 2012; Matos et al., 2017). Tanto os materiais, como o substrato exercem, pois, influência no sucesso do tratamento, e a relação entre os mesmos deve ser compreendida em profundidade (Milia et al., 2012).

Quanto ao substrato dentinário erodido, apresenta características físicas e químicas diferentes daquelas do normal/hígido, expressas, a priori, por uma superfície amolecida em esmalte, com a progressão da lesão e o avanço em dentina, a estrutura é configurada por ser esponjosa e desmineralizada (Ganss et al., 2014). Ora, em 
similaridade ao que se nota para a dentina afetada por cárie (Haj-Ali et al., 2006; Balooch et al., 2008; Pugach et al., 2009), a qualidade de interfaces adesivas estabelecidas nesse substrato tem sido considerada bem inferior à daquelas estabelecidas no normal (Zimmerli et al., 2012).

\subsection{RESTAURAÇÃO DO SUBSTRATO DENTINÁRIO ERODIDO}

Preparar o substrato dentinário a fim de torná-lo apto a receber uma resina composta como material restaurador implica a aplicação de substâncias constituídas por ácidos, solventes e monômeros para que se estabeleça, então, uma interface adesiva, satisfatória e duradoura em uma concepção ideal (Carvalho et al., 2004).

O grau de comprometimento desse substrato influencia, porém, negativamente em sua propensão à interação com materiais adesivos, em similaridade ao que se aprecia no tocante ao aumento de sua proximidade do órgão pulpar (Yoshikawa et al., 2012).

Mesmo para esmalte, substrato favorável ao estabelecimento de interfaces adesivas, valores de resistência de união ao conjunto sistema adesivo-resina composta obtidos quando de seu comprometimento por desafio erosivo são inferiores àqueles obtidos quando da conservação do substrato normal, já que irregularidades e alterações superficiais resultam em hibridização menos satisfatória (Wang et al., 2014a). Em sentido similar, mas especificamente em dentina e utilizando-se sistema adesivo do tipo condicione e lave, valores de resistência de união ao substrato normal são superiores àqueles ao erodido, inclusive ao longo do tempo (Cruz et al., 2015). Utilizando-se adesivo autocondicionante, nota-se menor prejuízo do desafio erosivo a esses valores imediatamente; após 1 ano de envelhecimento, no entanto, tais valores são claramente reduzidos pela condição do substrato (Sattabanasuk et al., 2007; Schmidlin et al., 2008).

Devido à perda estrutural e à redução da dureza da dentina causadas pela erosão, limitações são impostas à adesão de materiais resinosos a este substrato, tal qual ao afetado por cárie, com estrutura morfológica e histologicamente alterada (de Lourdes; Chavez 1979; Pinheiro et al., 2008). Há, porém, evidências científicas que suportam a remoção incompleta do tecido cariado, mantendo-se a dentina afetada 
nas paredes de fundo da cavidade, preservando-se maior quantidade de estrutura remanescente (Mertz-Fairhurst et al., 1998; Banerjee et al., 2000; Maltz et al., 2007, 2013, Browning et al., 2013; Schwendicke et al., 2013): isso resulta em implicações na capacidade de adesão (Kinney et al., 1995; Marshall et al., 1997), que devem ser contornadas pela remoção dessa dentina das paredes circundantes, favorecendo-se o selamento marginal da restauração (Maltz et al., 2007).

Via de regra, quando da opção por sistemas adesivos do tipo condicione e lave, a dentina é condicionada por um ácido fosfórico, que promove remoção da camada de esfregaço (smear layer), desobliteração dos túbulos dentinários e ampliação de seus lúmens, e desmineralização da detina intertubular, expondo-se a trama de colágeno que constitui sua matriz orgânica (Pashley; Carvalho, 1997).

Nesse substrato devidamente permeável, os monômeros resinosos do sistema adesivo penetram no interior túbulos dentinários, formando os tags resinosos, e permeiam a trama colágena, caracterizando, então, quando da polimerização, a camada híbrida (Nakabayashi et al., 1982; Pashley; Carvalho, 1997; Perdigão, 2010).

A incorreta infiltração dos monômeros resinosos e, por conseguinte, a conservação de fibrilas colágenas expostas e não envoltas por resina (Breschi et al., 2010), diante de umidade, pode resultar em prejuízo da resistência de união ao longo do tempo, justamente em função de sua degradação pelas enzimas proteolíticas do próprio hospedeiro, ativadas pelo baixo pH do ácido fosfórico (Pashley et al., 2004, 2011; Breschi et al., 2008).

Haja vista, nesse sentido, a condição da dentina afetada por cárie, e particularmente daquela erodida, reconhecidamente desmineralizadas, antes mesmo da aplicação do ácido fosfórico, entende-se porque nesses substratos são estabelecidas interfaces adesivas ainda menos satisfatórias e duradouras: mais dificuldade têm os monômeros de infiltrar a trama colágena por completo (Wang et al., 2007; Zimmerli et al., 2012; Mena-Serrano et al., 2013). Ademais, tais substratos são mais úmidos que o dentinário normal, o que os torna mais susceptíveis à degradação hidrolítica, além de, de início, já ser comprometida a correta conversão dos monômeros em polímeros (Lussi et al., 2011; Zimmerli et al., 2012). Assim sendo, a resistência de união de materiais resinosos à dentina erodida é diminuída e a longevidade da interface adesiva, prejudicada (Cersosimo et al., 2016; Amsler et al., 2017; Frattes et al., 2017). 
Para equiparar os valores de resistência de união à dentina erodida àqueles à normal, a asperização com pontas diamantadas mostra-se das mais satisfatórias opções (Zimmerli et al., 2012). No entanto, a fim de minimizar ou suspender a progressão do desgaste erosivo e favorecer a restauração adesiva do substrato dentinário, inclusive erodido, de maneira conservadora, inibidores de proteinases e agentes de estabelecimento de ligações cruzadas entre fibrilas de colágeno vêm sendo estudados (Kato et al., 2009a; Magalhães et al., 2009b; Mirkarimi; Toomarian, 2012; Tjäderhane et al., 2013a, 2013b; De Moraes et al., 2016; Boteon et al., 2017a, 2017b; Leme-Kraus et al., 2017).

\subsection{INIBIDORES DE PROTEINASES E AGENTES DE ESTABELECIMENTO DE LIGAÇÕES CRUZADAS ENTRE FIBRILAS DE COLÁGENO}

A atividade das proteinases pode ser regulada pela a2-macroglobulina, um inibidor endógeno em fluidos tissulares, por meio do aprisionamento das mesmas em seu interior, não inibindo a MMP, mas impedindo sua atividade nos substratos (Strickland et al., 1990; Brew et al., 2000; Sternlicht; Werb, 2001; Folgueras et al., 2004). Existem, ainda, os inibidores teciduais de MMPs (tissue inhibitors of metalloproteinases - TIMPs), capazes de controlar a atividade de todas as MMPs já identificadas (Hannas et al., 2007; Arakaki et al., 2009). Estes são, contudo, inibidores endógenos, de ação localizada e reversível, presentes na cavidade oral (Hannas et al., 2007) que só se expressam diante de um desarranjo tecidual (Visse; Nagase, 2003). Em outras palavras, o equilíbrio das MMPs e dos TIMPs é crítico para a remodelação da MEC (Nagase et al., 2006), mesmo que esforços se destinem à busca por aumento da especificidade dos TIMPs, por meio de transferência de genes expressos no local em que se deseja atuação (Nagase et al., 2006).

Em contrapartida, inibidores enzimáticos sintéticos e naturais de origem externa têm sido estudados no que se refere à conservação da camada híbrida em restaurações adesivas e mesmo à contenção da evolução de processos patológicos de perda de estrutura dentinária (Tjäderhane et al., 2013b). Dentre eles, destacam-se a clorexidina $(\mathrm{CHX})$, muito utilizada como agente antimicrobiano, e a 
epigalocatequina-3-galato (EGCG) um polifenol proveniente do princípio ativo do chá verde (Chaussain-Miller et al., 2006).

A CHX atua modificando a estrutura tridimensional das MMPs e quelando os íons cálcio e zinco, responsáveis por sua ativação (Osorio et al., 2011). Tal composto sintético é capaz de inativar essas enzimas, em especial, as colagenases (Pashley et al., 2004) mesmo em baixas concentrações (Breschi et al., 2009, 2010). Atua, ainda, inibindo as cisteíno catepsinas pela interação tridimensional da $\mathrm{CHX}$ com aminoácidos dos sítios ativos dessas enzimas (Scaffa et al., 2012).

Nesta perspectiva, a fim de coibir a degradação da interface adesiva, preservando-se a camada híbrida, Hebling et al. (2005), como pioneiros nessa linha de pesquisa, e por meio de estudo in vivo, utilizaram uma solução de $\mathrm{CHX}$ a $2 \%$ na restauração de dentes decíduos, como primer antiproteolítico, depois do condicionamento com ácido fósforico e previamente à aplicação de um sistema adesivo do tipo condicione e lave de 2 passos, impregnando a cavidade com essa solução por 30 segundos e secando-a, suavemente, em seguida, a fim de manter a dentina úmida. Depois da restauração com resina composta, e diante da esfoliação, decorridos aproximadamente 6 meses, avaliaram a qualidade da interface adesiva por meio de microscopia eletrônica de transmissão. Observaram, quando da aplicação da CHX, uma camada híbrida menos degradada se comparada com a estabelecida no grupo controle, onde se evidenciou maior impregnação de nitrato de prata (nanoinfiltração).

Estudos de Carrilho et al. (2007a, 2007b) analisaram, então, in vitro, interfaces adesivas estabelecidas em dentina tratada com $\mathrm{CHX}$ a $2 \%$, como primer antiproteolítico, por 60 segundos, após o condicionamento ácido, ou alterativamente com água destilada, por meio testes de microtração (resistência de união) e microscopia eletrônica de varredura (análise do padrão de fratura dos palitos). A aplicação de $\mathrm{CHX}$ não exerceu influência significante, imediatamente, nem sobre os valores de resistência de união, nem sobre os padrões de fratura, quando comparada à de água (controle). Após 6 meses de envelhecimento em saliva artificial, a RU foi menor do que imediatamente para as duas condições, contudo significativamente menos para o grupo em que se aplicou $\mathrm{CHX}$. Além disso, o padrão de fratura mais prevalente para os espécimes do grupo controle, independentemente do envelhecimento, foi o ocorrido na própria camada híbrida, em sua porção mais 
superficial, ou na mais profunda. Por outro lado, após 6 meses de envelhecimento, o padrão de fratura predominante do grupo em que se aplicou $\mathrm{CHX}$ passou a ser 0 acontecido na camada de adesivo propriamente ou até na resina composta.

Breschi e coloboradores (2010) também demonstraram, por meio da observação por zimografia, a potencial atividade inibitória gelatinolítica da dentina, quando da aplicação de soluções de CHX, como primer antiproteolítico, nas mais diversas concentrações. Além disso, evidenciaram que a $\mathrm{CHX}$ pode minimizar por até 2 anos a diminuição dos valores de $\mathrm{RU}$ à dentina e mesmo a nanoinfiltração da interface adesiva aí estabelecida. Diante disso, sugeriu-se que a $\mathrm{CHX}$, como primer antiproteolítico, poderia ser adotada em procedimentos restauradores adesivos como forma de melhorar a estabilidade da camada híbrida, e consequentemente, a longevidade da união (Moon et al., 2010). Por sinal, bem recentemente, Loguercio et al. (2016) mostraram que aumenta a estabilidade da interface adesiva por até 5 anos.

Ainda, a fim de se minorar as limitações relacionadas à toxicidade da $\mathrm{CHX}$, soluções com concentrações menores dessa substância, como 0,2\% e 0,002\%, foram analisadas no mesmo contexto e mostraram-se tão eficazes quanto aquelas a $2 \%$ (Gendron et al., 1999; Breschi et al., 2009, 2010; Loguercio et al., 2009; Francisconidos-Rios et al., 2015b). O mesmo se relevou eficaz quando da incorporação da $\mathrm{CHX}$ aos próprios sistemas adesivos (Sabatini, 2013; Malaquias et al., 2018).

Contrariamente, outros autores mostraram que a aplicação de $\mathrm{CHX}$ como inibidor de proteases não favorece a qualidade e/ou a longevidade de restaurações adesivas (de-Melo et al., 2013; Sabatini, 2013; Montagner et al., 2015; Perote et al., 2015; Silva et al., 2015; Giacomini et al., 2017; Farias-Neto et al., 2018). Montagner et al. (2015) realizaram um estudo clínico restaurando cavidades de classe V, tratando-as com uma solução de $\mathrm{CHX}$ ou não, e acompanhando-as por 6 meses: a CHX não exerceu influência significante sobre a taxa de retenção da restaurações. Mesmo com acompanhamentos mais longos, por 18 e 36 meses, resultados correspondentes foram verificados (Dutra-Correa et al., 2013; Sartori et al., 2013). In vitro, notou-se, da mesma maneira, similitude entre a resistência de união do conjunto adesivo condicione e lave simplificado-resina composta à dentina, quando da aplicação ou não da CHX como primer antiproteolítico (de-Melo et al., 2013; Sabatini 2013; Perote et al., 2015) e, em alguns casos, especialmente para a dentina erodida, por refrigerante à base de cola ou suco de laranja, mesmo influência negativa desta, 
quando da avaliação imediata dos espécimes (Silva et al., 2015; Giacomini et al., 2017; Farias-Neto et al., 2018).

Para condições distintas de substrato, que não especificamente a dentina normal/hígida, inclusive, estudos até apontam efeitos favoráveis da aplicação de $\mathrm{CHX}$ a $2 \%$, como primer antiproteolítico: ela diminui a nanoinfiltração da interface adesiva estabelecida em dentina afetada por cárie (Carrilho et al., 2007a, 2007b; Breschi et al., 2010), bem como mantém estáveis os valores de RU à dentina erodida por até 6 meses (Apayco, 2013; Sabatini, 2013; Francisconi-dos-Rios et al., 2015a, 2015b). Apesar disso, não torna os valores de $\mathrm{RU}$ à dentina erodida equilalentes àqueles à dentina normal, nem imediatamente (Farias-Neto et al., 2018) nem após envelhecimento (Apayco, 2013; Francisconi-dos-Rios et al., 2015b, 2015a), e também não impede o decréscimo dos mesmos quando de envelhecimento mais longo (12 meses) (Francisconi-dos-Rios et al., 2015a).

Por outra perspectiva, porém, no que se refere ao susbtrato dentinário alterado, a $\mathrm{CHX}$, como agente antiproteolítco, tem se mostrado eficaz no controle da progressão do desgaste erosivo: quando aplicada sob a forma de enxaguatório bucal, a $0,12 \%$, foi capaz de reduzir a desmineralização e a perda de estrutura dentinária (Magalhães et al., 2009b). Na forma de gel, inibiu completamente o desgaste erosivo decorrente de ciclagem de $\mathrm{pH}$ com refrigerante à base de cola (Magalhães et al., 2009b; Kato et al., 2010a), talvez pelo maior tempo do contato com a superfície (Kato et al., 2010a).

Alternativa à $\mathrm{CHX}$, tanto na conservação de interfaces adesivas, quanto no controle da progressão do desgaste erosivo, especialmente em função de seu potencial citotóxico (Costa et al., 1999; Kato et al., 2009a, 2012; Lessa et al., 2010a; Mirkarimi; Toomarian, 2012; Wang et al., 2018), é a EGCG. Além de ser natural, de fácil obtenção e de baixo custo, esse polifenol proveniente do extrato de chá verde não oferece risco à polpa, como o oferecem as soluções de $\mathrm{CHX}$, ainda que nem sempre quando se considera a difusão transdentinária (Lessa et al., 2010b), nas mais diversas concentrações, independentemente do tempo de contato com células odontoblasto-símiles em cultura (Lessa et al., 2010a).

Acredita-se que a EGCG atua ligando-se às colagenases por meio do estabelecimento de pontes de hidrogênio e de interações hidrofóbicas, alterando a conformação de seus sítios catalíticos, ou mascarando-os, impedindo a ligação dos 
mesmos com íons metálicos que tornam as proteases ativas (Cheng et al., 2003; Madhan et al., 2007).

Quanto ao papel da EGCG no estabelecimento e conservação de interfaces adesivas, evidenciam-se efeitos favoráveis no tocante aos valores de resistência de união ao substrato dentinário diante de envelhecimento por 6 meses, tanto quando aplicada como primer antiproteolítico (Santiago et al., 2013), como quando incorporada a adesivos do tipo condicione e lave (de Macedo et al., 2018). Aliás, nesse segundo caso, a EGCG não prejudica a própria polimerização dos adesivos (de Macedo et al., 2018). Contudo, quando incorporada a adesivos autocondicionantes, que não o ClearFill SE Bond, a força de união é prejudicada pela incorreta conversão dos monômeros em polímeros (Khamverdi et al., 2015; de Macedo et al., 2018).

Relativamente a seu desempenho no controle da progressão do desgaste erosivo, a EGCG mostra-se também bastante eficaz (Kato et al., 2009a, 2012): menor perda de microdureza superficial e túbulos dentinários com embocaduras de menores diâmetros são observados quando de sua aplicação, comparativamente a diferentes controles (Kato et al., 2009a; Mirkarimi; Toomarian, 2012; Wang et al., 2018). A propósito, quando incorporada a um refrigerante à base de cola, é capaz de reduzir seu potencial erosivo (Barbosa et al., 2011).

A imersão, por 1 minuto, da dentina em solução de chá verde (Kato et al., 2009a; De Moraes et al., 2016), ou de seu extrato propriamente (Magalhães et al., 2009b), antes de desafio erosivo, reduz ou impede o desgaste superficial (Kato et al., 2009a; De Moraes et al., 2016) e controla o aumento de sua rugosidade (Mirkarimi; Toomarian, 2012; De Moraes et al., 2016), por suposto em função da manutenção da camada orgânica (Kato et al., 2009a), não mais degradada pelas proteases, como outrora abordado (Kato et al., 2012).

Favorecem, por fim, a resistência da matriz orgânica à degradação, agentes simultaneamente inibidores de proteases e indutores do estabelecimento de ligações cruzadas entre as fibrilas de colágeno, tais quais as proantocianidinas (PACs), encontradas facilmente na natureza em plantas, frutas, sementes e, destacavelemente, no extrato de semente de uva (Bedran-Russo et al., 2013). Por serem de origem natural, as PACs possuem baixo custo e baixa toxicidade (BedranRusso et al., 2013), principalmente se comparadas com outros indutores, como o formaldeído e o glutaraldeído, que além de citotóxicos, são instáveis (Han et al., 2003). 
As PACs, oligoméricas, são polifenóis provenientes do grupo tanino condensado (Han et al., 2003). Têm diversidade estrutural pela variação monomérica da flavan-3-ol, construída por cadeias aromáticas e suas hidroxilas (Shi et al., 2003), pelas diferentes ligações entre as cadeias, e pelos seus diversos comprimentos (Hümmer; Schreier, 2008).

Pontes de hidrogênio estabelecidas entre a carbonila da amida proteica e a hidroxila fenólica da PAC podem favorecer a estabilidade da estrutura colágena, aumentando sua resistência à degradação enzimático-hidrolítica (Stenzel et al., 1974), além de sua temperatura de desnaturação (Danilov et al., 2008). A prolina, proteína presente em exuberância no colágeno, é um aminoácido com oxigênio do grupo carbonila dispondo de alta especificidade para ligações com a PAC (Hagerman; Butler, 1981). Sua cadeia lateral apolar não permite que se estabeleçam pontes de hidrogênio, e sim, interações hidrofóbicas; quando estas acontecem, o contato com a água é minimizado pelas forças não-covalentes, proporcionando estabilidade ao tecido (Mota, 2005).

Com base nessa premissa, estudos reportaram a eficácia do extrato de semente de uva a 6,5\%, quando utilizado como parte do tratamento adesivo do substrato dentinário, depois de seu condicionamento com ácido fosfórico, por 1 hora, na resistência de união de materiais adesivos ao mesmo e na melhora das suas propriedades mecânicas (Al-Ammar et al., 2009; Dos Santos et al., 2011; Leme-Kraus et al., 2017). O maior número de ligações cruzadas estabelecidas nesse caso pode ser evidenciado por meio de marcação com o corante fluorescente rodamina $B$ e, indiretamente, pela redução da micropermeabilidade do substrato (Aydin et al., 2016). Em se considerando a questão do tempo, demasiado extenso para a prática clínica, Delgado et al. (2015) verificaram, oportunamente, que a ação de PACs, por curtos períodos (particularmente 15 e 30 segundos, mas mesmo 5 segundos), é apta a ao menos inibir a atividade de certas MMPs.

Originalmente, ainda, géis contendo PACs, independentemente de sua concentração, mostraram-se promissores ao controle da progressão do desgaste erosivo do substrato dentinário, pela estabilização da matriz orgânica desmineralizada (Boteon et al., 2017a, 2017b; Leme-Kraus et al., 2017).

Há que se verificar, pois, o papel de todas essas substâncias (CHX, EGCG e PAC), numa associação de ambos os contextos em que se mostram mais ou menos 
favoráveis: existiria relação de sua aplicação como agente para controle da progressão do desgaste erosivo com a qualidade de interfaces adesivas estabelecidas nesse substrato? 


\section{PROPOSIÇÃO}

O objetivo deste estudo in vitro é avaliar, de imediato, o efeito de inibidores de proteases (CHX e EGCG) e de um agente também promotor do estabelecimento de ligações cruzadas entre fibrilas de colágeno (PAC), usados como estratégias para prevenção/controle do desgaste, na resistência de união (RU) do conjunto sistema adesivo condicione e lave simplificado-resina composta à dentina erodida, comparada à normal.

Como hipótese alternativa, pressupõe-se que tais agentes, sem diferenças entre si, serão capazes de determinar, por meio da preservação/controle do desgaste erosivo, um substrato tão favorável à adesão com os materiais resinosos quanto o normal. 



\section{MATERIAL E MÉTODOS}

\subsection{DELINEAMENTO EXPERIMENTAL}

Este estudo in vitro, conduzido de acordo com o preconizado pelo "CRIS Guidelines" (Checklist for Reporting In-vitro Studies; Krithikadatta et al., 2014), inclusive em sequência aleatória e de maneira cega, avaliou, imediatamente, a resistência de união do conjunto sistema adesivo condicione e lave simplificado-resina composta à dentina, considerando-se como fatores experimentais a condição desse substrato, em dois níveis ( $\mathrm{N}$ : normal; $\mathrm{E}$ : erodido), e a aplicação de géis para prevenção/controle do desgaste erosivo, com diferentes princípios ativos, em cinco níveis (C: controle/sem aplicação; P: placebo/sem princípio ativo; $\mathrm{CHX}$ : digluconato de clorexidina a 0,12\%; EGCG: epigalocatequina-3-galato a $400 \mu \mathrm{m}$; PAC: proantocianidina a $10 \%$ ). Ademais, considerando-se os mesmos fatores, nos mesmos níveis, avaliou-se qualitativamente a interface adesiva por meio de microscopia confocal de varredura a laser (MCVL).

As variáveis quantitativa e qualitativa de resposta foram, respectivamente, os valores de resistência de união à microtração ( $\mu \mathrm{TBS}$ ), em MPa, considerando-se cada dente como unidade experimental, e a descrição de imagens obtidas por meio de MCVL. O padrão de fratura dos palitos foi determinado com o auxílio de um microscópio digital (50x de aumento).

\subsection{OBTENÇÃO DOS DENTES HUMANOS}

Após aprovação do projeto pelo Comitê de Ética em Pesquisa da Faculdade de Odontologia da Universidade de São Paulo (Anexo A), comprometeu-se o Biobanco da FOUSP - Divisão de Dentes Humanos a fornecer 100 terceiros molares humanos hígidos para condução de testes piloto (20 dentes) e para a realização do estudo propriamente dito (70 dentes). Determinou-se, pois, após seleção dos dentes de acordo com suas devidas dimensões, dez grupos experimentais de 7 dentes cada. Um dente extra para cada grupo, ou seja, mais dez dentes (10 dentes), foram, ainda, 
utilizados para devido tratamento e avaliação qualitativa da interface adesiva neles estabelecida por meio de MCVL. Note-se, pois, que se somando os dentes destinados aos testes piloto (20), ao estudo propriamente dito (70, divididos em dez grupos com 7 cada) e à avaliação por meio de MCVL (10, um referente a cada grupo experimental), totalizam-se os 100 terceiros molares acima descritos. Estes foram limpos com curetas periodontais para remoção de todo e qualquer resíduo de tecido gengival aderido à superfície dentária e, posteriormente, armazenados em solução de $\mathrm{NaCl}$ $0,9 \%$ e $\mathrm{NaN}_{3}, 0,02 \%$, renovada periodicamente, onde ficaram imersos durante todo $\mathrm{o}$ período de preparo dos espécimes. Por meio de seccionamento em máquina de corte de precisão (Isomet Low Speed Saw; Buehler, Lake Bluff, IL, EUA), a porção coronária foi separada da porção radicular: a primeira, no desenrolar do trabalho, foi consumida, em função do preparo de palitos para microtração, não restando material biológico a ser, ao final do estudo, devidamente descartado ou armazenado; a segunda foi devolvida ao Biobanco da FOUSP - Divisão de Dentes Humanos, já que não foi utilizada.

\subsection{EXPOSIÇÃO DA DENTINA E DETERMINAÇÃO DOS GRUPOS EXPERIMENTAIS}

Do total de 100 dentes, excetuando-se os utilizados em testes piloto (20) e os que foram utilizados para MCVL (10), cada um dos 70 dentes selecionados para 0 estudo propriamente dito foi, em seu devido momento, fixado com cera pegajosa no centro de um dispositivo metálico que foi acoplado à máquina de corte de precisão Isomet Low Speed Saw. Com o auxílio de um disco diamantado dupla face refrigerado com água destilada, posicionado perpendicularmente ao longo eixo do dente, a uma velocidade de $300 \mathrm{rpm}$, o terço oclusal foi removido (Figura 4.1A), para exposição da dentina coronária, subjacente ao esmalte. Similarmente, inclusive para se facilitar 0 seccionamento dos espécimes em palitos, posteriormente ao tratamento restaurador, a porção radicular foi removida, por meio de corte paralelo ao primeiro (Figura 4.1B). 
Figura 4.1 - A: Remoção do terço oclusal de cada terceiro molar, para exposição da dentina coronária, subjacente ao esmalte; B: a aspecto do espécime após remoção da porção radicular, por meio de corte paralelo ao primeiro
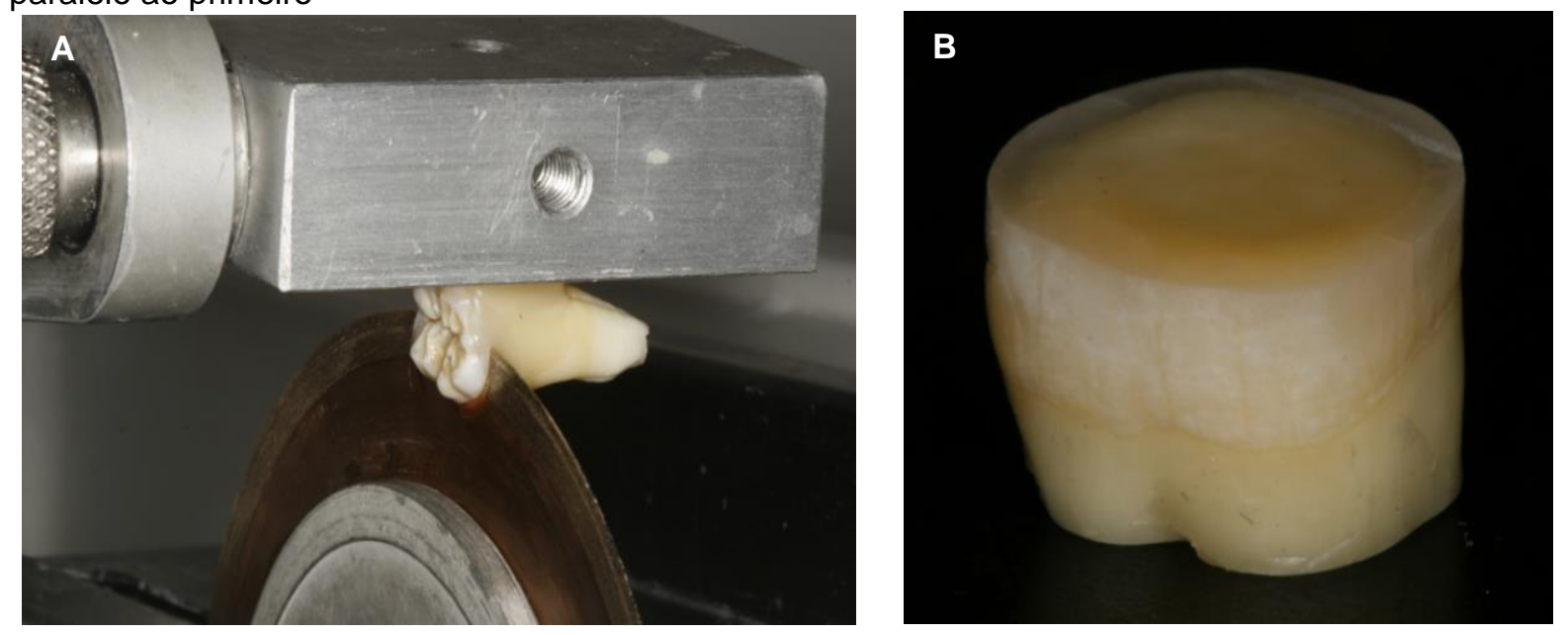

Fonte: A autora

A superfície de dentina dos espécimes foi submetida apenas à ação de uma lixa de carbeto de silício de granulação 600, por 1 minuto, sob refrigeração constante com água destilada, em uma politriz metalográfica, para padronizar a smear layer formada sobre a mesma (Tay; Pashley, 2001), determinando-se o substrato normal (N) (Figura 4.2A), ou sequencialmente a erosão inicial por um refrigerante à base cola (Figura 4.2B), determinando-se o substrato erodido $(\mathrm{E})$.

Figura 4.2 - A: Ação de uma lixa de carbeto de silício de granulação 600, por 1 minuto, sob refrigeração constante com água destilada, em uma politriz metalográfica, para padronizar a smear layer formada sobre a superfície de dentina, determinando-se o substrato normal (N); B: subsequente erosão inicial por um refrigerante à base cola, determinando-se o substrato erodido $(\mathrm{E})$
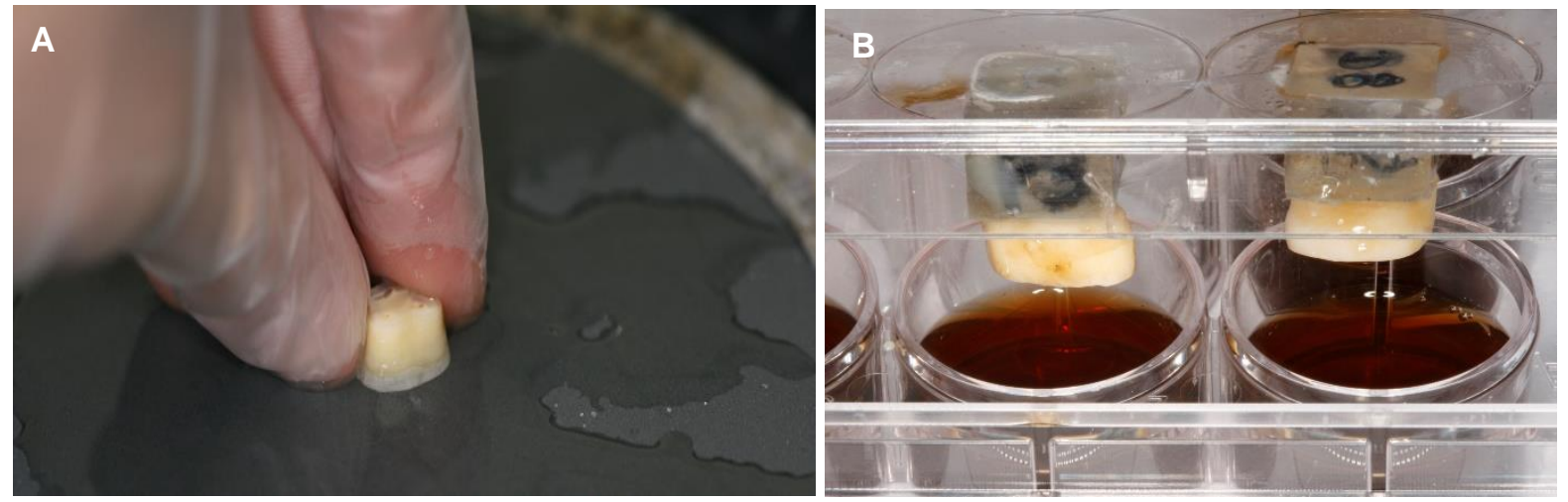

Fonte: A autora 
Foi, então, tratada por meio da aplicação de um dos géis, com diferentes princípios ativos, para prevenção/controle do desgaste erosivo (C: controle/sem aplicação; P: placebo/sem princípio ativo; $\mathrm{CHX}$ : digluconato de clorexidina a 0,12\%; EGCG: epigalocatequina-3-galato a $400 \mu \mathrm{m}$; PAC: proantocianidina a $10 \%$ ), determinando-se, por fim, os seguintes grupos experimentais:

Quadro 4.1 - Grupos experimentais

\begin{tabular}{|c|c|c|}
\hline Grupo & $\begin{array}{l}\text { Condição do } \\
\text { substrato dentinário }\end{array}$ & $\begin{array}{l}\text { Princípio ativo presente no gel para } \\
\text { prevenção/controle do desgaste erosivo }\end{array}$ \\
\hline $\begin{array}{l}\text { N.C } \\
(n=7)\end{array}$ & & $\begin{array}{l}\text { Sem aplicação de gel } \\
\text { (C: controle) }\end{array}$ \\
\hline $\begin{array}{c}\text { N.P } \\
(n=7)\end{array}$ & & $\begin{array}{l}\text { Sem princípio ativo } \\
\text { (P: placebo) }\end{array}$ \\
\hline $\begin{array}{l}\text { N.CHX } \\
(n=7)\end{array}$ & $\operatorname{Normal}(\mathrm{N})$ & $\begin{array}{l}\text { Digluconato de clorexidina a } 0,12 \% \\
\text { (CHX) }\end{array}$ \\
\hline $\begin{array}{l}\text { N.EGCG } \\
(\mathrm{n}=7)\end{array}$ & & $\begin{array}{c}\text { Epigalocatequina 3-galato a } 400 \mu \mathrm{m} \\
\text { (EGCG) }\end{array}$ \\
\hline $\begin{array}{l}\text { N.PAC } \\
(\mathrm{n}=7)\end{array}$ & & $\begin{array}{l}\text { Proantocianidina a } 10 \% \\
\text { (PAC) }\end{array}$ \\
\hline $\begin{array}{l}\text { E.C } \\
(n=7)\end{array}$ & & $\begin{array}{l}\text { Sem aplicação de gel } \\
\text { (C: controle) }\end{array}$ \\
\hline $\begin{array}{l}\text { E.P } \\
(n=7)\end{array}$ & & $\begin{array}{l}\text { Sem princípio ativo } \\
\quad(P: \text { placebo })\end{array}$ \\
\hline $\begin{array}{l}\text { E.CHX } \\
(n=7)\end{array}$ & Erodido $(\mathrm{E})$ & $\begin{array}{l}\text { Digluconato de clorexidina a } 0,12 \% \\
(\mathrm{CHX})\end{array}$ \\
\hline $\begin{array}{l}\text { E.EGCG } \\
(n=7)\end{array}$ & & $\begin{array}{l}\text { Epigalocatequina 3-galato a } 400 \mu \mathrm{m} \\
\text { (EGCG) }\end{array}$ \\
\hline $\begin{array}{c}\text { E.PAC } \\
(n=7)\end{array}$ & & $\begin{array}{l}\text { Proantocianidina a } 10 \% \\
\text { (PAC) }\end{array}$ \\
\hline
\end{tabular}




\subsection{TRATAMENTO DO SUBSTRATO DENTINÁRIO}

Finalizados os testes piloto (20 dentes, dos 100 totais, já utilizados), dos 70 dentes pertencentes ao estudo propriamente dito, as superfícies de dentina de 35 foram, então, diretamente conduzidas à etapa seguinte do experimento (procedimentos adesivos/restauradores), determinando-se condição controle para a variável substrato ( $\mathrm{N}$ : normal).

As de outros 35 dentes foram submetidas a desafio erosivo inicial, por meio da ação de refrigerante à base de cola (Coca-Cola ${ }^{\circledR}$; água carbonada, extrato de noz de cola, cafeína, aroma natural, corante caramelo IV, acidulante ácido fosfórico, edulcorantes artificiais, conservador benzoato de sódio, regulador de acidez citrato de sódio; $6,30 \mathrm{ml}$ por espécime; $\mathrm{pH}$ 2,5), por 5 minutos, em temperatura ambiente, a fim de se iniciar, posteriormente à aplicação dos géis para prevenção/controle do desgaste erosivo, a ciclagem de $\mathrm{pH}$ com substrato já previamente desmineralizado (adaptado de Kato et al. 2012; Boteon et al. 2017a).

Do total de espécimes com substrato normal, um quinto, ou seja, 7, foram diretamente conduzidos à etapa seguinte do experimento, determinando-se, agora, condição controle (C: controle/sem aplicação; N.C [n=7]) para a variável aplicação de géis para prevenção/controle do desgaste erosivo, com diferentes princípios ativos. Outro quinto, isto é, outros 7 dentes, tiveram a superfície dentinária submetida a aplicação de gel placebo/sem princípio ativo ( $P$; hidroxietilcelulose, propilenoglicol, metilparabeno, imidazolidinilureia e água deionizada; N.P [ $n=7]$ ): com micropincel (Brush Fine Aplicadores Descartáveis, KG Sorensen, Cotia/SP - Brasil), em fina camada, e, após ação passiva por 5 min, remoção com hastes flexíveis com pontas de algodão (Cotonete, Johnson \& Johnson do Brasil Indústria e Comércio de Produtos para Saúde Ltda., São José dos Campos/SP - Brasil) . Em seguida, descansaram em umidade relativa e em temperatura ambiente por $2 \mathrm{~h}$ (Vertuan et al. 2018). Conforme este protocolo, cada um dos quintos remanescentes foram submetidos a aplicação de gel com digluconato de clorexidina a $0,12 \%$ (CHX; N.CHX [n=7]), com epigalocatequina-3-galato a $400 \mu \mathrm{m}$ (EGCG; N.EGCG [n=7]) ou com proantocianidina a 10\% (PAC; N.PAC [n=7]) como respectivos princípios ativos (Figura 4.3), 
Figura 4.3 - Aplicação de um dos géis, com diferentes princípios ativos, para prevenção/controle do desgaste erosivo (C: controle/sem aplicação; P: placebo/sem princípio ativo; CHX: digluconato de clorexidina a 0,12\%; EGCG: epigalocatequina-3-galato a $400 \mu \mathrm{m}$; PAC: proantocianidina a $10 \%)$

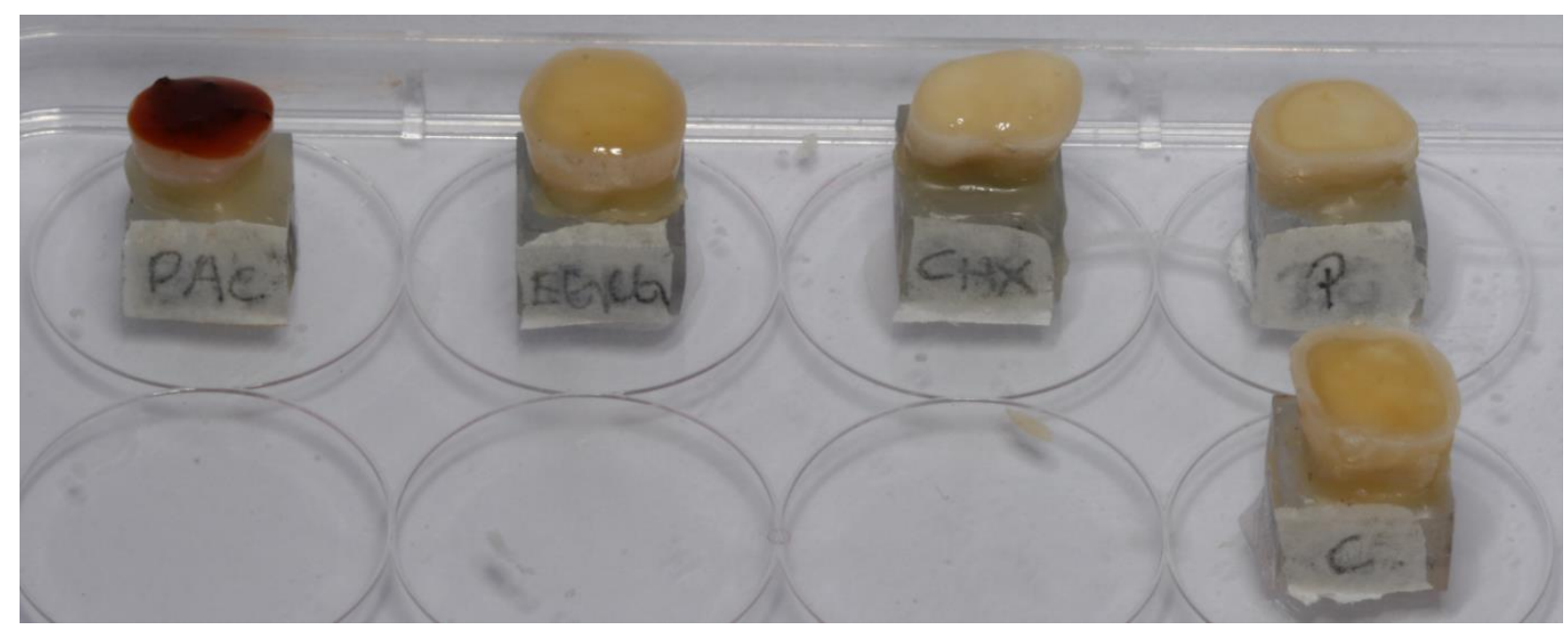

Fonte: A autora

Os espécimes a serem submetidos a ciclagem de $\mathrm{pH}$, para fatídico estabelecimento do substrato erodido $(E)$, foram tratados, quanto à aplicação dos géis para prevenção/controle do desgaste erosivo, exatamente da forma como acima descrito (E.C [n=7], E.P [n=7], E.CHX [n=7], E.EGCG [n=7] e E.PAC [n=7]), após $12 \mathrm{~h}$ da desmineralização inicial, tempo em que permaneceram armazenados em saliva artificial $\left(\mathrm{CaCl}_{2}\right.$ 0,70 mM/L; $\mathrm{MgCl}_{2} .6 \mathrm{H}_{2} \mathrm{O} 0,20 \mathrm{mM} / \mathrm{L} ; \mathrm{KH}_{2} \mathrm{PO}_{4} 4,00 \mathrm{mM} / \mathrm{L} ; \mathrm{KCl} 30,0$ $\mathrm{mM} / \mathrm{L}$; $\mathrm{NaN}_{3}$ 0,30 mM/L; Tampão HEPES [ácido] 20,0 mM/L), em temperatura ambiente. Para realização da ciclagem de $\mathrm{pH}$, por 5 dias, os espécimes foram desafiados pelo refrigerante à base de cola (Coca-Cola ${ }^{\circledR} ; 6,30 \mathrm{ml}$ por espécime; um novo frasco aberto a cada desafio), três vezes ao dia (8, 13 e 18h), por 5 minutos, em temperatura ambiente (Figura 4.4). Antes e depois, foram devidamente lavados, por $20 \mathrm{~s}$, com água destilada. Nos intervalos entre os desafios, inclusive durante a noite, foram armazenados em saliva artificial, substituída diariamente (Francisconi-dos-Rios et al. 2015b; Vertuan et al. 2018). 
Figura 4.4 - Ciclagem de pH, para fatídico estabelecimento do substrato erodido (E): imersão em refrigerante à base de cola (Coca-Cola ${ }^{\circledR} ; 6,30 \mathrm{ml}$ por espécime; um novo frasco aberto a cada desafio), três vezes ao dia (8, 13 e 18h), por 5 minutos, durante 5 dias, e armazenagem em saliva artificial, substituída diariamente, nos intervalos entre os desafios e durante a noite

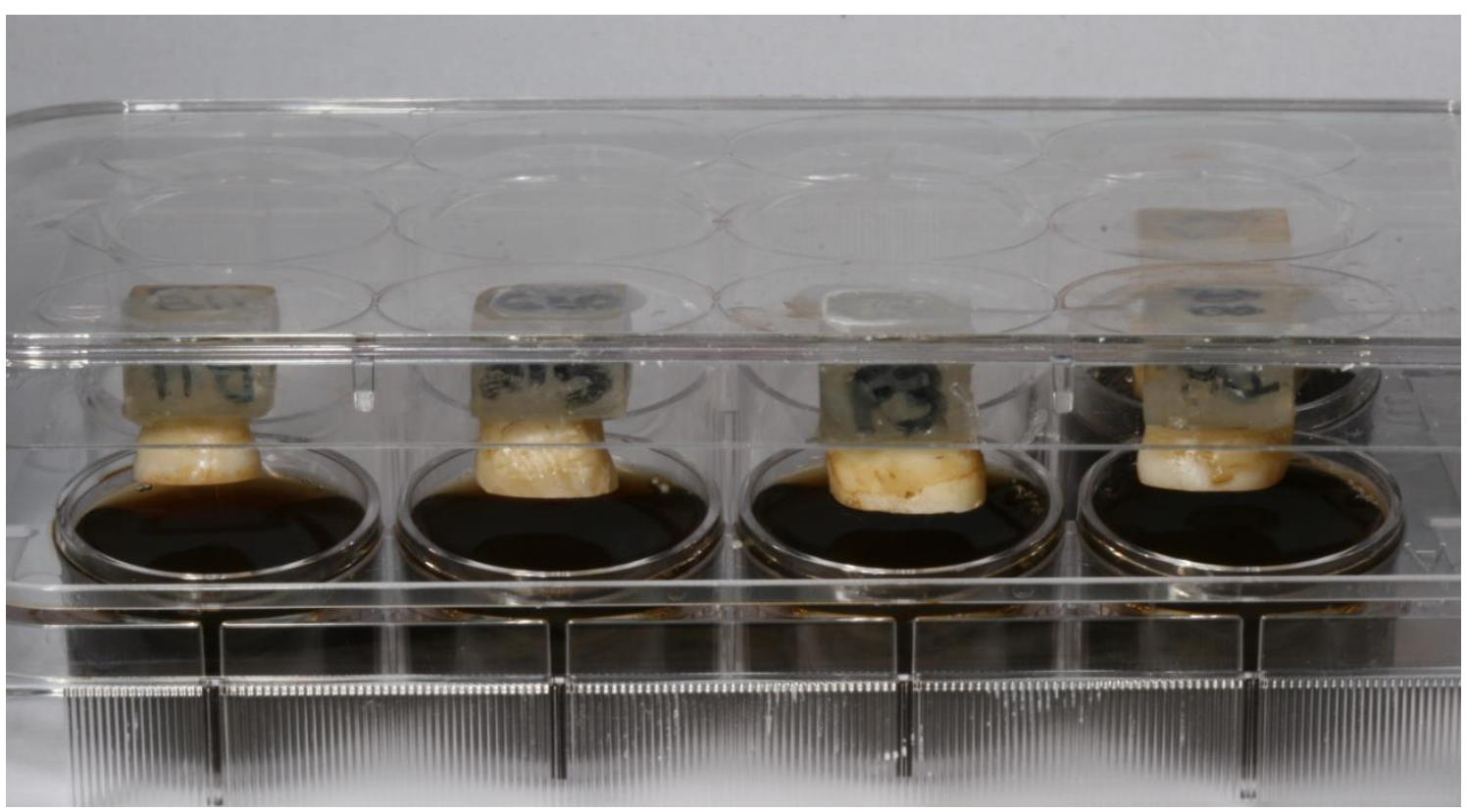

Fonte: A autora

\subsection{PROCEDIMENTOS ADESIVOS/RESTAURADORES}

Findas cada e todas as etapas do tratamento do substrato dentinário, conforme grupos experimentais, as respectivas superfícies de todos os espécimes foram, então, condicionadas com ácido fosfórico a 37\% (Etching Dental Gel, Dentsply Indústria e Comércio; Rio de Janeiro, RJ, Brasil) (Figura 4.5A), por 15 segundos, lavadas pelo dobro do tempo (Figura 4.5B), e secas com papel absorvente (Figura 4.5C). 
Figura 4.5 - A: Condicionamento da superfície de dentina de todos os espécimes com ácido fosfórico a $37 \%$, por 15 segundos; B: lavagem pelo dobro do tempo; C: secagem com papel absorvente
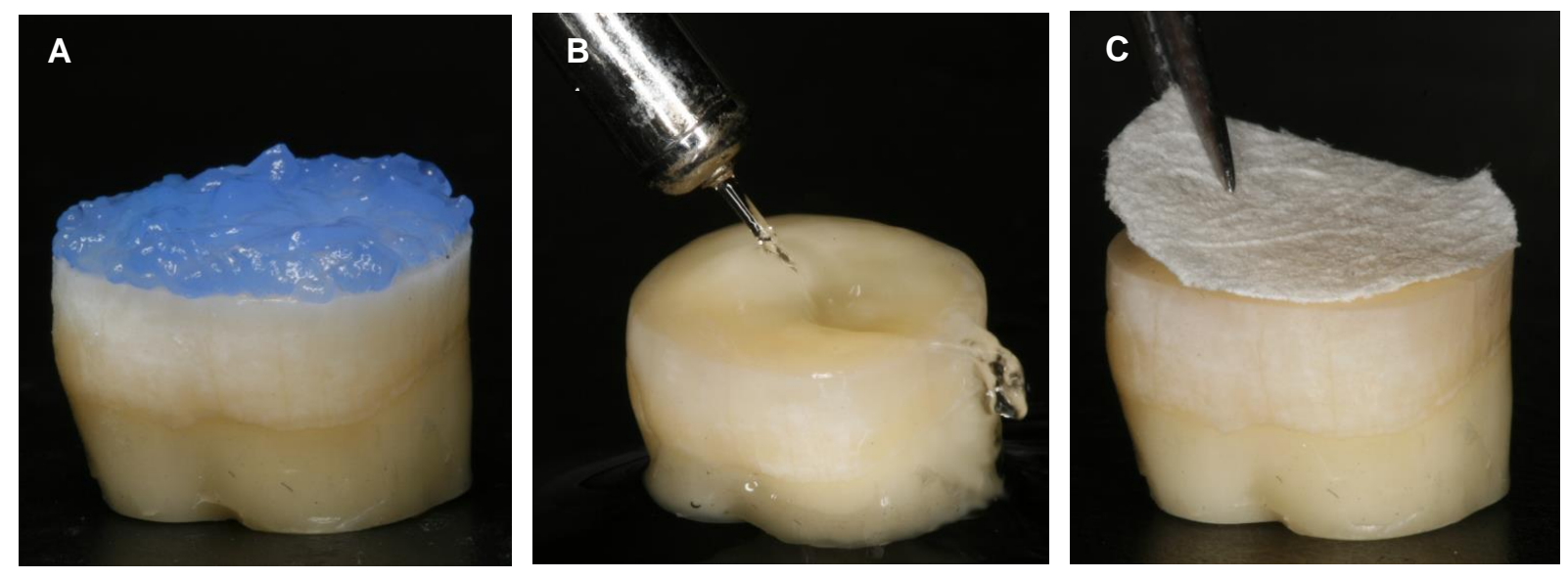

Fonte: A autora

Em seguida, receberam aplicação do sistema adesivo condicione e lave simplificado Adper ${ }^{\mathrm{TM}}$ Single Bond $2^{\circledR}$ (3M ESPE Division, St. Paul/MN - EUA), conforme instruções do fabricante: de forma ativa (15 s), em duas camadas finas, com um leve jato de ar para facilitação da evaporação do solvente (Figura 4.6A), e fotoativação por 10 segundos $\left(1000 \mathrm{~mW} / \mathrm{cm}^{2}\right.$; Radii-cal, SDI, Bayswater, Vitoria, Austrália) (Figura 4.6B).

Figura 4.6 - A: Aplicação de adesivo, de forma ativa (15 s), em duas camadas finas, com um leve jato de ar para facilitação da evaporação do solvente; B: fotoativação por 10 segundos
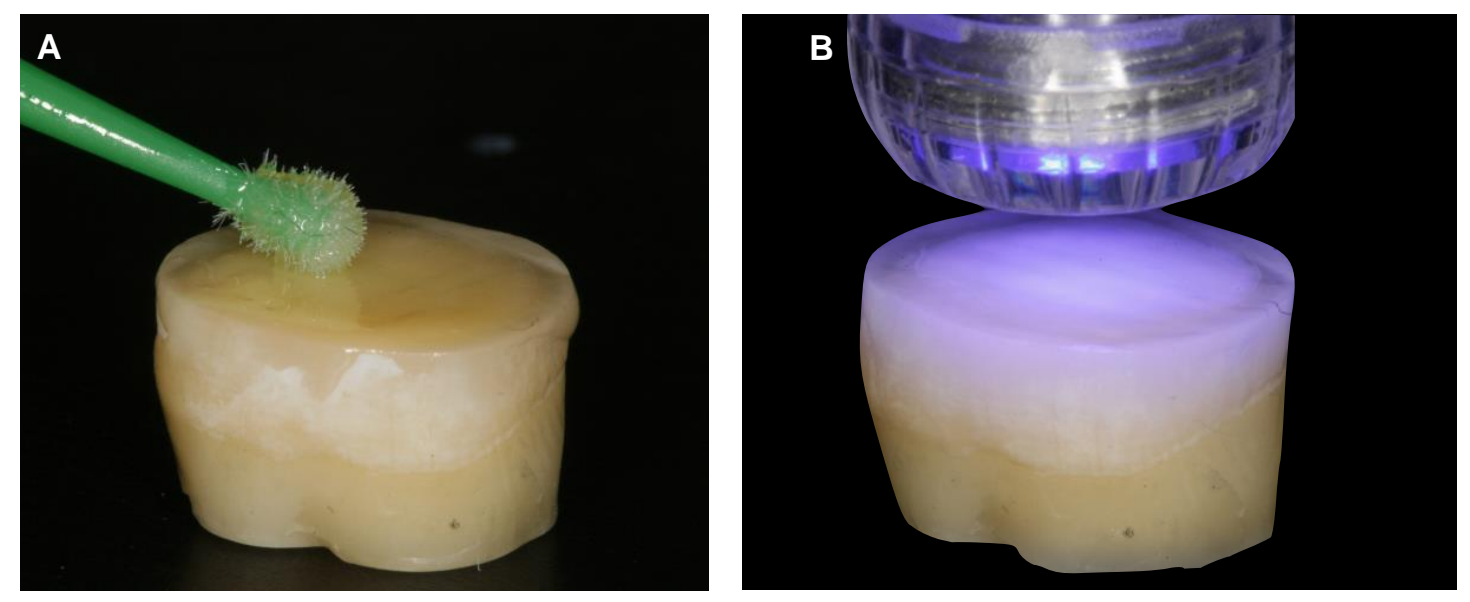

Fonte: A autora 
Dois incrementos ( $2 \mathrm{~mm}$ de espessura cada) da resina composta nanoparticulada (Filtek ${ }^{\mathrm{TM}} \mathrm{Z350} \mathrm{XT}^{\circledR}{ }^{\circledR}$-cor A2; 3M ESPE Division, St. Paul/MN - EUA) foram aposicionados sobre os espécimes (Figura 4.7A e 4.7B) e cada um deles foi fotoativado por 20 segundos (Figura 4.7C).

Figura 4.7 - A: Aposição do primeiro incremento de resina composta sobre o substrato; B: mensuração de espessura ( 2 mm), com paquímetro, após acomodação; C: fotoativação por 20 segundos
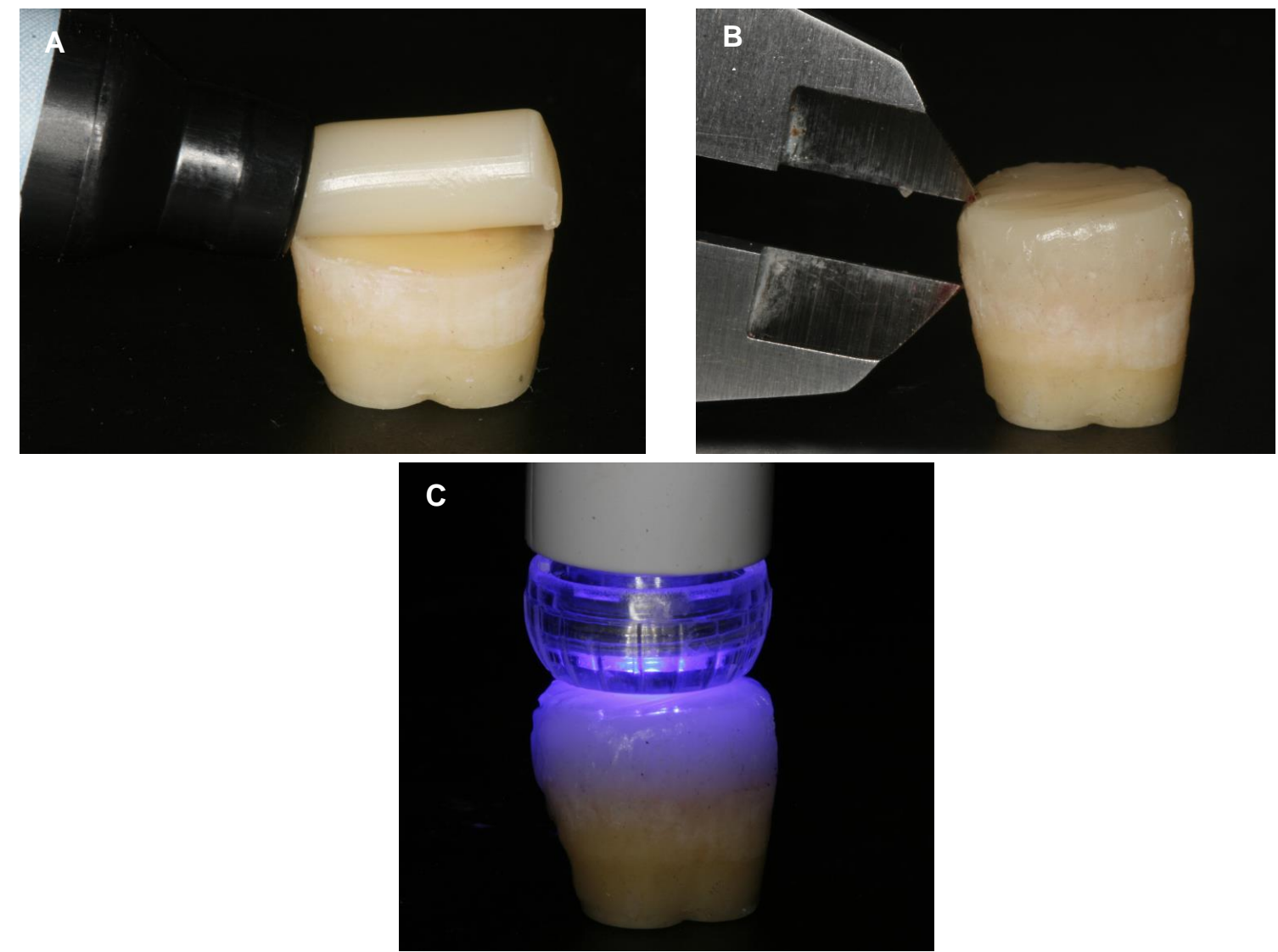

Fonte: A autora

\subsection{TESTES DE MICROTRAÇÃO}

O conjunto espécime dentário-resina composta foi levado à máquina de corte para seccionamento, perpendicular à interface adesiva, tanto no sentido vestíbulolingual (Figura 4.8A e 4.8B), quanto no mésio-distal (Figura 4.8C), para obtenção de palitos (9 a 31 por dente, 19 em média) constituídos de resina composta e dentina com área de secção transversal de aproximadamente $0,81 \mathrm{~mm}^{2}$ (Figura 4.8D). 
Figura 4.8 - A e B: Seccionamento do conjunto espécime dentário-resina composta, perpendicular à interface adesiva, no sentindo vestíbulo-lingual; C: seccionamento no sentido mésio-distal; D: obtenção de palitos com área de secção transversal de aproximadamente $0,81 \mathrm{~mm}^{2}$
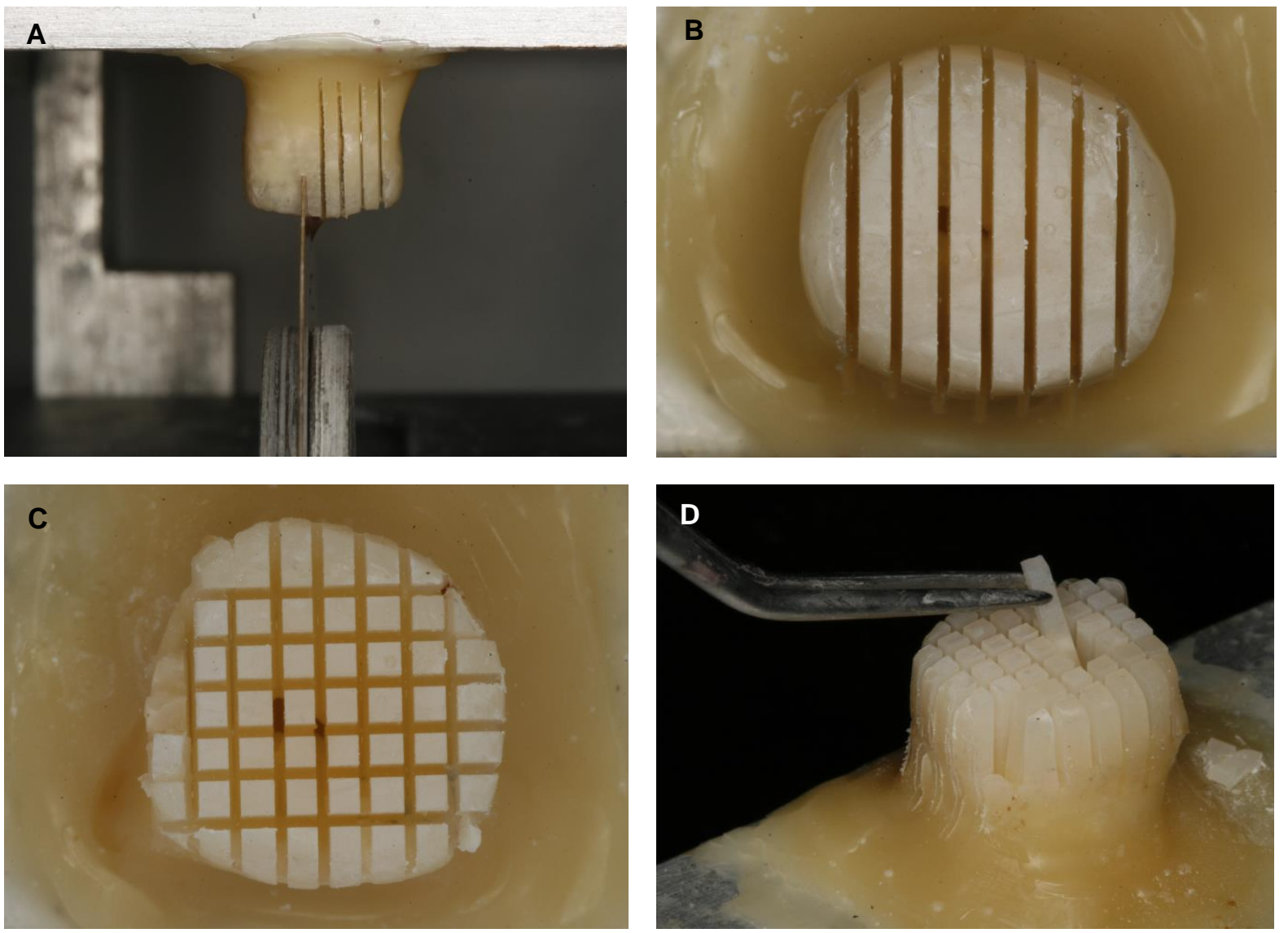

Fonte: A autora

Os palitos obtidos, para este estudo, de cada dente, foram individualmente fixados com um adesivo à base de cianocrilato, pelas extremidades, simetricamente em relação à interface adesiva, a um "Jig de Geraldeli" (Figura 4.9A), dispositivo específico para testes de microtração, e levados a uma máquina de testes universal Instron 5942 (Instron Industrial Products, Grove City/PA - EUA) (Figura 4.9B). Foram, então, testados sob força de tração (célula de carga de $50 \mathrm{kgf}$ ) perpendicular à interface adesiva, a uma velocidade de $0,5 \mathrm{~mm} / \mathrm{min}$, até sua falha (Figura $4.9 \mathrm{C}$ ).

A tensão necessária para causar ruptura dos espécimes foi determinada pela razão entre a carga (Kgf) no momento da fratura e a área da seção transversal do espécime em $\mathrm{cm}^{2}$. Os valores obtidos foram convertidos a MPa. 
Figura 4.9 - A: Fixação de um palito pelas extremidades, simetricamente em relação à interface adesiva, a um "Jig de Geraldeli"; B: adaptação do dispositivo contento o palito em máquina de testes universal Instron 5942; C: teste sob força de tração (célula de carga de 50 kgf) perpendicular à interface adesiva, a uma velocidade de $0,5 \mathrm{~mm} / \mathrm{min}$, até falha do palito
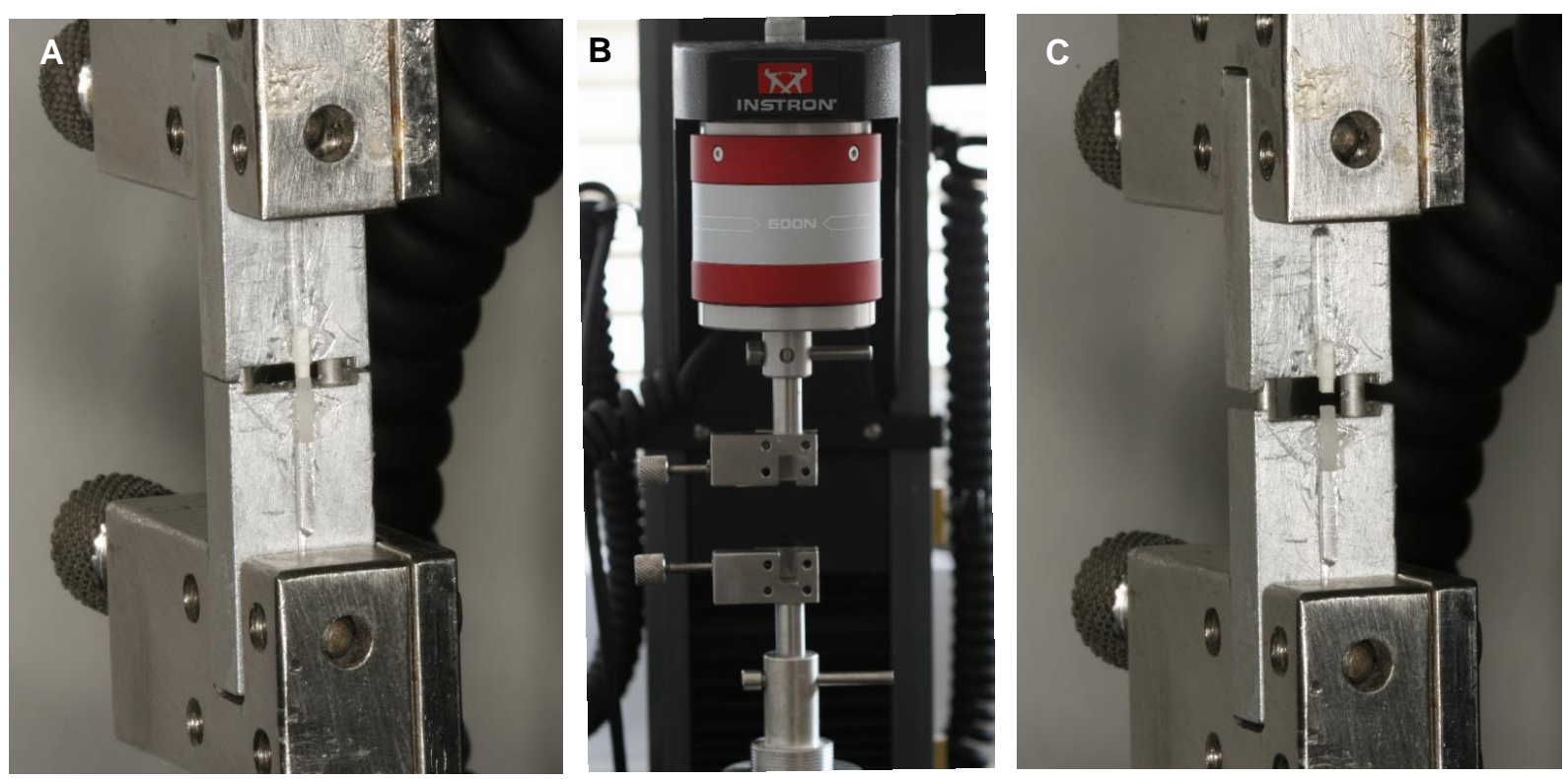

Fonte: A autora

Após a fratura, os palitos foram removidos do dispositivo de ensaio utilizandose uma lâmina de bisturi № 12. As superfícies fraturadas de ambos os segmentos foram analisadas com o auxílio de um microscópio digital (Dino-Lite Digital Microscope ${ }^{\circledR}$; AnMo Electronics Corp., New Taipei City/San-Chung District - Taiwan) (Figura 4.10), com 50x de aumento, para determinação do padrão de fratura (adesiva$A$, mista-M, coesiva em dentina-CD, coesiva em resina-CR) (Figura 4.11A a 4.11H).

Figura 4.10 - Microscópio digital utilizado para análise das superfícies fraturadas de ambos os segmentos de cada palito testado 
Figura 4.11 - Aspecto das superfícies de cada um dos segmentos de cada palito testado, em função dos possíveis padrões de fratura - A e B: falha adesiva; C e D: falha mista; E e F: falha coesiva em dentina; $\mathrm{G}$ e $\mathrm{H}$ : falha coesiva em resina
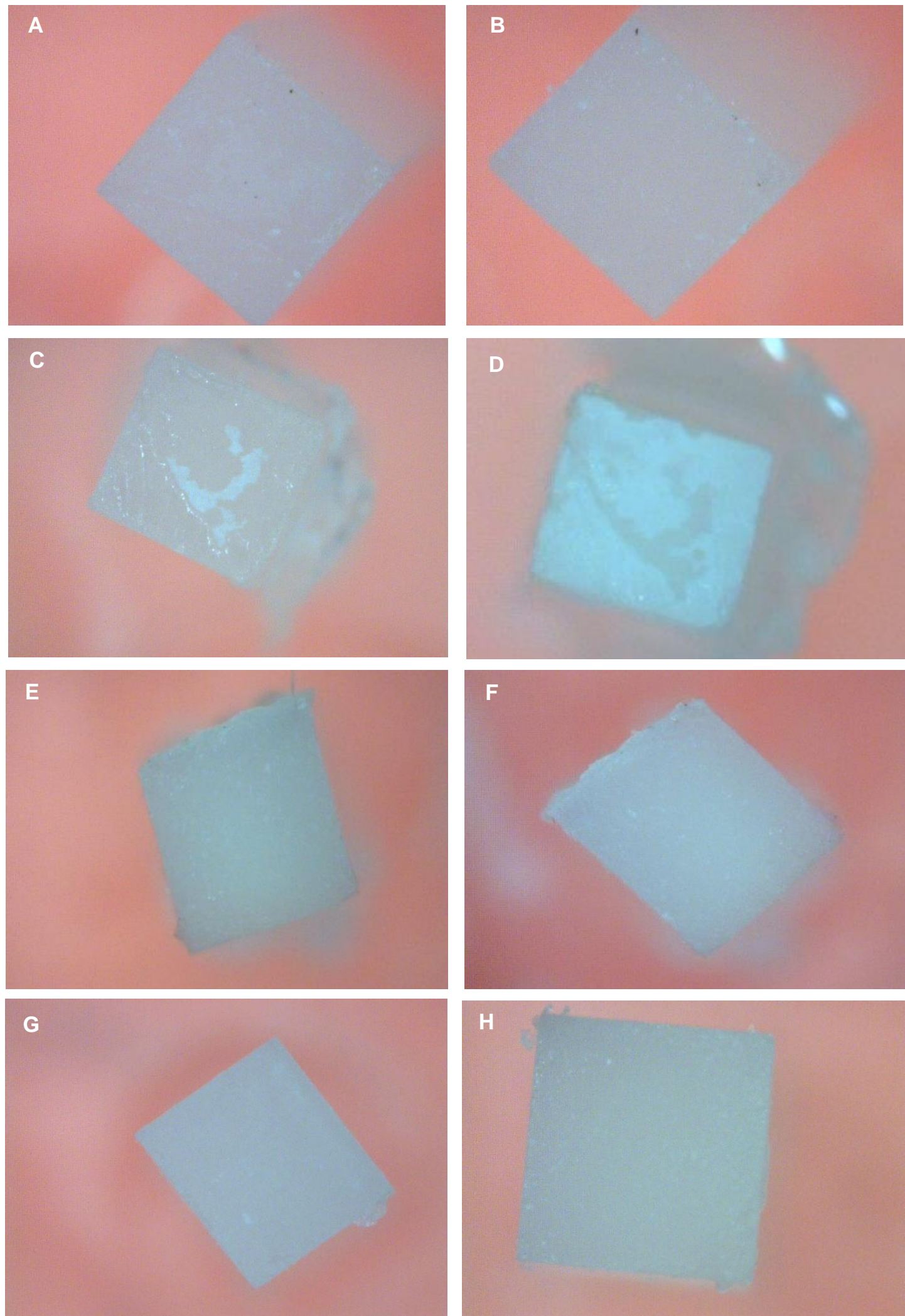

H

Fonte: A autora 


\subsection{AVALIAÇÃO EM MCVL}

Um dente extra para cada grupo foi tratado exatamente como os outros, mas o corante fluorescente rodamina B foi previamente adicionado $(0,16 \mathrm{mg} / \mathrm{ml}$; D'Alpino et al. 2006a, 2006b) ao sistema adesivo para permitir a avaliação qualitativa da interface adesiva. Tais dentes foram seccionados apenas mesio-distalmente (Figura 4.12): ambas as metades foram avaliadas por meio de MCVL (imagens com 40x de aumento; Zeiss LSM 780-NLO; Carl Zeiss Microscopy GmbH, Jena - Germany).

Figura 4.12 - Representação do dente extra de cada grupo, tratado exatamente como os outros, mas com o sistema adesivo previamente marcado pela adição do corante fluorescente rodamina $B(0,16 \mathrm{mg} / \mathrm{ml})$ e seccionado apenas mesio-distalmente, para avaliação qualitativa da interface adesiva por meio de MCVL

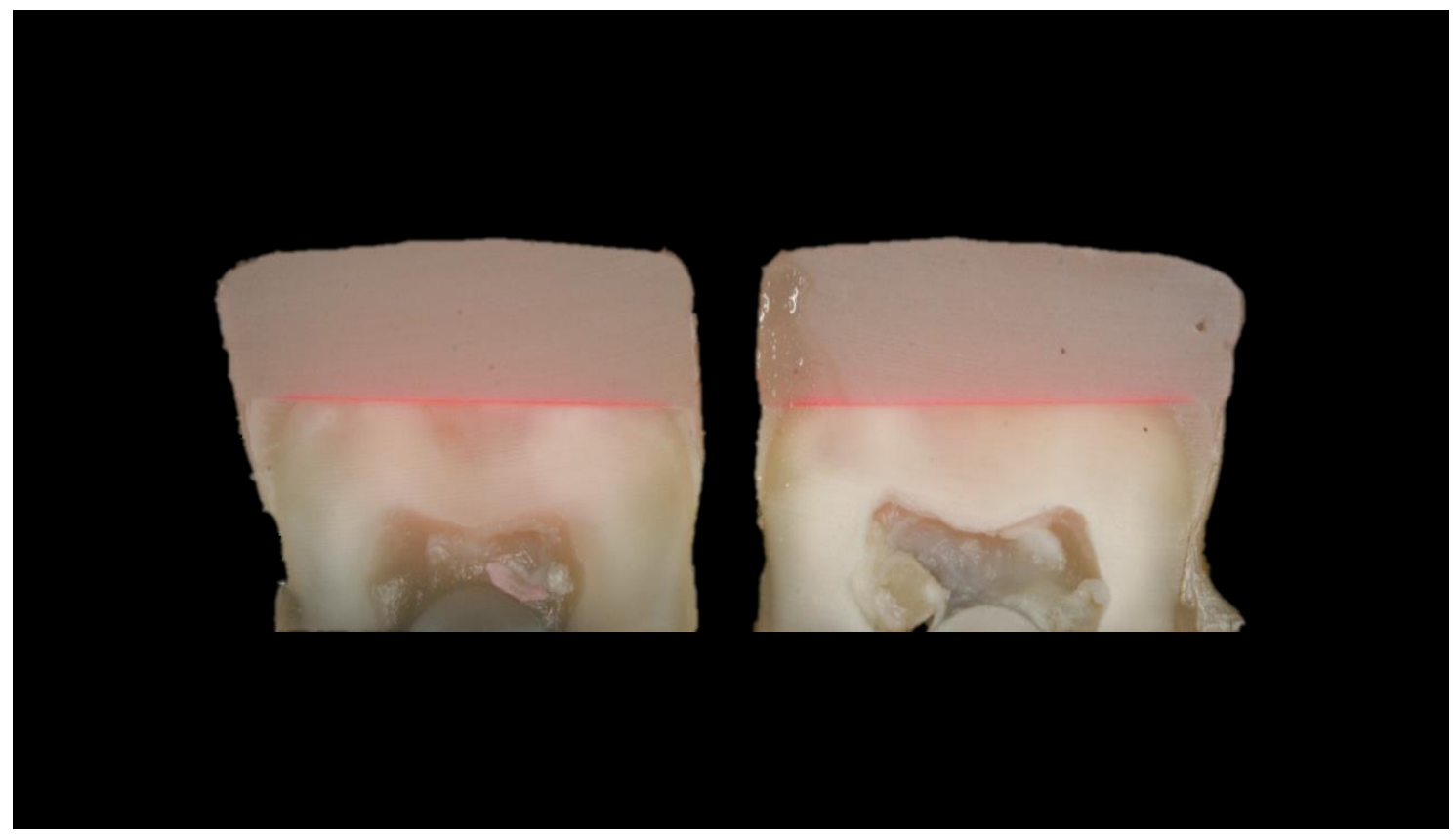

Fonte: A autora

\subsection{FORMA DE ANÁLISE DOS RESULTADOS}

Quanto à variável de resposta quantitativa, considerando-se cada dente como unidade experimental, os testes de Análise de Variância a 2 critérios e de Tukey foram 
aplicados, com nível de significância de 5\%. O programa estatístico utilizado foi o SigmaPlot 13 (Systat Software, Inc., San Jose/CA - EUA).

Quanto à variável de resposta qualitativa, com base em observação criteriosa das imagens obtidas por meio de MCVL, descreveram-se comparativamente as possíveis peculiaridades da camada híbrida e dos tags formados para cada grupo experimental. 


\section{$5 \quad$ RESULTADOS}

Analisando-se os dados obtidos pôde-se observar que, diferentemente do fator aplicação de géis para prevenção/controle do desgaste erosivo $(p=0,076)$, o fator condição do substrato dentinário exerceu influência significante sobre os resultados $(p<0,001)$. Ademais, não houve interação entre eles $(p=0,979)$.

Os valores médios de RU (MPa $\mathrm{Adp})$ do conjunto sistema adesivo condicione e lave simplificado-resina composta à dentina em função da condição do substrato (N: normal; E: erodido) e da aplicação de géis para prevenção/controle do desgaste erosivo (C: controle/sem aplicação; P: placebo/sem princípio ativo; $\mathrm{CHX}$ : digluconato de clorexidina a 0,12\%; EGCG: epigalocatequina-3-galato a $400 \mu \mathrm{m}$; PAC: proantocianidina a 10\%), são descritos no Gráfico 5.1 .

Gráfico 5.1 - Valores médios \pm desvio padrão de resistência de união (MPa) do conjunto sistema adesivo condicione e lave simplificado-resina composta à dentina em função da condição do substrato ( $\mathrm{N}$ : normal; $\mathrm{E}$ : erodido) e da aplicação de géis para prevenção/controle do desgaste erosivo (C: controle/sem aplicação; $\mathrm{P}$ : placebo/sem princípio ativo; $\mathrm{CHX:}$ digluconato de clorexidina a 0,12\%; EGCG: epigalocatequina-3-galato a $400 \mu \mathrm{m}$; PAC: proantocianidina a $10 \%)^{*}$

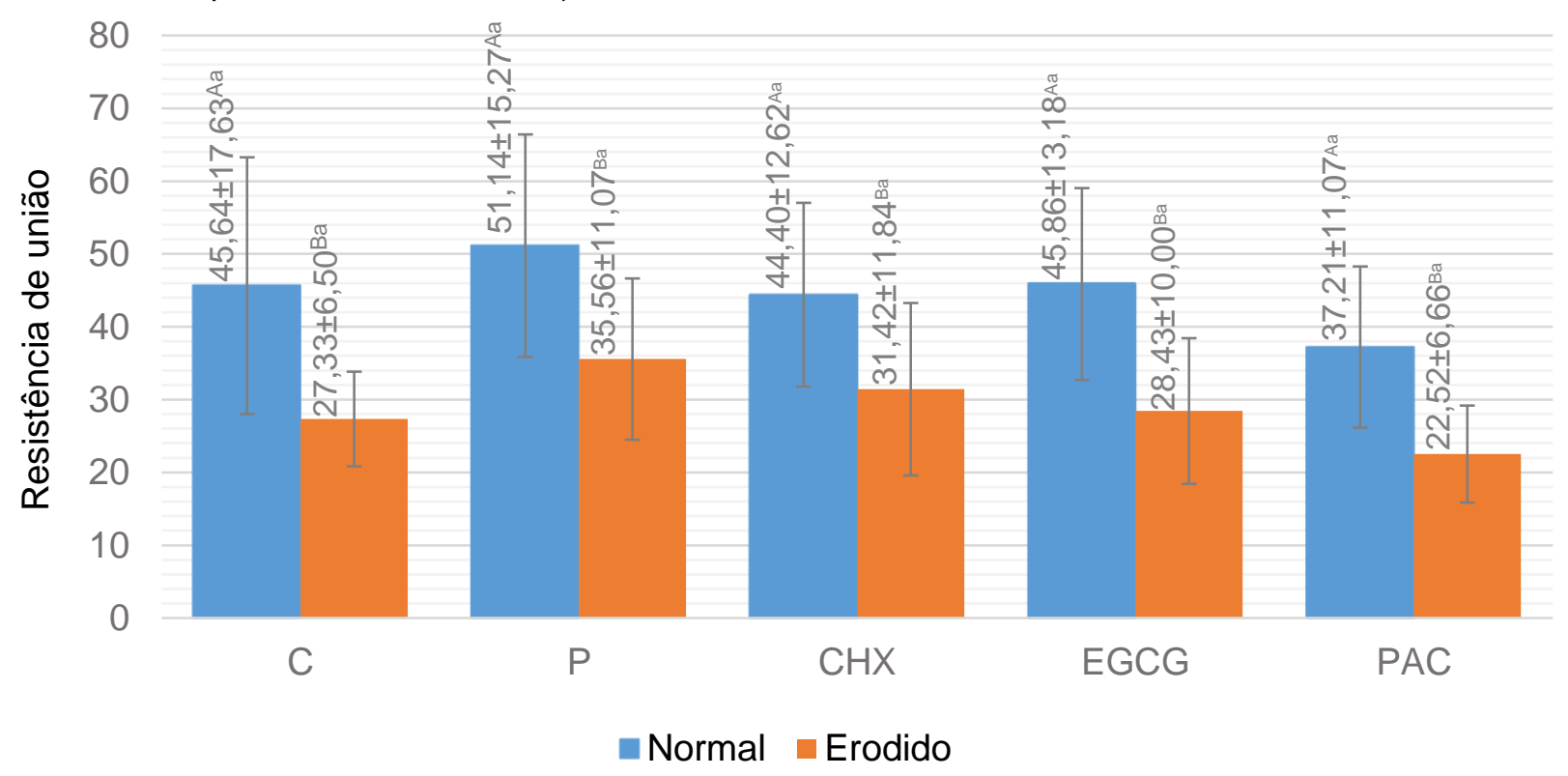

*Diferentes letras maiúsculas indicam diferença estatisticamente significante $(p<0,05)$ para o fator substrato dentinário $(\mathrm{N}, \mathrm{E})$. Diferentes letras minúsculas indicam diferença estatisticamente significante $(p<0,05)$ para o fator aplicação de géis para prevenção/controle do desgaste erosivo $(C, P, C H X$, EGCG, PAC). 
Há que se apontar, pois, que os valores de RU ao substrato erodido foram sempre inferiores que aqueles ao substrato normal, independentemente da aplicação, ou não, de qualquer um dos géis para prevenção/controle do desgaste erosivo.

Quanto à determinação do padrão de fratura dos palitos testados, pôde-se observar que as falhas adesivas e mistas foram predominantes em relação às coesivas, independentemente se em dentina ou em resina. Menores porcentagens de falhas coesivas ainda puderam ser verificadas para o substrato erodido, com relação ao normal (Gráfico 5.2).

Gráfico 5.2 - Percentual (\%) de falhas do tipo adesiva (A), mista (M), coesiva em dentina (CD) ou coesiva em resina (CR) em função em função da condição do substrato (N: normal; $E$ : erodido) e da aplicação de géis para prevenção/controle do desgaste erosivo (C: controle/sem aplicação; P: placebo/sem princípio ativo; CHX: digluconato de clorexidina a 0,12\%; EGCG: epigalocatequina 3-galato a $400 \mu \mathrm{m}$; PAC: proantocianidina a 10\%)

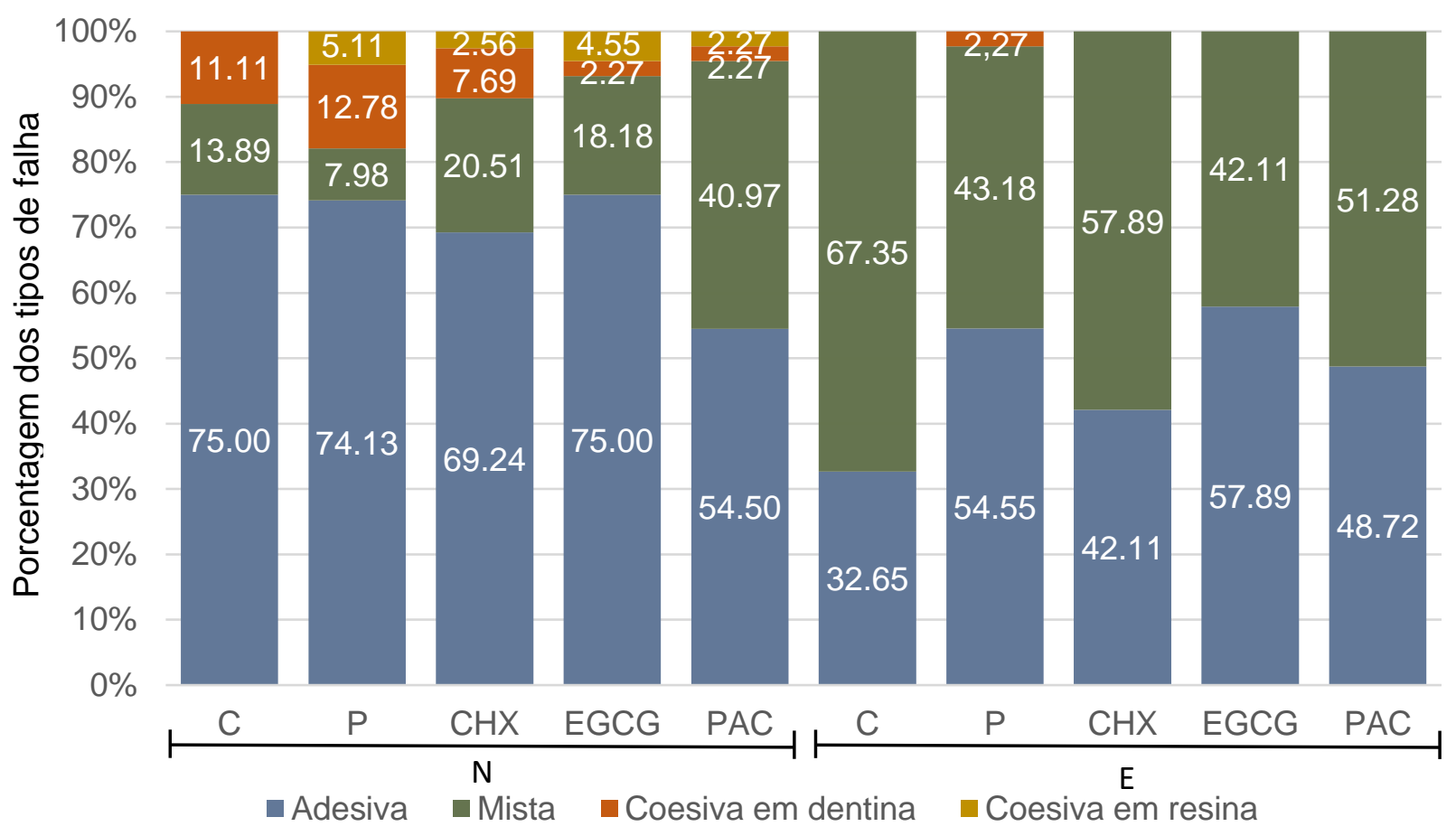

Qualitativamente, analisando-se as interfaces adesivas das superfícies seccionadas das metades vestibular e lingual do espécime, de cada grupo, hibridizado pelo sistema adesivo marcado com rodamina B, nota-se, para o substrato erodido, comparado ao normal, independetemente do tratamento com os géis para controle do desgaste, camada escura subjacente à de adesivo propriamente, entre os tags resinosos, representação da menor concentração de material marcado por rodamina B. Ademais, para o primeiro, comparado ao segundo, também à revelia do tratamento 
para controle do desgaste, notam-se tags resinosos com maior comprimento e em maior quantidade (Figuras 5.1A a 5.1J).

Figura 5.1 - Imagens de MCVL das interfaces adesivas em função da condição do substrato (N: normal, coluna à esquerda; $\mathrm{E}$ : erodido, coluna à direita) e da aplicação de géis para prevenção/controle do desgaste erosivo (C: controle/sem aplicação; P: placebo/sem princípio ativo; CHX: digluconato de clorexidina a 0,12\%; EGCG: epigalocatequina 3galato a $400 \mu \mathrm{m}$; PAC: proantocianidina a 10\%, em cada linha) - A: N.C; B: E.C; C: N.P; D: E.P; E: N.CHX; F: E.CHX; G: N.EGCG; H: E.EGCG; I: N.PAC; J: E.PAC
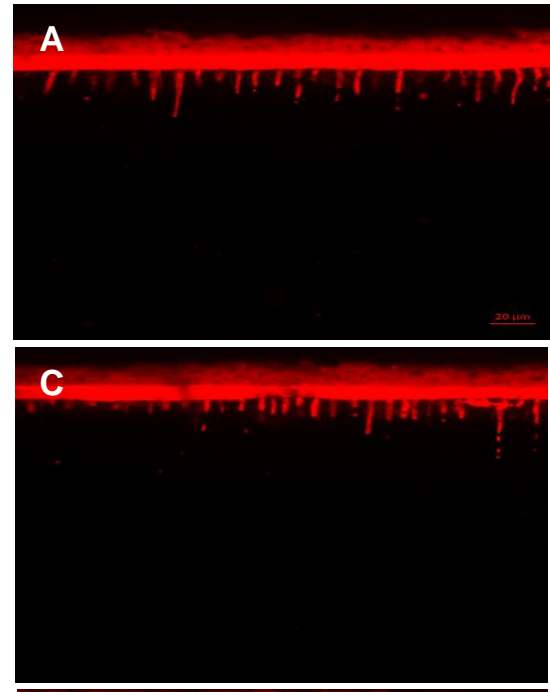

E

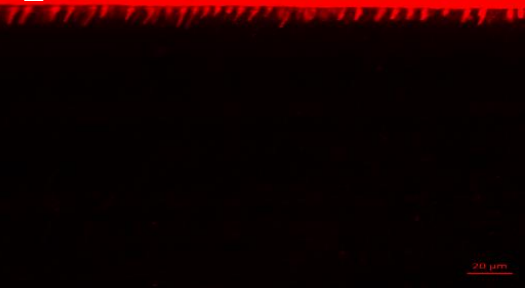

G

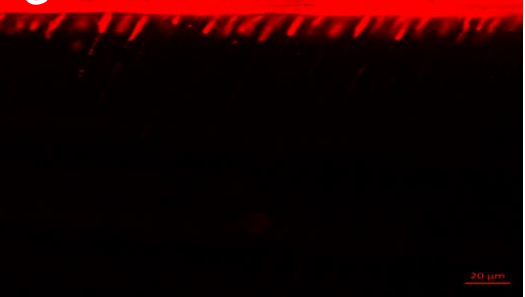

1

\section{B}

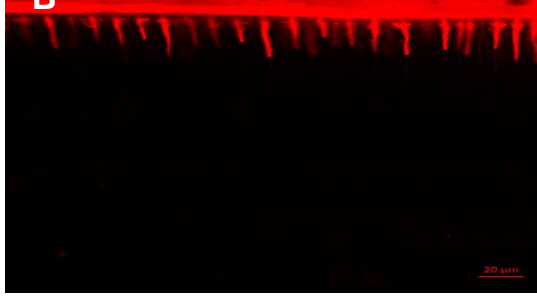

D

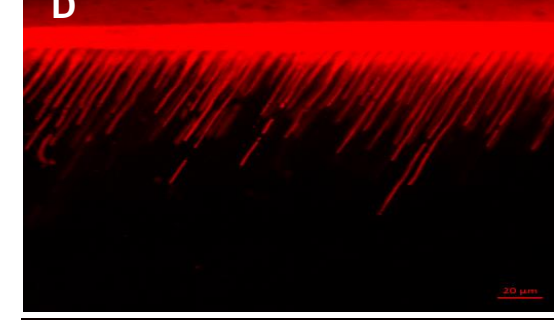

F

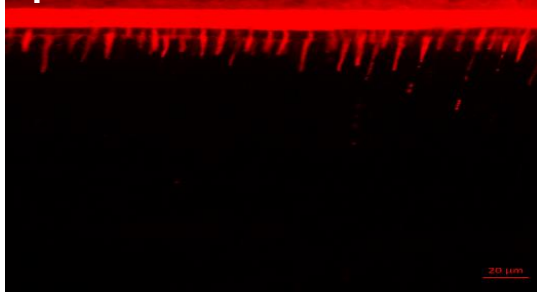

H

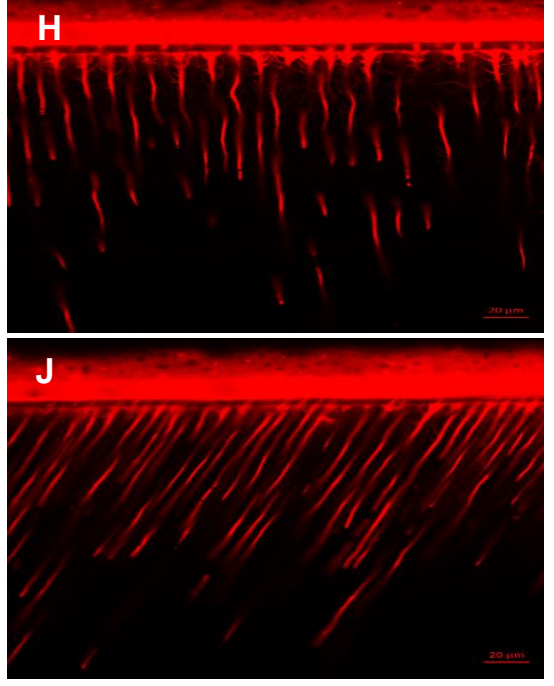

Fonte: A autora 



\section{DISCUSSÃO}

A atividade proteolítica, de maneira geral e, sobretudo, na dentina, passou a despertar o grande interesse da Odontologia, especialmente quando da identificação de sua participação na evolução de processos patológicos (Kleter et al., 1994; Tjäderhane et al., 1998; Buzalaf et al., 2012), em particular de lesões de cárie (Tjäderhane et al., 1998) e, por analogia, do desgaste erosivo (Kato et al., 2009a; Buzalaf et al., 2010, 2012).

Na progressão de lesões cariogênicas, as bactérias são responsáveis pela produção de ácidos que desmineralizam a parcela inorgânica do tecido dentinário, até que haja a exposição da matriz orgânica (Featherstone, 2008). A partir de então, as proteases do próprio hospedeiro é que propiciam a degradação do colágeno (Tjäderhane et al., 1998; Sulkala et al., 2001; Hannas et al., 2007), e o consequente avanço da cavitação, não diretamente relacionados aos microrganismos, como outrora se pensava (Katz et al., 1987; Tjäderhane et al., 1998; Chaussain-Miller et al., 2006).

Por princípio, então, haveriam de determinar papel crucial na progressão do desgaste erosivo em dentina, já que forças mecânicas, como as da escovação, até o valor de $4 \mathrm{~N}$, não são capazes de remover, mas sim de compactar, a trama de colágeno exposta pelo desafio ácido (Ganss et al., 2007, 2009; Kato et al., 2009a; Hannas et al., 2016). Em conservando-se tal trama, controla-se a progressão do desgaste erosivo (Klont; ten Cate, 1991b; Kleter et al., 1994; Ganss et al., 2004; Hara et al., 2005; Honório et al., 2008a, 2008b, Kato et al., 2009a, 2010a), já que a difusão iônica através dela é dificultada (Ganss et al., 2004; Hara et al., 2005). Daí a inferência da ação das MMPs e, quiçá, das CCs, no contexto, já que a degradação da matriz orgânica é que permite a evolução da perda tecidual (Buzalaf et al., 2015).

Nos casos, então, não raros, em que progride o desgaste erosivo, a ponto de tornar-se uma restauração, com resina composta, indicada para recuperação dos comprometimentos da função e da estética dos elementos dentários, ou mesmo, naqueles mais incipientes, para a lida com a dentina hipersensível (Davis; Winter, 1977; Hemmings et al., 2000; Litonjua et al., 2003; Lussi et al., 2004a; Bartlett; Sundaram, 2006; Reis et al., 2009; Dietschi; Argente, 2011), novamente há que se atribuir atenção à ação das enzimas proteolíticas da dentina, comprovadamente 
relacionadas à degradação de interfaces adesivas, em função da destruição das fibrilas colágenas expostas pelo condicionamento ácido e não completamente infiltradas por monômeros resinosos (Pashley et al., 2004, 2011; Hebling et al., 2005; Carrilho et al., 2007a, 2007b; Loguercio et al., 2009; Breschi et al., 2010)

Em ambos os contextos, porém, por fortuito, mostrou-se a aplicação de inibidores de proteases, tais quais a $\mathrm{CHX}$ e a EGCG, e de inibidores com potencial de também induzir o estabelecimento de ligações cruzadas entre as fibrilas de colágeno, como a PAC, capazes de conter, ou minimizar, a degradação da matriz colágena desmineralizada (Demeule et al., 2000; Garbisa et al., 2001; Sartor et al., 2002; Chaussain-Miller et al., 2006; Kato et al., 2009a, 2010a; Rios et al., 2009; Zimmerli et al., 2012; Wang et al., 2014a). Numa associação das circunstâncias, por sua vez, como outrora enfatizado, a aplicação de solução de $\mathrm{CHX}$, como primer antiproteolítico, depois do condicionamento com ácido fósforico e previamente à aplicação de um sistema adesivo do tipo condicione e lave de 2 passos, não foi capaz de tornar os valores de RU à dentina erodida análogos àqueles verificados para a dentina normal, seja imediatamente, seja após envelhecimento (6 ou 12 meses), mesmo que, a $2 \%$, os conservasse estáveis por até 6 , mas não 12, meses (Francisconi-dos-Rios et al. 2015a, 2015b). Pior ainda, prejudicou, imediatamente, a adesão tanto à dentina normal (Giacomini et al., 2017; Farias-Neto et al., 2018) quanto à erodida (Giacomini et al., 2017), e não a conservou estável, com o passar do tempo, no primeiro caso (Giacomini et al., 2017). Outra vez, por fim, tal uso, agora seguido de lavagem, estabeleceu valores de RU à dentina erodida equivalentes àqueles quando do não uso e inferiores àqueles à dentina normal (Deari et al., 2017).

Ora, em se considerando tais resultados, mas não se subestimando o potencial da $\mathrm{CHX}$, quando aplicada como agente para prevenção/controle do desgaste erosivo, alvitrou-se interessante avaliar a influência de sua aplicação, e pioneiramente da EGCG e da PAC, com tal objetivo, nos valores de RU do conjunto sistema adesivo condicione e lave simplificado-resina composta à dentina erodida, supondo-se que elas pudessem determinar, simultaneamente à minorada perda de estrutura dentária, substrato com zona superficial desmineralizada de espessura diferenciada (Deari et al., 2017), porventura menos desfavorável à interação com materiais resinosos. 
Não fora, porém, em nenhum dos casos, este o resultado obtido. Tanto quando da aplicação da CHX, da EGCG e da PAC, veiculadas por um gel, quanto quando do gel placebo e da não aplicação, os valores de RU à dentina erodida foram inferiores àqueles à dentina normal. Além disso, como, no que concerne à análise do padrão de fratura dos palitos testados, as falhas adesivas e/ou mistas foram majoritariamente observadas, admite-se, ora, que os valores de RU obtidos, passíveis de interpretação segura, refletem a real qualidade da união resina composta-substrato dentinário (Sano et al., 1994; Pashley et al., 1995, 1999).

Farias-Neto et al. (2018) observaram, de maneira semelhante, valores de RU à dentina tratada com solução de $\mathrm{CHX}$ a $2 \%$ (não gel a $0,12 \%$ ), para prevenção, talvez não propriamente controle, do desgaste erosivo, equivalentes àqueles à dentina tãosó erodida. Teoricamente, porém, na forma de gel, veículo agora adotado para carrear não só a CHX, mas também a EGCG e a PAC, tais princípios teriam melhor eficácia. Múltiplos bochechos com soluções contendo inibidores de proteases são tão ou menos efetivos no controle da progressão do desgaste erosivo que única aplicação de gel dos mesmos (Magalhães et al., 2009b; Kato et al., 2010a; Hannas et al., 2016).

Parece natural se supor, contudo, primordialmente, que não tenham sido qualquer dos princípios ativos, no presente estudo, capazes de minimizar ou impedir a progressão do desgaste erosivo. A consequente condição dos substratos é que legitimariam, por conseguinte, os resultados. Ao contrário, há que se reconhecer que Magalhães et al. (2009b) conseguiram reduzir o desgaste erosivo, e mesmo o erosivoabrasivo, da dentina ao utilizarem uma solução comercialmente disponível de digluconato de clorexidina a 0,12\% (Periogard; Colgate, Brasil); já Kato et al. (2010a), contê-lo com um gel à base de clorexidina, a 0,012\%. Comparativamente, reduziramno, por meio da aplicação de EGCG, em solução a 0,0014\%, e em gel a 400 $\mu$ M (Kato et al., 2009a, 2010a, 2012; De-Moraes et al., 2016). Ambas, CHX e EGCG, mostraram-se, ademais, in vivo, capazes de promover alteração do perfil proteico da película adquirida, aumentando a concentração de proteínas ricas em prolina, proteínas ligantes de cálcio e estaterina em sua composição, e, então, dificultando a progressão do desgaste erosivo (de Souza-e-Silva et al., 2017). Destaque-se, no entanto, a superioridade da EGCG, em relação à $\mathrm{CHX}$, no que se refere à rugosidade superficial do substrato dentinário erodido (De Moraes et al., 2016). Quanto à PAC, não só inibe proteases presentes na matriz dentinária, como melhora as propriedades 
mecânicas e dá estabilidade à matriz colágena pela formação de um complexo colágeno-PAC (Vertuan et al. 2018). Reduz, pois, no geral de maneira equipotente à CHX, mas desatrelada de certas limitações desta (toxicidade, por se dizer; Costa et al., 2001; Labbate et al., 2003; Lessa et al., 2010a) por ser um agente natural (Boteon et al., 2017a), os efeitos deletérios da erosão da dentina (Boteon et al., 2017a, 2017b; Vertuan et al., 2018).

Ora devem ter permitido, sim, os géis de CHX, EGCG e PAC, no presente estudo, a preservação da matriz colágena da dentina submetida a desafio erosivo, ainda que, por presumível, não de formas distintas entre si. Não deve ter havido perda tecidual, por assim dizer, embora isto não tenha sido avaliado: a desmineralização do substrato, mesmo que superficial, é que deve ter sido suficiente para prejudicar sua interação com o conjunto sistema adesivo condicione e lave simplificado-resina composta. Subvencionam esta elucubração as diferenças encontradas nas imagens de MCVL entre o substrato normal e o erodido, independentemente do tratamento recebido quanto ao controle do desgaste. Tags resinosos em maior número e comprimento, para o segundo caso, em que se submeteu os espécimes a desafio erosivo inicial, podem ser considerados reflexo da desmineralização, prévia à propiciada pela ciclagem de $\mathrm{pH}$ e pelo próprio condicionamento com ácido fosfórico, que típica e fundamentalmente resulta em exposição e ampliação da embocadura dos túbulos dentinários (Meurman et al., 1991). Sobeja, então, menor área para entrelaçamento das fibrilas colágenas com o sistema adesivo, ou seja, para formação da camada híbrida, factual responsável pela adesão ao substrato dentinário (Yoshiyama et al., 1995). Ademais, uma identificável camada escura subjacente à de adesivo propriamente, entre os tags resinosos, representação da menor concentração de material marcado por rodamina $B$, para o substrato erodido, pode ser inferência de que toda a espessura da trama de colágeno da dentina desmineralizada não fora devidamente impregnada pelo sistema adesivo, ou que não tenha se processado, pela intensa umidade, adequada conversão dos monômeros em polímeros, quadros relacionados à comprovada menor predisposição desse substrato à adesão de materiais resinosos (Cruz et al., 2012; Zimmerli et al., 2012).

Assim, se de fato as estratégias estudadas para controle do desgaste erosivo foram capazes de minimizar a perda tecidual, alternativas menos conservadoras para favorecer os valores de RU à dentina erodida seriam empregadas em região mais superficial, poupando-se, em última instância, estrutura dentária remanescente e 
empreendendo-se o exercício da odontologia minimamente invasiva. Dentre elas, mostra-se a mais efetiva a asperização da superfície com ponta diamantada, que, por remover a camada desmineralizada mais externa, iguala os valores de RU à dentina erodida àqueles à normal (Zimmerli et al., 2012). Talvez seja essa a técnica mais empregada pelos cirurgiões-dentistas, por ser barata e de rápida execução (Hannig et al., 2006; Kiomarsi et al., 2017). Contudo, não permite controle da quantidade de estrutura dentária desgastada (Garone-Filho, Silva, 2008), no geral superior à correspondente a camada desmineralizada, que parece ter em média apenas 3 a 7 $\mu \mathrm{m}$ (Zimmerli et al., 2012).

Outra possibilidade seria a irradiação com laser (de alta potência) de érbio, cromo: ítrio-escândio-gálio-granada (Er,Cr:YSGG; Ramos et al., 2015), inclusive com largura de pulso super curta (Cersosimo et al., 2016). Ela, no entanto, pode só ser efetiva quando da aplicação de adesivo autocondicionante (Ramos et al., 2015) ou não tornar os valores de RU à dentina erodida similares aos observados àqueles à normal (Cersosimo et al., 2016). Quanto à desproteinização com hipoclorito de sódio ( $\mathrm{NaOCl}$; Yamauti et al., 2003), parece mais efetiva quando adesivos universais são utilizados (Augusto et al., 2018; Siqueira et al., 2018): além de eliminar a porção orgânica, faz aumentar a relação $\mathrm{Ca} / \mathrm{P}$ na superfície da dentina (Baumgartner; Mader, 1987; Baumgartner; Cuenin, 1992) favorecendo sua interção com monômeros funcionais caracteristicamente encontrados nessa classe de adesivo (Siqueira et al., 2018).

Sob outra perspectiva, há de se ressaltar a importância de qualquer um dos geis avaliados, inclusive o placebo, não terem desfavorecido os valores de RU do conjunto sistema adesivo condicione e lave simplificado-resina composta à dentina, normal ou erodida. Em separado para esta última condição, reconheça-se que a retenção do material às lesões, no geral rasas e planas (Ganss et al., 2014), fundamenta-se no sucesso das estratégias adesivas aí empregadas (Zimmerli et al., 2012; Ramos et al., 2015; Augusto et al., 2018), que não devem, pois, ser ainda mais comprometidas. Podem continuar, assim, tais geis, a serem estudados como estratégias promissoras no controle da progressão do desgaste erosivo (Magalhães et al. 2009b; Kato et al. 2010a; Boteon et al. 2017a; Vertuan et al. 2018), sem que ensejem preocupação diferente, no tocante ao estabelecimento de uma interface 
adesiva, em qualquer dos substratos, caso uma restauração com resina composta venha a ser subsequente tratamento.

Por fim, o não prejuízo aos valores imediatos de $\mathrm{RU}$, tanto à dentina normal, quanto à erodida, diante do uso da CHX, da EGCG, e da PAC, e mesmo do placebo, é fundamental para subsidiar o estudo de seu papel nesse âmbito com o passar do tempo (Anexo B).

Têm-se observado que o envelhecimento, por meio do armazenamento de espécimes por períodos prolongados (até 12 ou mesmo 18 ou 24 meses), em água destilada/deionizada ou saliva artificial, reduz significativamente os valores de resistência de união de resinas compostas não apenas à dentina normal (Hashimoto et al., 2003, 2010; Tjäderhane et al., 2013a; Ekambaram et al., 2014), mas também, e de forma mais acentuada (Zimmerli et al., 2012), à dentina erodida, já inicialmente desfavorável ao estabelecimento de procedimentos adesivos (Zimmerli et al., 2012; Farias-Neto et al., 2018). Comprova-se a destacável capacidade à degradação da interface adesiva estabelecida em dentina erodida pela maior quantidade de falhas adesivas observadas em testes de microtração e pela infiltração de prata detectada em imagens de microscopia eletrônica de transmissão (Zimmerli et al., 2012).

Que os resultados do presente estudo sejam, então, relevante contribuição à incessante e fundamental busca por estratégias que favoreçam o estabelecimento de interfaces adesivas, já imediatamente, a substratos desfavoráveis à interação com materiais resinosos, via de regra encontrados em clínica (Giacomini et al., 2017). Sejam, ainda, propulsores da investigação da potencialidade de tais estratégias em determinar uma interação entre materiais resinosos e substrato dentinário menos suscetível à degradação, já que se assente que os valores imediatos de RU à dentina nem sempre se correlacionam com a estabilidade dessa união em longo prazo (Munck et al., 2005; Breschi et al., 2008; De Munck et al., 2015). 


\section{CONCLUSÃO}

Conclui-se que os inibidores de proteases (CHX e EGCG) e o agente também promotor do estabelecimento de ligações cruzadas entre fibrilas de colágeno (PAC), usados como estratégias para prevenção/controle do desgaste, não foram capazes de favorecer, tampouco de prejudicar, os valores de resistência de união (RU) do conjunto sistema adesivo condicione e lave simplificado-resina composta à dentina erodida, ou mesmo à normal, caso em que foram sempre superiores que aqueles à contraparte.

Rejeita-se, pois, a hipótese alternativa proposta, já que tais agentes, de formas equivalentes entre si e ao placebo e à não aplicação, não foram capazes de determinar, por meio da preservação/controle do desgaste erosivo, um substrato tão favorável à adesão com os materiais resinosos quanto o normal. 



\section{REFERÊNCIAS 1}

Al-Ammar A, Drummond JL, Bedran-Russo AK. The use of collagen cross-linking agents to enhance dentin bond strength. J Biomed Mater Res Part B Appl Biomater. 2009 Oct;91B(1):419-24.

Amsler F, Peutzfeldt A, Lussi A, Flury S. Long-Term Bond Strength of Self-Etch Adhesives to Normal and Artificially Eroded Dentin: Effect of Relative Humidity and Saliva Contamination. J Adhes Dent. 2017;19(2):169-76.

Apayco LC. Efeito da solução de clorexidina a 2\% na adesão de um sistema restaurador adesivo à dentina previamente erodida com refrigerante tipo cola regular e light. 2013.

Arakaki PA, Marques MR, Santos MCLG. MMP-1 polymorphism and its relationship to pathological processes. J Biosci. 2009 Jun;34(2):313-20.

Augusto M, Torres C, Pucci C, Schlueter N, Borges A. Bond Stability of a Universal Adhesive System to Eroded/Abraded Dentin After Deproteinization. Oper Dent. 2018 May;43(3):291-300.

Aydin B, Hassan LS, Viana G, Bedran-Russo AK. Assessing Collagen and Micropermeability at the Proanthocyanidin-treated Resin-Dentin Interface. J Adhes Dent. 2016;18(6):529-34.

Balooch M, Habelitz S, Kinney JH, Marshall SJ, Marshall GW. Mechanical properties of mineralized collagen fibrils as influenced by demineralization. J Struct Biol. 2008 Jun;162(3):404-10.

Banerjee A, Watson TF, Kidd EAM. Dentine Caries: Take It or Leave It? Dent Update. 2000 Jul 2;27(6):272-6.

Barbosa CS, Kato MT, Buzalaf MAR. Effect of supplementation of soft drinks with green tea extract on their erosive potential against dentine. Aust Dent J. 2011 Sep;56(3):317-21.

\footnotetext{
${ }^{1}$ De acordo com o estilo Vancouver.
} 
Barbour ME, Shellis RP, Parker DM, Allen GC, Addy M. An investigation of some food-approved polymers as agents to inhibit hydroxyapatite dissolution. Eur J Oral Sci. 2005 Dec;113(6):457-61.

Bartlett D, Sundaram G. An up to 3-year randomized clinical study comparing indirect and direct resin composites used to restore worn posterior teeth. Int J Prosthodont. 2006;19(6):613-7.

Baumgartner JC, Cuenin PR. Efficacy of several concentrations of sodium hypochlorite for root canal irrigation. J Endod. 1992 Dec;18(12):605-12.

Baumgartner JC, Mader CL. A scanning electron microscopic evaluation of four root canal irrigation regimens. J Endod. 1987 Apr;13(4):147-57.

Bedran-Russo AK, Karol S, Pashley DH, Viana G. Site specific properties of carious dentin matrices biomodified with collagen cross-linkers. Am J Dent. 2013 Oct;26(5):244-8.

Bedran-Russo AKB, Castellan CS, Shinohara MS, Hassan L, Antunes A. Characterization of biomodified dentin matrices for potential preventive and reparative therapies. Acta Biomater. 2011 Apr;7(4):1735-41.

Bedran-Russo AKB, Pereira PNR, Duarte WR, Drummond JL, Yamauchi M. Application of crosslinkers to dentin collagen enhances the ultimate tensile strength. J Biomed Mater Res Part B Appl Biomater. 2007 Jan;80B(1):268-72.

Bedran-Russo AKB, Yoo KJ, Ema KC, Pashley DH. Mechanical Properties of Tannicacid-treated Dentin Matrix. J Dent Res. 2009 Sep 18;88(9):807-11.

Birkedal-Hansen H, Moore WGI, Bodden MK, Windsor LJ, Birkedal-Hansen B, DeCarlo A, et al. Matrix Metalloproteinases: A Review. Crit Rev Oral Biol Med. 1993 Jan;4(2):197-250.

Boteon AP, Kato MT, Buzalaf MAR, Prakki A, Wang L, Rios D, et al. Effect of Proanthocyanidin-enriched extracts on the inhibition of wear and degradation of dentin demineralized organic matrix. Arch Oral Biol. 2017a Dec;84:118-24. 
Boteon AP, Prakki A, Rabelo Buzalaf MA, Rios D, Honorio HM. Effect of different concentrations and application times of proanthocyanidin gels on dentin erosion. Am J Dent. 2017b Apr;30(2):96-100.

Breschi L, Cammelli F, Visintini E, Mazzoni A, Vita F, Carrilho M, et al. Influence of chlorhexidine concentration on the durability of etch-and-rinse dentin bonds: a 12month in vitro study. J Adhes Dent. 2009 Jun;11(3):191-8.

Breschi L, Mazzoni A, Nato F, Carrilho M, Visintini E, Tjäderhane L, et al. Chlorhexidine stabilizes the adhesive interface: A 2-year in vitro study. Dent Mater. $2010 \mathrm{Apr} ; 26(4): 320-5$.

Breschi L, Mazzoni A, Ruggeri A, Cadenaro M, Di Lenarda R, De Stefano Dorigo E. Dental adhesion review: Aging and stability of the bonded interface. Dent Mater. 2008 Jan;24(1):90-101.

Brew K, Dinakarpandian D, Nagase H. Tissue inhibitors of metalloproteinases: evolution, structure and function. Biochim Biophys Acta. 2000 Mar 7;1477(1-2):26783.

Browning WD, Chan DCN, Swift EJ. Critical appraisal: approaches to caries removal: what the clinical evidence says. J Esthet Restor Dent. 2013 Apr;25(2):141-51.

Buck MR, Karustis DG, Day NA, Honn K V, Sloane BF. Degradation of extracellularmatrix proteins by human cathepsin B from normal and tumour tissues. Biochem $\mathrm{J}$. 1992 Feb 15;282 ( Pt 1):273-8.

Buzalaf MAR, Charone S, Tjäderhane L. Role of Host-Derived Proteinases in Dentine Caries and Erosion. Caries Res. 2015;49(1):30-7.

Buzalaf MAR, Hannas AR, Kato MT. Saliva and dental erosion. J Appl Oral Sci. 2010;20(5):493-502.

Buzalaf MAR, Kato MT, Hannas AR. The Role of Matrix Metalloproteinases in Dental Erosion. Adv Dent Res. 2012 Sep 16;24(2):72-6.

Carrilho MRO, Carvalho RM, de Goes MF, di Hipólito V, Geraldeli S, Tay FR, et al. Chlorhexidine Preserves Dentin Bond in vitro. J Dent Res. 2007a Jan 12;86(1):90-4. 
Carrilho MRO, Geraldeli S, Tay F, de Goes MF, Carvalho RM, Tjäderhane L, et al. In vivo Preservation of the Hybrid Layer by Chlorhexidine. J Dent Res. 2007b Jun 18;86(6):529-33.

Carvalho RM, Tay FR, Giannini M, Pashley DH. Effects of pre- and post-bonding hydration on bond strength to dentin. J Adhes Dent. 2004;6(1):13-7.

Castellan CS, Bedran-Russo AK, Karol S, Pereira PNR. Long-term stability of dentin matrix following treatment with various natural collagen cross-linkers. J Mech Behav Biomed Mater. 2011 Oct;4(7):1343-50.

Cerri PS, Pereira-Júnior JA, Biselli NB, Sasso-Cerri E. Mast cells and MMP-9 in the lamina propria during eruption of rat molars: quantitative and immunohistochemical evaluation. J Anat. 2010 Jun 16;217(2):no-no.

Cersosimo MCP, Matos AB, Couto RSD, Marques MM, de Freitas PM. Short-pulse Er:YAG laser increases bond strength of composite resin to sound and eroded dentin. J Biomed Opt. 2016 Apr 18;21(4):048001.

Chaussain-Miller C, Fioretti F, Goldberg M, Menashi S. The Role of Matrix Metalloproteinases (MMPs) in Human Caries. J Dent Res. 2006 Jan 11;85(1):22-32.

Cheng XW, Kuzuya M, Kanda S, Maeda K, Sasaki T, Wang QL, et al. Epigallocatechin-3-gallate binding to MMP-2 inhibits gelatinolytic activity without influencing the attachment to extracellular matrix proteins but enhances MMP-2 binding to TIMP-2. Arch Biochem Biophys. 2003 Jul 1;415(1):126-32.

Correr GM, Alonso RCB, Correa MA, Campos EA, Baratto-Filho F, Puppin-Rontani RM. Influence of diet and salivary characteristics on the prevalence of dental erosion among 12-year-old schoolchildren. J Dent Child (Chic). 2009;76(3):181-7.

Costa CA, Edwards CA, Hanks CT. Cytotoxic effects of cleansing solutions recommended for chemical lavage of pulp exposures. Am J Dent. 2001 Feb;14(1):25-30.

Costa CA, Vaerten MA, Edwards CA, Hanks CT. Cytotoxic effects of current dental adhesive systems on immortalized odontoblast cell line MDPC-23. Dent Mater. 1999 Nov;15(6):434-41. 
Cruz JB, Bonini G, Lenzi TL, Imparato JCP, Raggio DP. Bonding stability of adhesive systems to eroded dentin. Braz Oral Res. 2015 Jul 7;29(1):1-6.

Cruz JB, Lenzi TL, Tedesco TK, Guglielmi C de AB, Raggio DP. Eroded dentin does not jeopardize the bond strength of adhesive restorative materials. Braz Oral Res. 2012;26(4):306-12.

D'Alpino PHP, Pereira JC, Svizero NR, Rueggeberg FA, Pashley DH. Factors affecting use of fluorescent agents in identification of resin-based polymers. J Adhes Dent. 2006a Oct;8(5):285-92.

D'Alpino PHP, Pereira JC, Svizero NR, Rueggeberg FA, Pashley DH. Use of fluorescent compounds in assessing bonded resin-based restorations: A literature review. J Dent. 2006b Oct;34(9):623-34.

Danilov NA, Ignatieva NY, lomdina EN, Semenova SA, Rudenskaya GN, Grokhovskaya TE, et al. Stabilization of scleral collagen by glycerol aldehyde crosslinking. Biochim Biophys Acta. 2008 May;1780(5):764-72.

Davis WB, Winter PJ. Dietary erosion of adult dentine and enamel. Protection with a fluoride toothpaste. Br Dent J. 1977 Aug 16;143(4):116-9.

De-Macedo FAA, Souza NO, Lemos MVS, De-Paula DM, Santiago SL, Feitosa VP. Dentin bonding and physicochemical properties of adhesives incorporated with epigallocatechin-3-gallate. Odontology. 2018 May 23;

de-Melo MAS, Goes D da C, de-Moraes MDR, Santiago SL, Rodrigues LKA. Effect of chlorhexidine on the bond strength of a self-etch adhesive system to sound and demineralized dentin. Braz Oral Res. 2013 Apr 9;27(3):218-24.

De-Moraes MDR, Carneiro JRM, Passos VF, Santiago SL. Effect of green tea as a protective measure against dental erosion in coronary dentine. Braz Oral Res. 2016;30(1):13.

De-Munck J, Poitevin A, Lührs A-K, Pongprueksa P, Van Ende A, Van Landuyt KL, et al. Interfacial fracture toughness of aged adhesive-dentin interfaces. Dent Mater. 2015 Apr;31(4):462-72. 
Deari S, Wegehaupt FJ, Tauböck TT, Attin T. Influence of Different Pretreatments on the Microtensile Bond Strength to Eroded Dentin. J Adhes Dent. 2017;19(2):147-55.

Delgado C, Lopes Salles Scheffel L C, Débora, Henke Scheffel R, Pashley D, Hebling J. Redução da atividade proteolítica da dentina após curtos períodos de aplicação de proantocianidina Reduction of the dentin proteolytic activity after short periods of application of proanthocyanidin. Rev Odontol da Unesp. 2015;44:355-9.

Demeule M, Brossard M, Pagé M, Gingras D, Béliveau R. Matrix metalloproteinase inhibition by green tea catechins. Biochim Biophys Acta. 2000 Mar 16;1478(1):51-60.

Dickinson DP. Cysteine peptidases of mammals: their biological roles and potential effects in the oral cavity and other tissues in health and disease. Crit Rev Oral Biol Med. 2002;13(3):238-75.

Dietschi D, Argente A. A comprehensive and conservative approach for the restoration of abrasion and erosion. part II: clinical procedures and case report. Eur $\mathrm{J}$ Esthet Dent. 2011;6(2):142-59.

Dos-Santos PH, Karol S, Bedran-Russo AK. Long-term nano-mechanical properties of biomodified dentin-resin interface components. J Biomech. 2011 Jun;44(9):16914.

Dutra-Correa M, Saraceni CH, Ciaramicoli MT, Kiyan VH, Queiroz CS. Effect of chlorhexidine on the 18-month clinical performance of two adhesives. J Adhes Dent. 2013 Jun;15(3):287-92.

Ekambaram M, Yiu CKY, Matinlinna JP, King NM, Tay FR. Adjunctive application of chlorhexidine and ethanol-wet bonding on durability of bonds to sound and cariesaffected dentine. J Dent. 2014 Jun;42(6):709-19.

El-Badrawy MK, Yousef AM, Shaalan D, Elsamanoudy AZ. Matrix metalloproteinase9 expression in lung cancer patients and its relation to serum mmp-9 activity, pathologic type, and prognosis. J Bronchology Interv Pulmonol. 2014 Oct;21(4):32734.

Farias-Neto A de M, Landmayer K, Liberatti GA, Silva JC V, Aguilera JFO, Wang L, et al. Clorexidina para prevenção/controle do desgaste, ou como parte do tratamento adesivo, na resistência de união à dentina erodida. Braz Oral Res. 2018;32(2):307. 
Farias MMAG, Tames DR, Ferreira R, Bahi FC, Morreto J. Propriedades erosivas de sucos de frutas industrializados recomendados como suplemento alimentar para crianças. JBP, J Bras Odontopediatr Odontol Bebê. 2000;111-7.

Featherstone J. Dental caries: a dynamic disease process. Aust Dent J. 2008 Sep;53(3):286-91.

Folgueras AR, Pendas AM, Sanchez LM, Lopez-Otin C. Matrix metalloproteinases in cancer: from new functions to improved inhibition strategies. Int J Dev Biol. 2004;48(5-6):411-24.

Francisconi-dos-Rios LF, Calabria MP, Casas-Apayco LC, Honório HM, Carrilho MRDO, Pereira JC, et al. Chlorhexidine does not improve but preserves bond strength to eroded dentin. Am J Dent. 2015a Feb;28(1):28-32.

Francisconi-dos-Rios LF, Casas-Apayco LC, Calabria MP, Francisconi PAS, Borges AFS, Wang L. Role of chlorhexidine in bond strength to artificially eroded dentin over time. J Adhes Dent. 2015b Apr;17(2):133-9.

Frattes FC, Augusto MG, Torres CRG, Pucci CR, Borges AB. Bond Strength to Eroded Enamel and Dentin Using a Universal Adhesive System. J Adhes Dent. 2017;19(2):121-7.

Fushida CE, Cury JA. Estudo in situ do efeito da freqüência de ingestão de CocaCola na erosão do esmalte-dentina e reversão pela saliva. Rev Odontol da Univ São Paulo. 1999 Apr;13(2):127-34.

Ganss C. Definition of Erosion and Links to Tooth Wear. In: Dental Erosion. Basel: Karger; 2006. p. 9-16.

Ganss C, Hardt M, Blazek D, Klimek J, Schlueter N. Effects of toothbrushing force on the mineral content and demineralized organic matrix of eroded dentine. Eur $\mathrm{J}$ Oral Sci. 2009 Jun;117(3):255-60.

Ganss C, Klimek J, Starck C. Quantitative analysis of the impact of the organic matrix on the fluoride effect on erosion progression in human dentine using longitudinal microradiography. Arch Oral Biol. 2004 Nov;49(11):931-5. 
Ganss C, Lussi A, Schlueter N. The Histological Features and Physical Properties of Eroded Dental Hard Tissues. In: Monographs Oral Science. 2014. p. 99-107.

Ganss C, Schlueter N, Hardt M, von Hinckeldey J, Klimek J. Effects of toothbrushing on eroded dentine. Eur J Oral Sci. 2007 Oct;115(5):390-6.

Garbisa S, Sartor L, Biggin S, Salvato B, Benelli R, Albini A. Tumor gelatinases and invasion inhibited by the green tea flavanol epigallocatechin-3-gallate. Cancer. 2001 Feb 15;91(4):822-32.

Garone-Filho W, Silva VA. Lesões não cariosas: o novo desafio da odontologia. Santos; 2008.

Gendron R, Grenier D, Sorsa T, Mayrand D. Inhibition of the activities of matrix metalloproteinases 2, 8, and 9 by chlorhexidine. Clin Diagn Lab Immunol. 1999 May;6(3):437-9.

Georges S, Ruiz Velasco C, Trichet V, Fortun Y, Heymann D, Padrines M. Proteases and bone remodelling. Cytokine Growth Factor Rev. 2009 Feb;20(1):29-41.

Giacomini M, Scaffa P, Chaves L, Vidal C, Machado T, Honório H, et al. Role of Proteolytic Enzyme Inhibitors on Carious and Eroded Dentin Associated With a Universal Bonding System. Oper Dent. 2017 Nov;42(6):E188-96.

Gravelle BL, Hagen TW, Mayhew SL, Crumpton B, Sanders T, Horne V. Soft drinks and in vitro dental erosion. Gen Dent. 2015;63(4):33-8.

Hagerman AE, Butler LG. The specificity of proanthocyanidin-protein interactions. J Biol Chem. 1981 May 10;256(9):4494-7.

Haj-Ali R, Walker M, Williams K, Wang Y, Spencer P. Histomorphologic Characterization of Noncarious and Caries-Affected Dentin/Adhesive Interfaces. J Prosthodont. 2006 Mar;15(2):82-8.

Han B, Jaurequi J, Tang BW, Nimni ME. Proanthocyanidin: A natural crosslinking reagent for stabilizing collagen matrices. J Biomed Mater Res. 2003 Apr 1;65A(1):118-24. 
Hannas AR, Kato MT, Cardoso C de AB, Magalhães AC, Pereira JC, Tjäderhane L, et al. Preventive effect of toothpastes with MMP inhibitors on human dentine erosion and abrasion in vitro. J Appl Oral Sci. 2016 Feb;24(1):61-6.

Hannas AR, Pereira JC, Granjeiro JM, Tjäderhane L. The role of matrix metalloproteinases in the oral environment. Acta Odontol Scand. 2007 Jan 2;65(1):1-13.

Hannig C, Laubach S, Hahn P, Attin T. Shear bond strength of repaired adhesive filling materials using different repair procedures. J Adhes Dent. 2006 Feb;8(1):3540.

Hara AT, Ando M, Cury JA, Serra MC, González-Cabezas C, Zero DT. Influence of the Organic Matrix on Root Dentine Erosion by Citric Acid. Caries Res.

2005;39(2):134-8.

Hashimoto M, Fujita S, Nagano F, Ohno H, Endo K. Ten-years degradation of resindentin bonds. Eur J Oral Sci. 2010 Jul 12;118(4):404-10.

Hashimoto M, Ohno H, Sano H, Kaga M, Oguchi H. Degradation patterns of different adhesives and bonding procedures. J Biomed Mater Res B Appl Biomater. 2003 Jul 15;66(1):324-30.

Hebling J, Pashley DH, Tjäderhane L, Tay FR. Chlorhexidine Arrests Subclinical Degradation of Dentin Hybrid Layers in vivo. J Dent Res. 2005 Aug 11;84(8):741-6.

Hemmings KW, Darbar UR, Vaughan S. Tooth wear treated with direct composite restorations at an increased vertical dimension: results at 30 months. J Prosthet Dent. 2000 Mar;83(3):287-93.

Honório HM, Rios D, Francisconi LF, Magalhães AC, Machado MAAM, Buzalaf MAR. Effect of prolonged erosive $\mathrm{pH}$ cycling on different restorative materials. J Oral Rehabil. 2008a Dec;35(12):947-53.

Honório HM, Rios D, Santos CF, Magalhães AC, Buzalaf MAR, Machado MAAM. Effects of Erosive, Cariogenic or Combined Erosive/Cariogenic Challenges on Human Enamel. Caries Res. 2008b;42(6):454-9. 
Hümmer W, Schreier P. Analysis of proanthocyanidins. Mol Nutr Food Res. 2008 Dec;52(12):1381-98.

Huysmans MCDNJM, Chew HP, Ellwood RP. Clinical Studies of Dental Erosion and Erosive Wear. Caries Res. 2011;45(s1):60-8.

Ingman T, Sorsa T, Michaelis J, Konttinen YT. Matrix metalloproteinases-1, -3 , and -8 in adult periodontitis in situ. An immunohistochemical study. Ann N Y Acad Sci. 1994 Sep 6;732:459-61.

Jaeggi T, Lussi A. Prevalence, Incidence and Distribution of Erosion. In: Monographs in oral science. 2014. p. 55-73.

Kato MT, Leite AL, Hannas AR, Buzalaf MAR. Gels containing MMP inhibitors prevent dental erosion in situ. J Dent Res. 2010a May 3;89(5):468-72.

Kato MT, Leite AL, Hannas AR, Calabria MP, Magalhães AC, Pereira JC, et al. Impact of Protease Inhibitors on Dentin Matrix Degradation by Collagenase. J Dent Res. 2012 Dec 28;91(12):1119-23.

Kato MT, Leite AL, Hannas AR, Oliveira RC, Pereira JC, Tjäderhane L, et al. Effect of Iron on Matrix Metalloproteinase Inhibition and on the Prevention of Dentine Erosion. Caries Res. 2010b;44(3):309-16.

Kato MT, Magalhães AC, Rios D, Hannas AR, Attin T, Buzalaf MAR. Protective effect of green tea on dentin erosion and abrasion. J Appl Oral Sci. 2009a;17(6):560-4.

Kato MT, de Moraes Italiani F, de Araújo JJ, Garcia MD, de Carvalho Sales-Peres $\mathrm{SH}$, Buzalaf MAR. Preventive effect of an iron varnish on bovine enamel erosion in vitro. J Dent. 2009b Mar;37(3):233-6.

Katz S, Park KK, Palenik CJ. In-vitro root surface caries studies. J Oral Med. 1987;42(1):40-8.

Khamverdi Z, Rezaei-Soufi L, Rostamzadeh T. The Effect of Epigallocatechin Gallate on the Dentin Bond Durability of Two Self-etch Adhesives. J Dent (Shiraz, Iran). 2015 Jun;16(2):68-74. 
Kilpatrick N, Mahoney EK. Dental erosion: part 2. The management of dental erosion. N Z Dent J. 2004 Jun;100(2):42-7.

Kinney JH, Balooch M, Haupt DL, Marshall SJ, Marshall GW. Mineral distribution and dimensional changes in human dentin during demineralization. J Dent Res. 1995 May 8;74(5):1179-84.

Kiomarsi N, Espahbodi M, Chiniforush N, Karazifard MJ, Kamangar SSH. In vitro evaluation of repair bond strength of composite: Effect of surface treatments with bur and laser and application of universal adhesive. Laser Ther. 2017 Sep 30;26(3):17380.

Kleter GA, Damen JJ, Everts V, Niehof J, Ten Cate JM. The influence of the organic matrix on demineralization of bovine root dentin in vitro. J Dent Res. 1994 Sep 8;73(9):1523-9.

Klont $\mathrm{B}$, ten Cate $\mathrm{JM}$. Remineralization of bovine incisor root lesions in vitro: the role of the collagenous matrix. Caries Res. 1991a;25(1):39-45.

Klont B, ten Cate JM. Susceptibility of the Collagenous Matrix from Bovine Incisor Roots to Proteolysis after in vitro Lesion Formation. Caries Res. 1991b;25(1):46-50.

Komori PCP, Pashley DH, Tjäderhane L, Breschi L, Mazzoni A, de Goes MF, et al. Effect of $2 \%$ chlorhexidine digluconate on the bond strength to normal versus cariesaffected dentin. Oper Dent. 2009 Mar;34(2):157-65.

Krithikadatta J, Gopikrishna V, Datta M. CRIS Guidelines (Checklist for Reporting Invitro Studies): A concept note on the need for standardized guidelines for improving quality and transparency in reporting in-vitro studies in experimental dental research. J Conserv Dent. 2014 Jul;17(4):301-4.

Labbate R, Lehn CN, Denardin OVP. Efeito da clorexidina na mucosite induzida por radioterapia em câncer de cabeça e pescoço. Rev Bras Otorrinolaringol. 2003 Jun;69(3):349-54.

Lafleur MA, Handsley MM, Edwards DR. Metalloproteinases and their inhibitors in angiogenesis. Expert Rev Mol Med. 2003 Sep 22;5(23):1-39. 
Lambrechts P, Van Meerbeek B, Perdigão J, Gladys S, Braem M, Vanherle G. Restorative therapy for erosive lesions. Eur J Oral Sci. 1996 Apr;104(2 ( Pt 2)):229_ 40.

Larsen MJ. Chemical Events during Tooth Dissolution. J Dent Res. 1990 Feb 4;69(2_suppl):575-80.

Larsen MJ, Nyvad B. Enamel Erosion by Some Soft Drinks and Orange Juices Relative to Their $\mathrm{pH}$, Buffering Effect and Contents of Calcium Phosphate. Caries Res. 1999;33(1):81-7.

Leme-Kraus AA, Aydin B, Vidal CMP, Phansalkar R., Nam JW, McAlpine J, et al. Biostability of the Proanthocyanidins-Dentin Complex and Adhesion Studies. J Dent Res. 2017 Apr 7;96(4):406-12.

Leme RMP, Antônio De Faria R, Juliana ;, Gomes B, Daniel J, Mello B De, et al. Comparação in vitro do efeito de bebidas ácidas no desenvolvimento da erosão dental: análise por microscopia eletrônica de varredura comparison in vitro of the effect of acidic drinks in the development of dental erosion: analysis by scanning electron mic. Vol. 27, Original Article Biosci. J. 2011.

Lessa FCR, Aranha AMF, Nogueira I, Giro EMA, Hebling J, Costa CA de S. Toxicity of chlorhexidine on odontoblast-like cells. J Appl Oral Sci. 2010a;18(1):50-8.

Lessa FCR, Nogueira I, Huck C, Hebling J, Costa CA de S. Transdentinal cytotoxic effects of different concentrations of chlorhexidine gel applied on acid-conditioned dentin substrate. J Biomed Mater Res B Appl Biomater. 2010b Jan;92(1):40-7.

Li M, Yang G, Xie B, Babu K, Huang C. Changes in matrix metalloproteinase-9 levels during progression of atrial fibrillation. J Int Med Res. 2014 Feb 17;42(1):224-30.

Li Z, Yasuda Y, Li W, Bogyo M, Katz N, Gordon RE, et al. Regulation of Collagenase Activities of Human Cathepsins by Glycosaminoglycans. J Biol Chem. 2004 Feb 13;279(7):5470-9.

Litonjua LA, Andreana S, Bush PJ, Cohen RE. Tooth wear: attrition, erosion, and abrasion. Quintessence Int. 2003 Jun;34(6):435-46. 
Loguercio AD, Hass V, Gutierrez MF, Luque-Martinez IV, Szezs A, Stanislawczuk R, et al. Five-year Effects of Chlorhexidine on the In Vitro Durability of Resin/Dentin Interfaces. J Adhes Dent. 2016;18(1):35-42.

Loguercio AD, Stanislawczuk R, Polli LG, Costa JA, Michel MD, Reis A. Influence of chlorhexidine digluconate concentration and application time on resin-dentin bond strength durability. Eur J Oral Sci. 2009 Oct;117(5):587-96.

Loke C, Lee J, Sander S, Mei L, Farella M. Factors affecting intra-oral pH - a review. J Oral Rehabil. 2016 Oct;43(10):778-85.

de Lourdes M, Chavez L. [Histological study to evaluate structural elements of healthy and carious dentin]. ADM. 1979;36(1):62-84.

Lussi A, Carvalho TS. Erosive Tooth Wear: A Multifactorial Condition of Growing Concern and Increasing Knowledge. In: Monographs in oral science. 2014. p. 1-15.

Lussi A, Hellwig E, Zero D, Jaeggi T. Erosive tooth wear: diagnosis, risk factors and prevention. Am J Dent. 2006 Dec;19(6):319-25.

Lussi A, Jaeggi T, Schaffner M. Prevention and minimally invasive treatment of erosions. Oral Health Prev Dent. 2004a;2 Suppl 1:321-5.

Lussi A, Jaeggi T, Zero D. The Role of Diet in the Aetiology of Dental Erosion. Caries Res. 2004b;38(1):34-44.

Lussi A, Schlueter N, Rakhmatullina E, Ganss C. Dental erosion--an overview with emphasis on chemical and histopathological aspects. Caries Res. 2011;45 Suppl 1(s1):2-12.

Madhan B, Krishnamoorthy G, Rao JR, Nair BU. Role of green tea polyphenols in the inhibition of collagenolytic activity by collagenase. Int J Biol Macromol. 2007 Jun 1;41(1):16-22.

Magalhães AC, Moraes SM, Rios D, Buzalaf MAR. Effect of ion supplementation of a commercial soft drink on tooth enamel erosion. Food Addit Contam Part A. 2009a Feb;26(2):152-6. 
Magalhães AC, Wiegand A, Buzalaf MAR. Use of dentifrices to prevent erosive tooth wear: harmful or helpful? Braz Oral Res. 2014 Jan 14;28(spe):1-6.

Magalhães AC, Wiegand A, Rios D, Hannas A, Attin T, Buzalaf MAR. Chlorhexidine and green tea extract reduce dentin erosion and abrasion in situ. J Dent. 2009b Dec;37(12):994-8.

Makela M, Salo T, Uitto V-J, Larjava H. Matrix Metalloproteinases (MMP-2 and MMP9) of the Oral Cavity: Cellular Origin and Relationship to Periodontal Status. J Dent Res. 1994 Aug 18;73(8):1397-406.

Malaquias P, Gutierrez MF, Hass V, Stanislawczuk R, Bandeca MC, Arrais C, et al. Two-year Effects of Chlorhexidine-containing Adhesives on the In Vitro Durability of Resin-dentin Interfaces and Modeling of Drug Release. Oper Dent. 2018 Mar;43(2):201-12.

Maltz M, Jardim JJ, Mestrinho HD, Yamaguti PM, Podestá K, Moura MS, et al. Partial Removal of Carious Dentine: A Multicenter Randomized Controlled Trial and 18Month Follow-Up Results. Caries Res. 2013;47(2):103-9.

Maltz M, Oliveira EF, Fontanella V, Carminatti G. Deep Caries Lesions after Incomplete Dentine Caries Removal: 40-Month Follow-Up Study. Caries Res. 2007;41(6):493-6.

Marshall GW, Marshall SJ, Kinney JH, Balooch M. The dentin substrate: structure and properties related to bonding. J Dent. 1997 Nov;25(6):441-58.

Martin-De Las Heras S, Valenzuela A, Overall CM. The matrix metalloproteinase gelatinase A in human dentine. Arch Oral Biol. 2000 Sep;45(9):757-65.

Matos AB, Trevelin LT, Silva BTF da, Francisconi-Dos-Rios LF, Siriani LK, Cardoso MV. Bonding efficiency and durability: current possibilities. Braz Oral Res. 2017 Aug 28;31(suppl 1):e57.

Mena-Serrano AP, Garcia EJ, Perez MM, Martins GC, Grande RHM, Loguercio AD, et al. Effect of the application time of phosphoric acid and self-etch adhesive systems to sclerotic dentin. J Appl Oral Sci. 2013 Apr;21(2):196-202. 
Mertz-Fairhurst EJ, Curtis JW, Ergle JW, Rueggeberg FA, Adair SM.

Ultraconservative and cariostatic sealed restorations: results at year 10. J Am Dent Assoc. 1998 Jan;129(1):55-66.

Meurman $\mathrm{JH}$, ten Cate $\mathrm{JM}$. Pathogenesis and modifying factors of dental erosion. Eur J Oral Sci. 1996 Apr;104(2 ( Pt 2)):199-206.

Meurman JH, Drysdale T, Frank RM. Experimental erosion of dentin. Scand J Dent Res. 1991 Dec;99(6):457-62.

Milia E, Cumbo E, Cardoso RJA, Gallina G. Current dental adhesives systems. A narrative review. Curr Pharm Des. 2012;18(34):5542-52.

Mirkarimi M, Toomarian L. Effect of green tea extract on the treatment of dentin erosion: an in vitro study. J Dent (Tehran). 2012;9(4):224-8.

Mogi M, Otogoto J. Expression of cathepsin-K in gingival crevicular fluid of patients with periodontitis. Arch Oral Biol. 2007 Sep;52(9):894-8.

Montagner AF, Perroni AP, Corrêa MB, Masotti AS, Pereira-Cenci T, Cenci MS, et al. Effect of pre-treatment with chlorhexidine on the retention of restorations: a randomized controlled trial. Braz Dent J. 2015;26(3):234-41.

Moon P, Weaver J, Brooks CN. Review of Matrix Metalloproteinases` Effect on the Hybrid Dentin Bond Layer Stability and Chlorhexidine Clinical Use to Prevent Bond Failure !2009-09-28 !2010-03-09 !2010-07-20 ! Open Dent J. 2010 Jul 20;4(1):147-52.

Motta VT. Bioquímica Básica. Autolab. São Paulo; 2007.

Munck J De, Landuyt K Van, Coutinho E, Poitevin A, Peumans M, Lambrechts P, et al. Micro-tensile bond strength of adhesives bonded to class-I cavity-bottom dentin after thermo-cycling. Dent Mater. 2005 Nov;21(11):999-1007.

Nagase H, Brew K. Designing TIMP (tissue inhibitor of metalloproteinases) variants that are selective metalloproteinase inhibitors. Biochem Soc Symp. 2003;(70):20112. 
Nagase H, VISSE R, MURPHY G. Structure and function of matrix metalloproteinases and TIMPs. Cardiovasc Res. 2006 Feb 15;69(3):562-73.

Nakabayashi N, Kojima K, Masuhara E. The promotion of adhesion by the infiltration of monomers into tooth substrates. J Biomed Mater Res. 1982 May;16(3):265-73.

Nascimento FD, Minciotti CL, Geraldeli S, Carrilho MR, Pashley DH, Tay FR, et al. Cysteine Cathepsins in Human Carious Dentin. J Dent Res. 2011 Apr 19;90(4):50611.

Obermajer N, Jevnikar Z, Doljak B, Kos J. Role of Cysteine Cathepsins in Matrix Degradation and Cell Signalling. Connect Tissue Res. 2008 Jan 6;49(3-4):193-6.

Oshiro M, Yamaguchi K, Takamizawa T, Inage H, Watanabe T, Irokawa A, et al. Effect of CPP-ACP paste on tooth mineralization: an FE-SEM study. J Oral Sci. 2007 Jun;49(2):115-20.

Osorio R, Yamauti M, Osorio E, Ruiz-Requena ME, Pashley D, Tay F, et al. Effect of dentin etching and chlorhexidine application on metalloproteinase-mediated collagen degradation. Eur J Oral Sci. 2011 Feb;119(1):79-85.

Pashley DH, Carvalho RM. Dentine permeability and dentine adhesion. J Dent. 1997 Sep;25(5):355-72.

Pashley DH, Carvalho RM, Sano H, Nakajima M, Yoshiyama M, Shono Y, et al. The microtensile bond test: a review. J Adhes Dent. 1999;1(4):299-309.

Pashley DH, Sano H, Ciucchi B, Yoshiyama M, Carvalho RM. Adhesion testing of dentin bonding agents: A review. Dent Mater. 1995 Mar;11(2):117-25.

Pashley DH, Tay FR, Breschi L, Tjäderhane L, Carvalho RM, Carrilho M, et al. State of the art etch-and-rinse adhesives. Dent Mater. 2011 Jan;27(1):1-16.

Pashley DH, Tay FR, Yiu C, Hashimoto M, Breschi L, Carvalho RM, et al. Collagen Degradation by Host-derived Enzymes during Aging. J Dent Res. 2004 Mar 6;83(3):216-21. 
Perdigão J. Dentin bonding -Variables related to the clinical situation and the substrate treatment. Dent Mater. 2010 Feb;26(2):e24-37.

Perote LCCC, Kamozaki MBB, Gutierrez NC, Tay FR, Pucci CR. Effect of Matrix Metalloproteinase-inhibiting Solutions and Aging Methods on Dentin Bond Strength. J Adhes Dent. 2015 Aug;17(4):347-52.

Peutzfeldt A, Jaeggi T, Lussi A. Restorative Therapy of Erosive Lesions. In: Monographs Oral Science. 2014. p. 253-61.

Pinheiro SL, Frasson AD, Bincelli IN, Barros PP, Silva GH. Study of a morphometric model for histological evaluation of the collagen in dentin carious lesions. J Clin Pediatr Dent. 2008;33(2):123-6.

Pugach MK, Strother J, Darling CL, Fried D, Gansky SA, Marshall SJ, et al. Dentin caries zones: mineral, structure, and properties. J Dent Res. 2009 Jan;88(1):71-6.

Ramos TM, Ramos-Oliveira TM, de Freitas PM, Azambuja N, Esteves-Oliveira M, Gutknecht N, et al. Effects of Er:YAG and Er,Cr:YSGG laser irradiation on the adhesion to eroded dentin. Lasers Med Sci. 2015 Jan 7;30(1):17-26.

Reis A, Higashi C, Loguercio AD. Re-anatomization of Anterior Eroded Teeth by Stratification with Direct Composite Resin. J Esthet Restor Dent. 2009 Oct;21(5):304-16.

Rios D, Honório HM, Magalhães AC, Wiegand A, de Andrade Moreira Machado MA, Buzalaf MAR. Light cola drink is less erosive than the regular one: An in situ/ex vivo study. J Dent. 2009 Feb;37(2):163-6.

Rios D, Santos FCZ, Honório HM, Magalhães AC, Wang L, de Andrade Moreira Machado MA, et al. An in situ/ex vivo comparison of the ability of regular and light colas to induce enamel wear when erosion is combined with abrasion. Quintessence Int. 2011 Mar;42(3):e44-50.

Ryan ME, Ramamurthy S, Golub LM. Matrix metalloproteinases and their inhibition in periodontal treatment. Curr Opin Periodontol. 1996;3:85-96.

Sabatini C. Effect of a Chlorhexidine-containing Adhesive on Dentin Bond Strength Stability. Oper Dent. 2013 Nov;38(6):609-17. 
Sakashita N, Motooka Y, Suganuma M, Ohnishi K, Fujiwara Y, Nakagawa T, et al. A case of pulmonary capillary hemangiomatosis with pulmonary fibrosis associated with MMP-9 related pulmonary remodeling. Pathol Int. 2011 May;61(5):306-12.

Sano H, Shono T, Sonoda H, Takatsu T, Ciucchi B, Carvalho R, et al. Relationship between surface area for adhesion and tensile bond strength--evaluation of a microtensile bond test. Dent Mater. 1994 Jul;10(4):236-40.

Sano H, Takatsu T, Ciucchi B, Horner JA, Matthews WG, Pashley DH. Nanoleakage: leakage within the hybrid layer. Oper Dent. 1995a;20(1):18-25.

Sano H, Takatsu T, Ciucchi B, Russell CM, Pashley DH. Tensile Properties of Resininfiltrated Demineralized Human Dentin. J Dent Res. 1995b Apr 8;74(4):1093-102.

Santiago SL, Osorio R, Neri JR, Carvalho RM, Toledano M. Effect of the flavonoid epigallocatechin-3-gallate on resin-dentin bond strength. J Adhes Dent. 2013 Dec;15(6):535-40.

Sartor L, Pezzato E, Garbisa S. (-)Epigallocatechin-3-gallate inhibits leukocyte elastase: potential of the phyto-factor in hindering inflammation, emphysema, and invasion. J Leukoc Biol. 2002 Jan;71(1):73-9.

Sartori N, Peruchi L, Guimarães J, Silva S, Monteiro S, Baratieri L, et al. Clinical Effectiveness of a Hydrophobic Coating Used in Conjunction With a One-step Selfetch Adhesive: An 18-month Evaluation. Oper Dent. 2013 Apr;38(3):249-57.

Sattabanasuk V, Vachiramon V, Qian F, Armstrong SR. Resin-dentin bond strength as related to different surface preparation methods. J Dent. 2007 Jun;35(6):467-75.

Scaffa PMC, Vidal CMP, Barros N, Gesteira TF, Carmona AK, Breschi L, et al. Chlorhexidine inhibits the activity of dental cysteine cathepsins. J Dent Res. $2012 \mathrm{Apr}$ 19;91(4):420-5.

Schlueter N, Luka B. Erosive tooth wear - a review on global prevalence and on its prevalence in risk groups. Br Dent J. 2018 Mar 9;224(5):364-70.

Schmidlin PR, Siebenmann J, Kocher P, Seemann R, Attin T, Bindl A. Effects of deand remineralization of dentin on bond strengths yielded by one-, three-, and fourstep adhesives. J Adhes Dent. 2008 Feb;10(2):119-26. 
Schwendicke F, Dörfer CE, Paris S. Incomplete Caries Removal. J Dent Res. 2013 Apr 8;92(4):306-14.

Shi J, Yu J, Pohorly JE, Kakuda Y. Polyphenolics in grape seeds-biochemistry and functionality. J Med Food. 2003 Dec;6(4):291-9.

Silva EM da, Glir DH, Gill AWMC, Giovanini AF, Furuse AY, Gonzaga CC. Effect of Chlorhexidine on Dentin Bond Strength of Two Adhesive Systems after Storage in Different Media. Braz Dent J. 2015 Dec;26(6):642-7.

Siqueira F, Cardenas A, Gomes G, Chibinski A, Gomes O, Bandeca M, et al. ThreeYear Effects of Deproteinization on the In Vitro Durability of Resin/Dentin-Eroded Interfaces. Oper Dent. 2018 Jan;43(1):60-70.

de Souza-e-Silva CM, da Silva Ventura TM, de Pau L, la Silva Cassiano, de Lima Leite A, Buzalaf MAR. Effect of gels containing chlorhexidine or epigallocatechin-3gallate on the protein composition of the acquired enamel pellicle. Arch Oral Biol. 2017 Oct;82:92-8.

Spencer P, Wang Y, Walker MP, Swafford JR. Molecular Structure of Acid-etched Dentin Smear Layers-in situ Study. J Dent Res. 2001 Sep 8;80(9):1802-7.

Srinivasulu S, Vidhya S, Sujatha M, Mahalaxmi S. Shear bond strength of composite to deep dentin after treatment with two different collagen cross-linking agents at varying time intervals. Oper Dent. 2012 Sep;37(5):485-91.

Stenzel KH, Miyata T, Rubin AL. Collagen as a Biomaterial. Annu Rev Biophys Bioeng. 1974 Jun;3(1):231-53.

Sternlicht MD, Werb Z. How Matrix Metalloproteinases Regulate Cell Behavior. Annu Rev Cell Dev Biol. 2001 Nov;17(1):463-516.

Strickland DK, Ashcom JD, Williams S, Burgess WH, Migliorini M, Argraves WS. Sequence identity between the alpha 2-macroglobulin receptor and low density lipoprotein receptor-related protein suggests that this molecule is a multifunctional receptor. J Biol Chem. 1990 Oct 15;265(29):17401-4. 
Sulkala M, Wahlgren J, Larmas M, Sorsa T, Teronen O, Salo T, et al. The Effects of MMP Inhibitors on Human Salivary MMP Activity and Caries Progression in Rats. J Dent Res. 2001 Jun 8;80(6):1545-9.

Tahmassebi JF, Duggal MS, Malik-Kotru G, Curzon MEJ. Soft drinks and dental health: a review of the current literature. J Dent. 2006 Jan;34(1):2-11.

Tanaka A, Arai K, Kitamura Y, Matsuda H. Matrix metalloproteinase-9 production, a newly identified function of mast cell progenitors, is downregulated by c-kit receptor activation. Blood. 1999 Oct 1;94(7):2390-5.

Tay FR, Pashley DH. Aggressiveness of contemporary self-etching systems. I: Depth of penetration beyond dentin smear layers. Dent Mater. 2001 Jul;17(4):296-308.

Tersariol IL, Geraldeli S, Minciotti CL, Nascimento FD, Pääkkönen V, Martins MT, et al. Cysteine Cathepsins in Human Dentin-Pulp Complex. J Endod. 2010 Mar;36(3):475-81.

Tjäderhane L, Buzalaf MAR, Carrilho M, Chaussain C. Matrix metalloproteinases and other matrix proteinases in relation to cariology: the era of "dentin degradomics".

Caries Res. 2015 Feb 6;49(3):193-208.

Tjäderhane L, Larjava H, Sorsa T, Uitto VJ, Larmas M, Salo T. The activation and function of host matrix metalloproteinases in dentin matrix breakdown in caries lesions. J Dent Res. 1998 Aug 8;77(8):1622-9.

Tjäderhane L, Nascimento FD, Breschi L, Mazzoni A, Tersariol ILS, Geraldeli S, et al. Optimizing dentin bond durability: Control of collagen degradation by matrix metalloproteinases and cysteine cathepsins. Dent Mater. 2013a Jan;29(1):116-35.

Tjäderhane L, Nascimento FD, Breschi L, Mazzoni A, Tersariol ILS, Geraldeli S, et al. Strategies to prevent hydrolytic degradation of the hybrid layer-A review. Dent Mater. 2013b Oct;29(10):999-1011.

Tjäderhane L, Palosaari H, Wahlgren J, Larmas M, Sorsa T, Salo T. Human Odontoblast Culture Method: The Expression of Collagen and Matrix Metalloproteinases (MMPs). Adv Dent Res. 2001 Aug;15(1):55-8. 
Tsuji Y, Yamaza T, Kido MA, Goto T, Nakata S, Akamine A, et al. Expression of cathepsin $\mathrm{K}$ mRNA and protein in odontoclasts after experimental tooth movement in the mouse maxilla by in situ hybridization and immunoelectron microscopy. Cell Tissue Res. 2001 Mar;303(3):359-69.

Turk B, Bieth JG, Björk I, Dolenc I, Turk D, Cimerman N, et al. Regulation of the activity of lysosomal cysteine proteinases by $\mathrm{pH}$-induced inactivation and/or endogenous protein inhibitors, cystatins. Biol Chem Hoppe Seyler. 1995 Apr;376(4):225-30.

Turk B, Turk V, Turk D. Structural and functional aspects of papain-like cysteine proteinases and their protein inhibitors. Biol Chem. 1997;378(3-4):141-50.

Turk D, Guncar G. Lysosomal cysteine proteases (cathepsins): promising drug targets. Acta Crystallogr D Biol Crystallogr. 2003 Feb;59(Pt 2):203-13.

Turk V, Stoka V, Vasiljeva O, Renko M, Sun T, Turk B, et al. Cysteine cathepsins: From structure, function and regulation to new frontiers. Biochim Biophys Acta Proteins Proteomics. 2012 Jan;1824(1):68-88.

Vaidyanathan TK, Vaidyanathan J. Recent advances in the theory and mechanism of adhesive resin bonding to dentin: a critical review. J Biomed Mater Res B Appl Biomater. 2009 Feb;88(2):558-78.

Van-Landuyt KL, Snauwaert J, De Munck J, Peumans M, Yoshida Y, Poitevin A, et al. Systematic review of the chemical composition of contemporary dental adhesives. Biomaterials. 2007 Sep;28(26):3757-85.

Van-Strijp AJP, van Steenbergen TJM, ten Cate JM. Bacterial Colonization of Mineralized and Completely Demineralized Dentine in situ. Caries Res. 1997;31(4):349-55.

Vertuan M, Camim FS, Dokko JR, Prakki A, Rios D, Honório HM. Effect of cranberry on dentin subjected to dental erosion. Dent Mater. 2018 Jan 1;34(1):e125.

Vidal CMP, Tjäderhane L, Scaffa PM, Tersariol IL, Pashley D, Nader HB, et al. Abundance of MMPs and Cysteine Cathepsins in Caries-affected Dentin. J Dent Res. 2014 Mar 19;93(3):269-74. 
Vieira A, Overweg E, Ruben JL, Huysmans MCDNJM. Toothbrush abrasion, simulated tongue friction and attrition of eroded bovine enamel in vitro. J Dent. 2006 May;34(5):336-42.

Visse R, Nagase H. Matrix Metalloproteinases and Tissue Inhibitors of Metalloproteinases. Circ Res. 2003 May 2;92(8):827-39.

Voronets J, Lussi A. Thickness of softened human enamel removed by toothbrush abrasion: an in vitro study. Clin Oral Investig. 2010 Jun 5;14(3):251-6.

Wang L, Casas-Apayco LC, Hipólito AC, Dreibi VM, Giacomini MC, Bim Júnior O, et al. Effect of simulated intraoral erosion and/or abrasion effects on etch-and-rinse bonding to enamel. Am J Dent. 2014a Feb;27(1):29-34.

Wang Y-L, Chang C-C, Chi C-W, Chang H-H, Chiang Y-C, Chuang Y-C, et al. Erosive potential of soft drinks on human enamel: An in vitro study. J Formos Med Assoc. 2014b Nov;113(11):850-6.

Wang Y-L, Chang H-H, Chiang Y-C, Lu Y-C, Lin C-P. Effects of fluoride and epigallocatechin gallate on soft-drink-induced dental erosion of enamel and root dentin. J Formos Med Assoc. 2018 Apr;117(4):276-82.

Wang Y, Spencer P. Effect of acid etching time and technique on interfacial characteristics of the adhesive-dentin bond using differential staining. Eur J Oral Sci. 2004 Jun;112(3):293-9.

Wang Y, Spencer P, Walker MP. Chemical profile of adhesive/caries-affected dentin interfaces using Raman microspectroscopy. J Biomed Mater Res Part A. 2007 May;81A(2):279-86.

Xu X, Ma J, Li C, Zhao W, Xu Y. Regulation of chondrosarcoma invasion by MMP26. Tumor Biol. 2015 Jan 28;36(1):365-9.

Yamauti M, Hashimoto M, Sano H, Ohno H, Carvalho RM, Kaga M, et al. Degradation of resin-dentin bonds using $\mathrm{NaOCl}$ storage. Dent Mater. 2003 Jul;19(5):399-405. 
Yoshikawa T, Wattanawongpitak N, Cho E, Tagami J. Effect of remaining dentin thickness on bond strength of various adhesive systems to dentin. Dent Mater J. 2012;31(6):1033-8.

Yoshiyama M, Carvalho R, Sano H, Horner J, Brewer PD, Pashley DH. Interfacial morphology and strength of bonds made to superficial versus deep dentin. Am J Dent. 1995 Dec;8(6):297-302.

Yousef EM, Tahir MR, St-Pierre Y, Gaboury LA. MMP-9 expression varies according to molecular subtypes of breast cancer. BMC Cancer. 2014 Aug 23;14(1):609.

Zero DT. Etiology of dental erosion--extrinsic factors. Eur J Oral Sci. 1996 Apr;104(2 ( Pt 2)):162-77.

Zero DT, Lussi A. Erosion--chemical and biological factors of importance to the dental practitioner. Int Dent J. 2005;55(4 Suppl 1):285-90.

Zimmerli B, De Munck J, Lussi A, Lambrechts P, Van Meerbeek B. Long-term bonding to eroded dentin requires superficial bur preparation. Clin Oral Investig. 2012 Oct 8;16(5):1451-61. 

ANEXO A - Parecer consubstanciado do Comitê de Ética em Pesquisa em Seres Humanos da Faculdade de Odontologia da Universidade de São Paulo aprovando a condução do presente estudo

\section{USP - FACULDADE DE ODONTOLOGIA DA UNIVERSIDADE DE SÃO}

\section{PARECER CONSUBSTANCIADO DO CEP}

\section{DADOS DO PROJETO DE PESQUISA}

Título da Pesquisa: Controle do desgaste com inibidores de proteases e agente de estabelecimento de ligações cruzadas entre fibrilas de colágeno na resistência de união do conjunto adesivo-resina composta à dentina erodida

Pesquisador: Luciana Fávaro Francisconi dos Rios

Área Temática:

Versão: 1

CAAE: 90202918.6 .0000 .0075

Instituição Proponente: Faculdade de Odontologia da Universidade de São Paulo

Patrocinador Principal: Financiamento Próprio

\section{DADOS DO PARECER}

Número do Parecer: 2.701 .801

\section{Apresentação do Projeto:}

Busca-se minimizar ou prevenir a degradação das fibrilas colágenas, tanto no controle da progressão do desgaste erosivo em dentina, quanto na preservação das interfaces adesivas aí estabelecidas, por meio do uso de agentes antiproteolíticos (clorexidina/ $\mathrm{CHX}$ e epigalocatequina 3galato/EGCG) ou, ao mesmo tempo, promotores de ligações cruzadas entre elas (proantocianidina/PAC). O papel de algumas dessas estratégias no estabelecimento, e conservação, de interfaces adesivas em dentina erodida, substrato adverso à interação com materiais adesivos, tem sido, porém, pouquíssimas vezes reportado. Este estudo in vitro propõe-se a avaliar, pois, o efeito de tais agentes, usados como estratégias para prevenção/controle do desgaste, na resistência de união (RU) do conjunto sistema adesivo condicione e lave simplificado-resina composta à dentina erodida, comparada à normal. A dentina superficial oclusal de terceiros molares será apenas submetida à ação de uma lixa de SiC (\#600; 1 min; N: substrato normal) ou sequencialmente a desafio erosivo inicial (Coca-Cola $® ; 5$ min). Receberá, então, ou não (C: controle/sem aplicação), a aplicação de um dos géis com os seguintes princípios ativos - P: placebo/sem princípio ativo; CHX: digluconato de clorexidina a 0,12\%; EGCG: epigalocatequina 3-galato a $400 \mu \mathrm{m}$; PAC: proantocianidina a 10\%. Aquela de início desmineralizada ainda será submetida a ciclagem de $\mathrm{pH}$ (Coca-Cola $®$; imersões de $5 \mathrm{~min}, 3 \mathrm{x} / \mathrm{dia}, 5$ dias; E: substrato erodido). Após condicionamento (H 3 PO 4 a 37\%; 15 s; lavagem 30 s; secagem com papel

Endereço: Av Prof Lineu Prestes 2227

Bairro: Cidade Universitária

UF: SP Município: SAO PAULO

Telefone: (11)3091-7960 


\section{USP - FACULDADE DE ODONTOLOGIA DA UNIVERSIDADE DE SÃO}

Continuação do Parecer: 2.701.801

absorvente), o adesivo Adper TM Single Bond $2 \circledast$ será aplicado em todos os espécimes e a porção coronária, reconstruída com a resina Filtek TM Z350 ® . Transcorridas $24 \mathrm{~h}$ (água destilada/37C), os espécimes serão

seccionados em palitos e testados (TBS; 0,5 mm/min). Os valores de RU obtidos serão organizados considerando-se cada dente como unidade experimental e os testes de Análise de Variância a 2 critérios e de Tukey, se necessário, aplicados $(=0,05)$. Um dente extra para cada grupo será tratado exatamente como os outros, mas o corante fluorescente rodamina B será previamente adicionado $(0,16 \mathrm{mg} / \mathrm{mL})$ ao sistema adesivo para permitir a avaliação qualitativa da interface adesiva por meio de Microscopia Confocal de Varredura a Laser.

\section{Objetivo da Pesquisa:}

O objetivo deste estudo in vitro é avaliar, de imediato, o efeito de inibidores de proteases e de um agente também promotor do estabelecimento de ligações cruzadas entre fibrilas de colágeno, usados como estratégias para prevenção/controle do desgaste, na resistência de união (RU) do conjunto sistema adesivo condicione e lave simplificado-resina composta à dentina erodida, comparada à normal.

\section{Avaliação dos Riscos e Benefícios:}

Os riscos relacionados ao estudo, que será realizado, em laboratório, utilizando-se terceiros molares humanos hígidos extraídos, doados pelo Biobanco de Dentes Humanos da Faculdade de Odontologia-USP, de acordo com a resolução $n^{\circ} 466$ do Conselho Nacional de Saúde (Ministério da Saúde, DF), com as normas de biossegurança e guardando-se o sigilo ético, são praticamente equivalentes a zero.

O presente trabalho não trará qualquer benefício direto para o "sujeito da pesquisa", que participará da mesma, indiretamente, apenas por meio da doação de dentes extraídos. No entanto, sua realização visa avaliar estratégias que potencialmente possam favorecer a união de materiais resinosos à dentina erodida, um dos substratos sabidamente desfavoráveis a tal interação, nos quais, porém, rotineiramente em clínica, estabelecem -se as interfaces adesivas.

\section{Comentários e Considerações sobre a Pesquisa:}

Trata- se de um estudo em vitro em se analisa métodos alternativos para aumentar a resistência a união da resina ao dente, pode trazer uma evolução a material restaurador proporcionando melhores resultados clínicos

\section{Considerações sobre os Termos de apresentação obrigatória:}

Foram apresentados:

Endereço: Av Prof Lineu Prestes 2227

Bairro: Cidade Universitária

UF: SP Município: SAO PAULO

CEP: $\quad 05.508-900$

Telefone: (11)3091-7960

Fax: (11)3091-7814

E-mail: cepfo@usp.br 


\section{USP - FACULDADE DE ODONTOLOGIA DA UNIVERSIDADE DE SÃO}

\section{Patatereme}

Continuação do Parecer: 2.701 .801

Folha de rosto; Projeto detalhado, autorização do Laboratório de dentística, Carta do CEFAP, carta do Biobanco.

\section{Recomendações:}

Tendo em vista a legislação vigente, devem ser encaminhados ao CEP-FOUSP relatórios parciais anuais referentes ao andamento da pesquisa e relatório final, utilizando-se da opção "Enviar Notificação" (descrita no Manual "Submeter Notificação", disponível na Central de Suporte - canto superior direito do site www.saude.gov.br/plataformabrasil).

Qualquer alteração no projeto original deve ser apresentada "emenda" a este CEP, de forma objetiva e com justificativas para nova apreciação.

\section{Conclusões ou Pendências e Lista de Inadequações:}

Não há pendências.

\section{Considerações Finais a critério do CEP:}

Este parecer foi elaborado baseado nos documentos abaixo relacionados:

\begin{tabular}{|c|c|c|c|c|}
\hline Tipo Documento & Arquivo & Postagem & Autor & Situação \\
\hline $\begin{array}{l}\text { Informações Básicas } \\
\text { do Projeto }\end{array}$ & $\begin{array}{l}\text { PB_INFORMAÇŌES_BÁSICAS_DO_P } \\
\text { ROJETO 1123124.pdff }\end{array}$ & $\begin{array}{c}23 / 05 / 2018 \\
12: 09: 19\end{array}$ & & Aceito \\
\hline $\begin{array}{l}\text { Projeto Detalhado / } \\
\text { Brochura } \\
\text { Investigador }\end{array}$ & PROJETO_DETALHADO_CEP.pdf & $\begin{array}{c}23 / 05 / 2018 \\
12: 08: 52\end{array}$ & $\begin{array}{l}\text { Luciana Fávaro } \\
\text { Francisconi dos Rios }\end{array}$ & Aceito \\
\hline Outros & $\begin{array}{l}\text { Autorizacao_Anuencia_Uso_Confocal_C } \\
\text { EFAP.pdf }\end{array}$ & $\begin{array}{l}\text { 23/05/2018 } \\
12: 05: 14\end{array}$ & $\begin{array}{l}\text { Luciana Fávaro } \\
\text { Francisconi dos Rios }\end{array}$ & Aceito \\
\hline Outros & $\begin{array}{l}\text { Carta_AutorizacaoUso_LabDentistica_K } \\
\text { arin.pdf }\end{array}$ & $\begin{array}{l}23 / 05 / 2018 \\
12: 01: 22\end{array}$ & $\begin{array}{l}\text { Luciana Fávaro } \\
\text { Francisconi dos Rios }\end{array}$ & Aceito \\
\hline Outros & $\begin{array}{l}\text { Duvidas_Termos_Condicoes_uso_Valor } \\
\text { es_CONFOCAL_CEFAP.pdf }\end{array}$ & $\begin{array}{l}23 / 05 / 2018 \\
12: 00: 35\end{array}$ & $\begin{array}{l}\text { Luciana Fávaro } \\
\text { Francisconi dos Rios }\end{array}$ & Aceito \\
\hline Outros & Biobanco_Assinada.pdf & $\begin{array}{c}03 / 05 / 2018 \\
10: 12: 56\end{array}$ & $\begin{array}{l}\text { Luciana Fávaro } \\
\text { Francisconi dos Rios }\end{array}$ & Aceito \\
\hline Folha de Rosto & folhaDeRosto_Assinada.pdf & $\begin{array}{c}03 / 05 / 2018 \\
10: 09: 56\end{array}$ & $\begin{array}{l}\text { Luciana Fávaro } \\
\text { Francisconi dos Rios }\end{array}$ & Aceito \\
\hline
\end{tabular}

\section{Situação do Parecer:}

Endereço: Av Prof Lineu Prestes 2227

Bairro: Cidade Universitária
UF: SP
Município: SAO PAULO
Telefone: (11)3091-7960
Fax: (11)3091-7814
E-mail: cepfo@usp.br

CEP: $\quad 05.508-900$ 


\section{USP - FACULDADE DE ODONTOLOGIA DA UNIVERSIDADE DE SÃO}

Continuação do Parecer: 2.701.801

\section{Aprovado}

Necessita Apreciação da CONEP:

Não

SAO PAULO, 08 de Junho de 2018

Assinado por:

Maria Gabriela Haye Biazevic

(Coordenador) 
ANEXO B - Parecer consubstanciado do Comitê de Ética em Pesquisa em Seres Humanos da Faculdade de Odontologia da Universidade de São Paulo aprovando os resultados obtidos pelo desenrolar do projeto originalmente proposto, bem como anuindo continuidade do trabalho e adaptações necessárias à publicação de todos e cada um deles.

\section{USP - FACULDADE DE ODONTOLOGIA DA UNIVERSIDADE DE SÃO}

\section{PARECER CONSUBSTANCIADO DO CEP}

\section{DADOS DA EMENDA}

Título da Pesquisa: Controle do desgaste com inibidores de proteases e agente de estabelecimento de ligações cruzadas entre fibrilas de colágeno na resistência de união do conjunto adesivo-resina composta à dentina erodida

Pesquisador: Luciana Fávaro Francisconi dos Rios

Área Temática:

Versão: 2

CAAE: 90202918.6 .0000 .0075

Instituição Proponente: Faculdade de Odontologia da Universidade de São Paulo

Patrocinador Principal: Financiamento Próprio

\section{DADOS DO PARECER}

Número do Parecer: 3.011 .535

\section{Apresentação do Projeto:}

Trata-se de um estudo in vitro onde será avaliado a resistência de união do conjunto sistema adesivo condicione e lave simplificado-resina composta à dentina, considerando-se como fatores experimentais a condição desse substrato, em dois níveis ( $N$ : normal; $E$ : erodido), a aplicação de géis para prevenção/controle do desgaste erosivo, com diferentes princípios ativos, em cinco níveis (C: controle/sem aplicação; P: placebo/sem princípio ativo; $\mathrm{CHX}$ : digluconato de clorexidina a $0,12 \%$; EGCG: epigalocatequina 3-galato a $400 \mu \mathrm{m}$; PAC: proantocianidina a 10\%) e o envelhecimento dos espécimes/tempo, em três níveis (imediato, 6 meses e 12 meses). Ademais, considerando-se os mesmos fatores, nos mesmos níveis, avaliarse-á qualitativamente a interface adesiva por meio de microscopia confocal de varredura a laser (MCVL).As variáveis quantitativa e qualitativa de resposta serão, respectivamente, os valores de resistência de união à microtração ( $\mu$ TBS), em MPa,

considerando-se cada dente como unidade experimental, e a descrição de imagens obtidas por meio de MCVL. O padrão de fratura dos palitos será determinado com o auxílio de um microscópio digital (50x de aumento).

\section{Objetivo da Pesquisa:}

O objetivo deste estudo in vitro é avaliar, de imediato e ao longo do tempo, o efeito de inibidores de proteases e de um agente também promotor do estabelecimento de ligações cruzadas entre

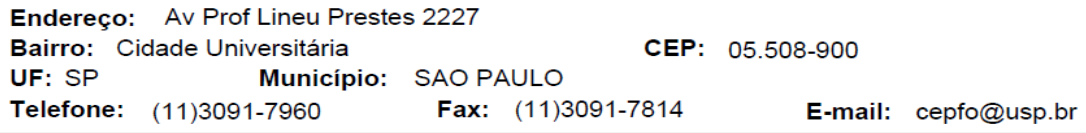




\section{USP - FACULDADE DE ODONTOLOGIA DA UNIVERSIDADE DE SÃO}

Continuação do Parecer: 3.011 .535

fibrilas de colágeno, usados como estratégias para prevenção/controle do desgaste, na resistência de união $(R U)$ do conjunto sistema adesivo condicione e lave simplificado-resina composta à dentina erodida, comparada à normal.

\section{Avaliação dos Riscos e Benefícios:}

Os riscos relacionados ao estudo, que será realizado, em laboratório, utilizando-se terceiros molares humanos hígidos extraídos, doados pelo Biobanco de Dentes Humanos da Faculdade de Odontologia-USP, de acordo com a resolução $n^{\circ} 466$ do Conselho Nacional de Saúde (Ministério da Saúde, DF), com as normas de biossegurança e guardando-se o sigilo ético, são praticamente equivalentes a zero.

O presente trabalho não trará qualquer benefício direto para o "sujeito da pesquisa", que participará da mesma, indiretamente, apenas por meio da doação de dentes extraídos. No entanto, sua realização visa avaliar estratégias que potencialmente possam favorecer a união, e sua durabilidade, de materiais resinosos à dentina erodida, um dos substratos sabidamente desfavoráveis a tal interação, nos quais, porém, rotineiramente em clínica,

estabelecem-se as interfaces adesivas.

\section{Comentários e Considerações sobre a Pesquisa:}

Este estudo in vitro é relevante cientificamente, pois propõe a utilização de novos agentes que proporcionam o efeito inibidor de proteases e de um agente promotor do estabelecimento de ligações cruzadas entre fibrilas de colágeno, usados como estratégias para prevenção/controle do desgaste, na resistência de união do conjunto sistema adesivo condicione e lave simplificado-resina composta à dentina erodida, comparada à normal.

\section{Considerações sobre os Termos de apresentação obrigatória:}

Foram apresentados: Projeto detalhado e relatório do andamento da pesquisa.

\section{Recomendações:}

Tendo em vista a legislação vigente, devem ser encaminhados ao CEP-FOUSP relatórios parciais anuais referentes ao andamento da pesquisa e relatório final, utilizando-se da opção "Enviar Notificação" (descrita no Manual "Submeter Notificação", disponível na Central de Suporte - canto superior direito do site www.saude.gov.br/plataformabrasil).

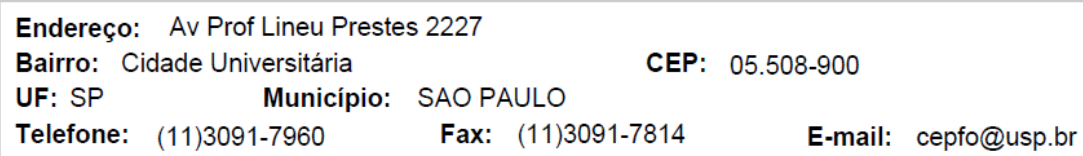




\section{USP - FACULDADE DE ODONTOLOGIA DA UNIVERSIDADE DE SÃO}

Continuação do Parecer: 3.011 .535

Qualquer alteração no projeto original deve ser apresentada "emenda" a este CEP, de forma objetiva e com justificativas para nova apreciação.

\section{Conclusões ou Pendências e Lista de Inadequações:}

Não há pendências na emenda.

\section{Considerações Finais a critério do CEP:}

Justificativa da emenda: No trabalho original, todos os palitos obtidos para cada grupo experimental seriam testados imediatamente (I), tão logo seccionados os espécimes que a eles dariam origem. Optou-se, no entanto, por se testar imediatamente apenas um terço do total dos palitos obtidos para cada dente e armazenar os demais em saliva artificial, a 37oC, para que sejam testados depois de transcorridos 6 (segundo terço) ou 12 meses (terceiro terço) de envelhecimento, períodos correspondentes a 02/01/2019-14/04/2019 e a 02/07/2018-14/10/2018, respectivamente.

Este parecer foi elaborado baseado nos documentos abaixo relacionados:

\begin{tabular}{|c|c|c|c|c|}
\hline Tipo Documento & Arquivo & Postagem & Autor & Situação \\
\hline $\begin{array}{l}\text { Informações Básicas } \\
\text { do Projeto }\end{array}$ & $\begin{array}{l}\text { PB_INFORMAÇÖES_BÁSICAS_124225 } \\
0 \text { Ė1.pdf }\end{array}$ & $\begin{array}{c}19 / 10 / 2018 \\
11: 17: 51 \\
\end{array}$ & & Aceito \\
\hline Outros & Relatorio_ResultImediatos.pdf & $\begin{array}{l}19 / 10 / 2018 \\
11: 16: 42\end{array}$ & $\begin{array}{l}\text { Luciana Fávaro } \\
\text { Francisconi dos Rios }\end{array}$ & Aceito \\
\hline $\begin{array}{l}\text { Projeto Detalhado / } \\
\text { Brochura } \\
\text { Investigador }\end{array}$ & PROJETO_DETALHADO_EMENDA.pdf & $\begin{array}{c}19 / 10 / 2018 \\
11: 14: 50\end{array}$ & $\begin{array}{l}\text { Luciana Fávaro } \\
\text { Francisconi dos Rios }\end{array}$ & Aceito \\
\hline Outros & $\begin{array}{l}\text { Autorizacao_Anuencia_Uso_Confocal_C } \\
\text { EFAP.pdf }\end{array}$ & $\begin{array}{c}23 / 05 / 2018 \\
12: 05: 14\end{array}$ & $\begin{array}{l}\text { Luciana Fávaro } \\
\text { Francisconi dos Rios }\end{array}$ & Aceito \\
\hline Outros & $\begin{array}{l}\text { Carta_AutorizacaoUso_LabDentistica_K } \\
\text { arin.pdf }\end{array}$ & $\begin{array}{c}23 / 05 / 2018 \\
12: 01: 22\end{array}$ & $\begin{array}{l}\text { Luciana Fávaro } \\
\text { Francisconi dos Rios }\end{array}$ & Aceito \\
\hline Outros & $\begin{array}{l}\text { Duvidas_Termos_Condicoes_uso_Valor } \\
\text { es_CONFOCAL_CEFAP.pdf }\end{array}$ & $\begin{array}{c}23 / 05 / 2018 \\
12: 00: 35\end{array}$ & $\begin{array}{l}\text { Luciana Fávaro } \\
\text { Francisconi dos Rios }\end{array}$ & Aceito \\
\hline Outros & Biobanco_Assinada.pdf & $\begin{array}{c}03 / 05 / 2018 \\
10: 12: 56\end{array}$ & $\begin{array}{l}\text { Luciana Fávaro } \\
\text { Francisconi dos Rios }\end{array}$ & Aceito \\
\hline Folha de Rosto & folhaDeRosto_Assinada.pdf & $\begin{array}{c}03 / 05 / 2018 \\
10: 09: 56\end{array}$ & $\begin{array}{l}\text { Luciana Fávaro } \\
\text { Francisconi dos Rios }\end{array}$ & Aceito \\
\hline
\end{tabular}

Endereço: Av Prof Lineu Prestes 2227

Bairro: Cidade Universitária

Município: SAO PAULO

Telefone: (11)3091-7960 Fax: (11)3091-7814 E-mail: cepfo@usp.br 


\section{USP - FACULDADE DE ODONTOLOGIA DA UNIVERSIDADE DE SÃO}

Continuação do Parecer: 3.011 .535

\section{Situação do Parecer:}

Aprovado

Necessita Apreciação da CONEP:

Não

SAO PAULO, 09 de Novembro de 2018

Assinado por:

Maria Gabriela Haye Biazevic

(Coordenador(a)) 